\title{
Development of an integrated model for process planning and parameter selection for machining processes
}

\author{
Deepak Prakash Gupta \\ West Virginia University
}

Follow this and additional works at: https://researchrepository.wvu.edu/etd

\section{Recommended Citation}

Gupta, Deepak Prakash, "Development of an integrated model for process planning and parameter selection for machining processes" (2007). Graduate Theses, Dissertations, and Problem Reports. 4305. https://researchrepository.wvu.edu/etd/4305

This Dissertation is protected by copyright and/or related rights. It has been brought to you by the The Research Repository @ WVU with permission from the rights-holder(s). You are free to use this Dissertation in any way that is permitted by the copyright and related rights legislation that applies to your use. For other uses you must obtain permission from the rights-holder(s) directly, unless additional rights are indicated by a Creative Commons license in the record and/ or on the work itself. This Dissertation has been accepted for inclusion in WVU Graduate Theses, Dissertations, and Problem Reports collection by an authorized administrator of The Research Repository @ WVU.

For more information, please contact researchrepository@mail.wvu.edu. 
Development of an Integrated Model for Process Planning and Parameter Selection for Machining Processes

\author{
Deepak Prakash Gupta \\ Dissertation submitted to the \\ College of Engineering and Mineral Resources \\ at West Virginia University \\ in partial fulfillment of the requirements \\ for the degree of
}

Doctor of Philosophy

in

Industrial Engineering

B. Gopalakrishnan, Ph.D., Chair

Wafik H. Iskander, Ph.D.

Robert C. Creese, Ph.D.

Dr. Feng Yang, Ph.D.

Dr. Kenneth Means, Ph.D.

Department of Industrial and Management Systems Engineering Morgantown, West Virginia

2007

Keywords: Process Planning, Process Sequencing, Parameter Selection, Machining Cost 


\section{ABSTRACT \\ Development of an Integrated Model for Process Planning and Parameter Selection for Machining Processes}

\section{Deepak Prakash Gupta}

The concept of "Do it right the first time" in the machining industry not only expects the best quality products but also at the best possible cost. The cost of machining depends on intelligent process planning and selection of machining parameters such as speed, feed, and depth of cut. The problem of machining parameter selection has received great attention by researchers and many techniques have been developed. A review of these techniques reveals that the selection of the machine and cutting tool is done before the process of cutting parameter selection and process sequencing, and often the selection is based on experience. The current research is an attempt to develop an integrated model (ExIMPro: EXpert system based Integrated model for Machining PROcesses) which finds the sequence of operations with set of machines, tools, and other process parameters to minimize the cost of machining for a cylindrical part. This system consists of existing expert system Machining Parameter SELection (MPSEL) for machine and tool selection and a Microsoft Excel ${ }^{\circledR}$ and Visual Basic ${ }^{\circledR}$ based parameter selection model. The present model focuses on turning and cylindrical grinding operations but other processes can be incorporated with little modification to the software. 


\section{ACKNOWLEDGEMENT}

I would like to thank Dr. Gopalakrishnan for his exceptional support as my primary research advisor throughout this research work. I would also like to thank Dr. Iskander, Dr. Creese, Dr. Yang, and Dr. Means for their invaluable assistance which helped me to improve the quality of this research work. I am indebted to my committee members for not only the help with this research work but also with my career and professional development.

I am grateful to Dr. Kenneth Currie at Tennessee Technological University for his excellent feedback that helped me think about possible extensions to this research work.

I am indebted to my parents and my brother and sisters for their continued emotional support. I also like to thank Dr. J.L. Gandhar and Dr. Pradeep Kumar (at IIT, Roorkee, India) for their never ending support throughout my career starting with my studies at IITR during 1996-2000.

Last but not the least, I am thankful to all my friends and colleagues who I worked with and pray God to give them all the success in their lives. 


\section{TABLE OF CONTENTS}

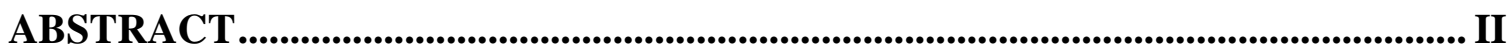

ACKNOWLEDGEMENT .........................................................................................III

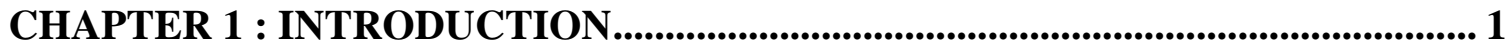

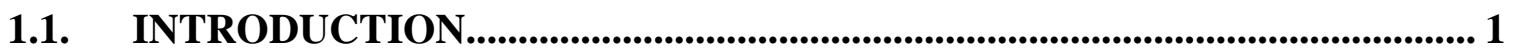

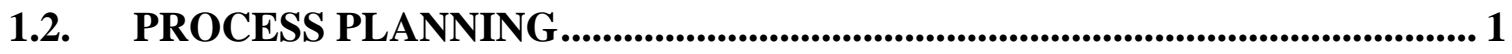

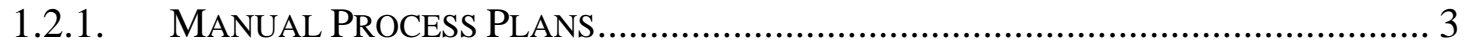

1.2.2. COMPUter-Aided Process Plans........................................................... 3

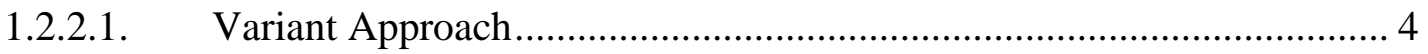

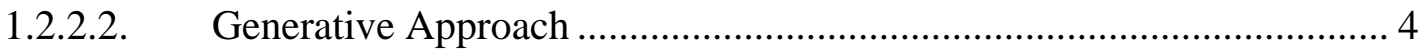

1.2.2.3. Semi-Generative Approach........................................................... 4

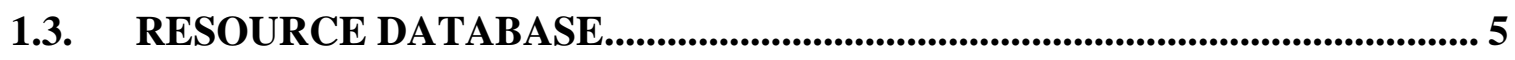

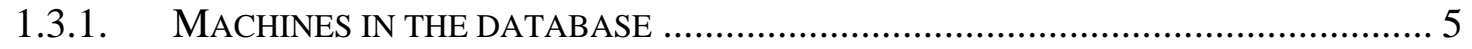

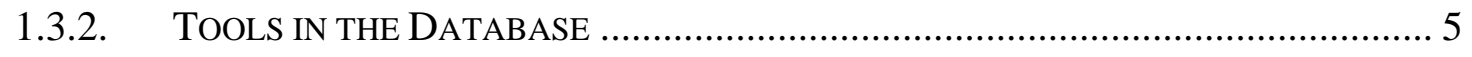

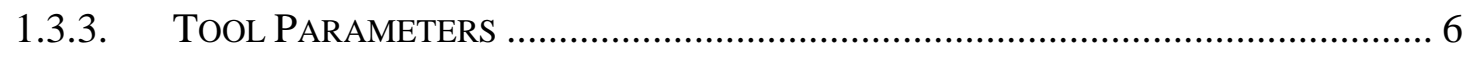

1.4. GENERALIZED EQUATIONS FOR MACHINING COSTS...................... 6

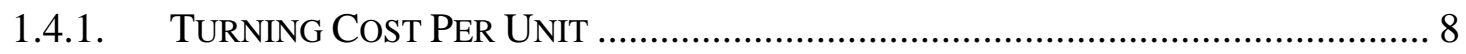

1.4.2. CYLINDRICAL GRINDING COST PER UNIT .................................................. 9

1.5. EXAMPLE PROCESS PLANNING PROBLEM............................................. 9

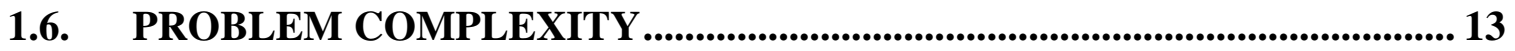

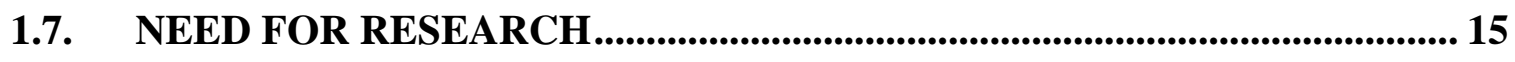

1.8. RESEARCH OBJECTIVES ................................................................................. 16

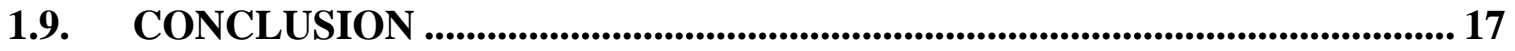

CHAPTER 2 : LITERATURE REVIEW ........................................................ 18

2.1 EXPERT SYSTEMS FOR PROCESS PLANNING ........................................... 18

2.2 OPTIMIZATION/HEURISTICS APPROACH FOR PROCESS PLANNING . 21

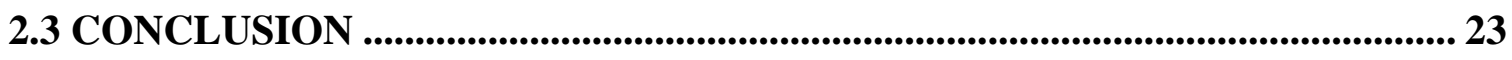

CHAPTER 3 : RESEARCH APPROACH......................................................... 24

3.1 AUTOMATED DIMENSION TRACKING ....................................................... 25

3.2 GENERATION OF POSSIBLE OPTIONS IN TURNING PROCESS ............. 27 
3.3 MODEL EXECUTION ............................................................................................. 29

3.4 OTHER POSSIBLE APPROACHES ...................................................................... 46

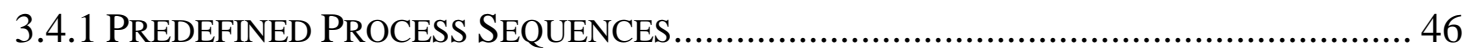

3.4.2 Interactive Process Planning Model ........................................................ 48

3.4.3 DEVELOPMENT OF EXPERT RULES …………….............................................. 48

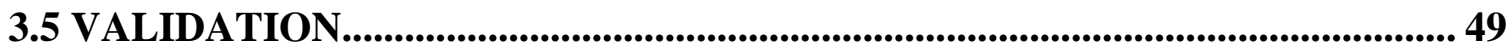

3.6 CONCLUSIONS ...................................................................................................... 50

CONCLUSION AND FUTURE WORK ........................................................................ 51

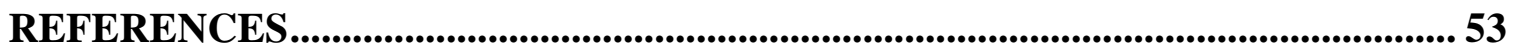

APPENDIX 1: MACHINING PARAMETER DATABASE ….................................... 57

APPENDIX 2: SAMPLE RESULTS FROM MPSEL................................................. 87 


\section{CHAPTER $1:$ INTRODUCTION}

\subsection{Introduction}

Application of computers in the manufacturing industry is growing every day. It was a long time ago when process planning and parameter selection were done manually through the use of several years of experience. Also, the chances of getting poor solutions were relatively high because of increasing complexity in the process planning activities. The ability to automate the decision making process through the use of computers has opened a new area of research. Several models have been developed to help the machining professionals achieve better cost and quality. Traditionally, computers have been used in different phases of the manufacturing process life cycle, i.e. conceptual design and product design, process planning, and manufacturing (Figure 1.1).

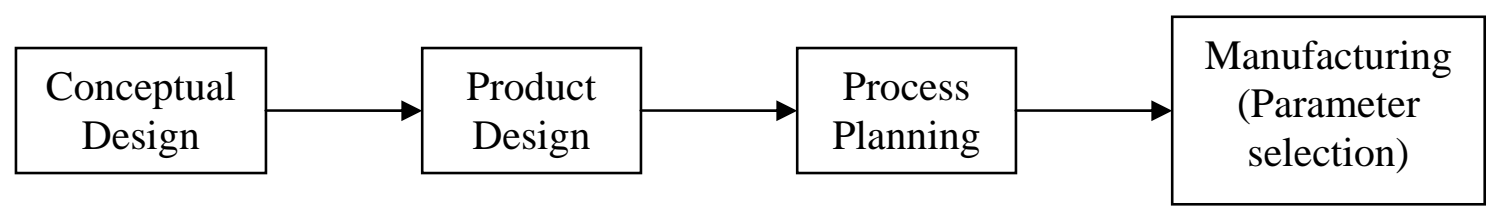

Figure 1.1: Traditional Phases in the Manufacturing Cycle

The present research is focused towards integrating the last two phases of this process: process planning and parameter selection. The planning activities involve the study of required characteristics in the final product and the process to convert the raw material into the final product. This activity results in the process sequence and a list of processes, machines, and machine tools that may be used to achieve the required characteristics. At this point, the process planner picks the "best combination" based on his/her experience and/or through an iteration process among the set of process sequences, machines, tools, and cutting parameters. It may be noted that unless a structured approach is utilized for this iteration, the results may not be satisfactory to achieve better cost and/or quality.

\subsection{Process Planning}

Process planning is an important part of every manufacturing industry. It can be defined as transforming the product design into detailed instruction for product manufacturing. 
In general, process planning in machining industry is defined as the transformation of product characteristics from the design stage into the operating instructions, i.e. the machines, tools and other parameters used for converting the raw material into the finished product. Since there may be several options to achieve the product characteristics, the process of selecting the best set of process sequence, machines, and machines tools is critical to minimize the cost of manufacturing and/or improve the quality. For any machining process, it is very important that all the parameters (design data, quality requirements, equipment capabilities, etc.) and product characteristics be considered to select the proper machines and machine tools. There are several approaches to process planning which can be categorized as follows (Figure 1.2). (Zang et al., 1994)

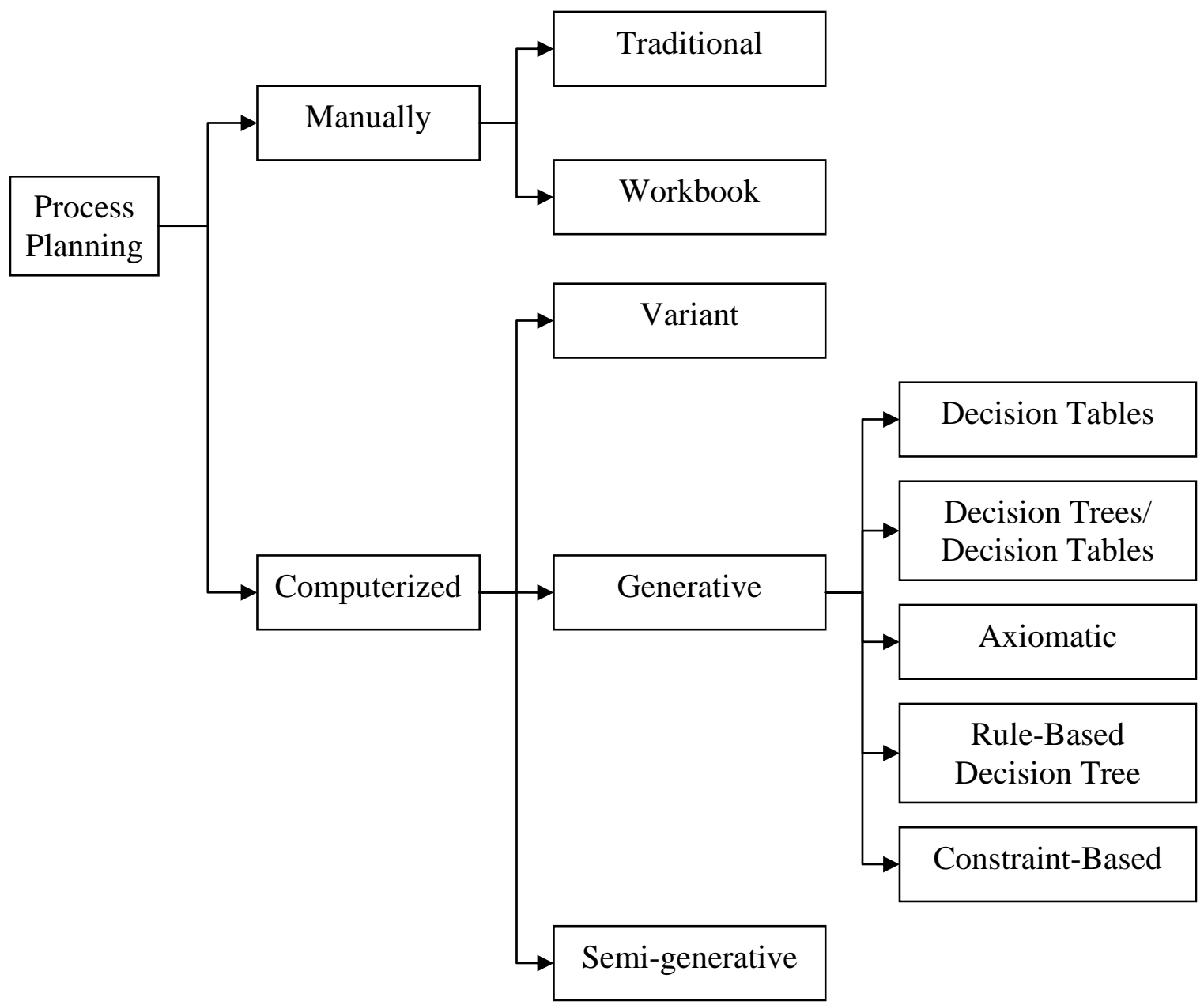

Figure 1.2: Process Planning Approaches (Zang et al., 1994) 


\subsubsection{Manual Process Plans}

Traditional Approach: This approach involves the study of the product design, matching the design to an existing part design (group technology), and modifying the process plan for the current part to suit the new part. It is obvious that this approach is simple but may not lead to a good process plan. The basic principle used by group technology is that the decisions in one situation can be applied to the decision to other situation(s) in the same group. The groups are formed based on different methods and the most common methods are: (a) classification (visual and coding) and (b) cluster analysis. Among other authors, the group technology concepts are discussed by Snead (1989), Kusiak (1990) and Singh (1996).

Workbook Approach: This category of manual process planning consists of a workbook with a menu of pre-sorted sequences of operations for given types of products. Adequate sequence of the processes may quickly be selected to produce the new design of part.

Based on the characteristics of the manual process plans, it is obvious that significant experience is necessary to produce a workable plan for new designs. The main advantage of the manual process plan is that it requires low investment and has high flexibility. On the other hand, the disadvantages include inconsistent process plan and difficulty to include new processes and products.

\subsubsection{Computer-Aided Process Plans}

It is interesting to note that even though there are many disadvantages to the manual process planning, many industries still use skilled workers to generate process plans. The importance of computerized process planning has been increasing in recent years because of shortage of skilled labor to perform this task, increasing complexity in the product design, and increased requirements of customization resulting in numerous product designs. The computerized systems reduce the amount of manual interaction and increase the accuracy and consistency of the process plans significantly. The computerized process planning is categorized as follows. 


\subsubsection{Variant Approach}

Similar to the manual process planning, the variant approach deals with developing the process plan by retrieving a process plan for similar/master part and modifying the plan for the new part under consideration. A classification and coding system is used to retrieve the standard design from the database. These process plans can be edited by incorporating the knowledge of the process planner and therefore possess similar advantages and disadvantages e.g. it may be hard to accommodate various shapes and structures under similar process plans. Variant approaches require less investment and time to store or generate new process plans.

\subsubsection{Generative Approach}

This approach involves the generation of a process plan from scratch and therefore requires no database for part families and previous process plans. The process plan for any part is developed based on the manufacturing algorithms, geometric data, logical decisions, and formulae. The input to the generative systems can be entered either through answering a set of interactive questions or through CAD module. The alternatives in generative approaches are discussed by Allen (1987).

\subsubsection{Semi-Generative Approach}

This approach is a combination of the variant and generative approaches. It is obvious that developing a true generative system is difficult because of the complicated product geometries and availability of resources. The semi-generative approach utilizes the benefits of these two systems and develops a good process plan which may not be as good as the one from generative approach but can be developed fairly easily and in much less time.

The proposed research is an example of the generative process planning approach. Based on the analysis of the current articles, it was noted that most of the research tries to find the combination of final solution in a sequential manner i.e. the process sequencing problem is solved before the parameter selection/optimization process is performed. In 
some cases, the processes will have predefined tools and machines, and the parameter optimization/selection process is performed only on the given combination. At this point, it may be noted that a single process may be performed using several machines, tools and other resources. As an example, the machine and tool selection is based on characteristics such as physical properties of the work material, selected process, etc. Since there may be several machines and tools that can be used for a given material and process, it is not advisable to predefine the set of machines and tools and perform the process planning activity. This implies that the process planning exercise may result in better results if both the elements (process sequencing and process characteristics) are considered at the same time to achieve certain product characteristics. The present research uses the machine tool database present in the MPSEL program (Gopalakrishnan, 1989). The list of resources in this database is as follows.

\subsection{Resource Database}

The MPSEL program consists of the following machines and tools for turning and cylindrical grinding operations.

\subsubsection{Machines in the database \\ Turning Operation}

Engine Lathe

Turret Lathe

Single Spindle Auto

NC Lathe

\section{Cylindrical Grinding}

Cylindrical Grinding Machine

\subsubsection{Tools in the Database}

A sample of tools available in the MPSEL database is given in Table 1.1. The notation for the tools is based on the type and grade of the tool. For example, "hss" is for high speed steel, "cr" is for carbide tools, "cer" is for ceramic tools, and "gr" is for grinding tools. Also, the numbers associated with these letters are the special grades of the tools. 
Table 1.1: List of Tools in the MPSEL Database

\begin{tabular}{|l|l|}
\hline Tool Name & Tool Name \\
\hline HSS & sp_hss_m2_m3 \\
\hline Carbide & sp_cr_c7_c6 \\
\hline Ceramic & gr_wheel_hard \\
\hline
\end{tabular}

\subsubsection{Tool Parameters}

The parameters related to the selection of tools for turning and grinding processes are given in Appendix 1. It should be noted that these are arbitrary values and may change for a specific factory. The values have been assumed based on the machining data handbook and are presented here to show how the model works. The values in the database can be changed for any specific factory database. It may be noted that the generalized equations used in the model are based on sharpening and indexing but for simplicity it is assumed that the tools cannot be sharpened or indexed and therefore the corresponding values (number of times sharpened and/or indexed) are not included in the database. All HSS tools are solid tools. In case of using tool inserts, the tool is discarded after using all the edges in the insert (no re-sharpening needed). When doing one or more operations on the same machine without changing the orientation of the part, the job setup time is incurred for the first operation only, and subsequent operations have a job setup time of zero.

\subsection{Generalized Equations for Machining Costs}

The model developed in this research utilizes the generalized equations for the calculation of machining cost per unit. As stated before, the cost of re-sharpening and indexing is assumed to be zero they are not allowed in the present model. The notations used in the model are as follows.

a approach of tool to work; in.

C total cost for machining one work piece; \$/work piece

$\mathrm{C}_{\mathrm{c}} \quad$ cost of each insert or inserted blade; \$/blade

$\mathrm{C}_{\mathrm{p}} \quad$ purchase cost of tool or cutter; $\$ /$ cutter 
$\mathrm{C}_{\mathrm{w}} \quad$ cost of grinding wheel for re-sharpening tool or cutter; \$/cutter

d depth of cut; in.

D diameter of work in turning; in.

e pre-travel and over-travel of cutter past work piece; in.

$\mathrm{f}_{\mathrm{r}} \quad$ feed per revolution; in./rev.

G labor + overhead on tool grinder; \$/min

$\mathrm{k}_{1}$ number of times lathe tool, or milling cutter, or drill, is re-sharpened before discarded

$\mathrm{k}_{2}$ number of times lathe tool or milling cutter is re-sharpened before inserts or blades are re-brazed or reset

$\mathrm{k}_{3} \quad$ number of times blades (or inserts) are re-sharpened (or indexed) before blades (or inserts) are discarded

L length of work piece in turning and milling or sum of lengths of all holes of same diameter in drilling, reaming, tapping; in.

M labor + overhead cost on lathe, milling machine or drilling machine; $\$ / \mathrm{min}$.

$\mathrm{N}_{\mathrm{L}} \quad$ number of work pieces in lot

$\mathrm{r} \quad$ rapid traverse rate; in./min.

$t_{b} \quad$ time to re-braze lathe tool or cutter teeth or reset blades; in.

$t_{c} \quad$ time to change tool or index inserts in cutter; min./cutter

$t_{L} \quad$ time to load and unload the work piece; min./unit

$\mathrm{t}_{\mathrm{o}} \quad$ time to setup machine tool for operation; min.

$t_{s} \quad$ time to re-sharpen lathe tool, milling cutter, or drill; min./tool

$\mathrm{T}$ tool life measured in minutes to dull a lathe tool; min.

$\mathrm{T}_{\mathrm{t}} \quad$ tool life measured in inches travel of work or tool to dull a drill or one milling cutter tooth; in.

V cutting speed; ft./min.

w width of cut; in.

W grinding wheel cost to sharpen tool or cutter; \$/cutter

$\mathrm{Z} \quad$ number of teeth in milling cutter 
An example illustration with some of the parameters is given in Figure 1.3 (Creese et al., 1992).

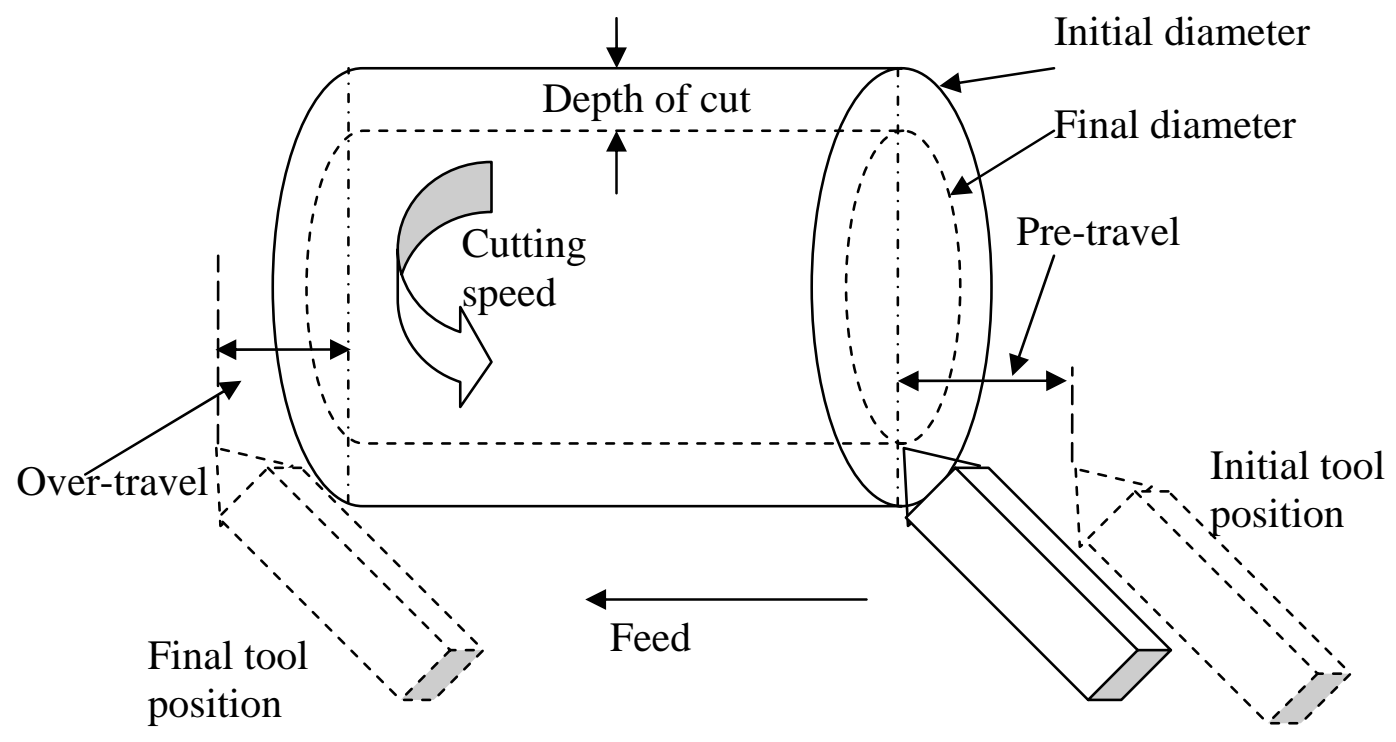

Figure 1.3: Example Machining Parameters

The equations developed for different processes are as follows. (Machining Data Handbook, 1980)

\subsubsection{Turning Cost Per Unit}

The following components are considered for calculating the cost for turning operation.

1. Labor related cost components:
a. Feed time
b. Rapid traverse time
c. Load and unload time
d. Setup time
e. Tool change time

2. Tool related cost components:
a. Depreciation cost
b. Tool re-sharpening cost
c. Re-brazing or blade reset cost
d. Insert or blade cost 


\section{e. Grinding wheel cost}

Based on these components, the cost per unit for a turning operation is given as,

$$
C=M\left[\frac{D(e+L)}{3.82 f_{r} V}+\frac{2 a+e+L}{r}+t_{L}+\frac{t_{o}}{N_{L}}+\frac{D L t_{c}}{3.82 f_{r} V T}\right]+\frac{D L}{3.82 f_{r} V T}\left[\frac{C_{P}}{k_{1}+1}+G t_{s}+\frac{G t_{b}}{k_{2}}+\frac{C_{c}}{k_{3}}+C_{w}\right]
$$

\subsubsection{Cylindrical Grinding Cost Per Unit}

The following components are considered for calculating the cost for grinding operation.

1. Labor related cost components:
a. Feed time
b. Rapid traverse time
c. Load and unload time
d. Setup time
e. Tool change time

2. Tool related cost components:
a. Depreciation cost
b. Dressing cost
c. Dressing tool cost

Based on these components, the cost per unit for a grinding operation is given as,

$$
C=M\left[\frac{D(e+L)}{3.82 f_{r} V}+\frac{2 a+e+L}{r}+t_{L}+\frac{t_{o}}{N_{L}}+\frac{D L t_{c}}{3.82 f_{r} V T}\right]+\frac{D L}{3.82 f_{r} V T}\left[\frac{C_{P}}{k_{1}+1}+G t_{s}+C_{w}\right]
$$

\subsection{Example Process Planning Problem}

To illustrate the steps followed in a process planning optimization process, an example part (Figure 1.4) is considered with initial dimensions of 7.0 inches (length) and 4.5 inches (outside diameter). Since the final dimensions are 6.0 inches (length) and 4.0 inches (outside diameter), turning and facing/milling processes are required for the product. Furthermore, drilling, tapping, milling (T-slot), and grinding processes are required to achieve the final product characteristics. 


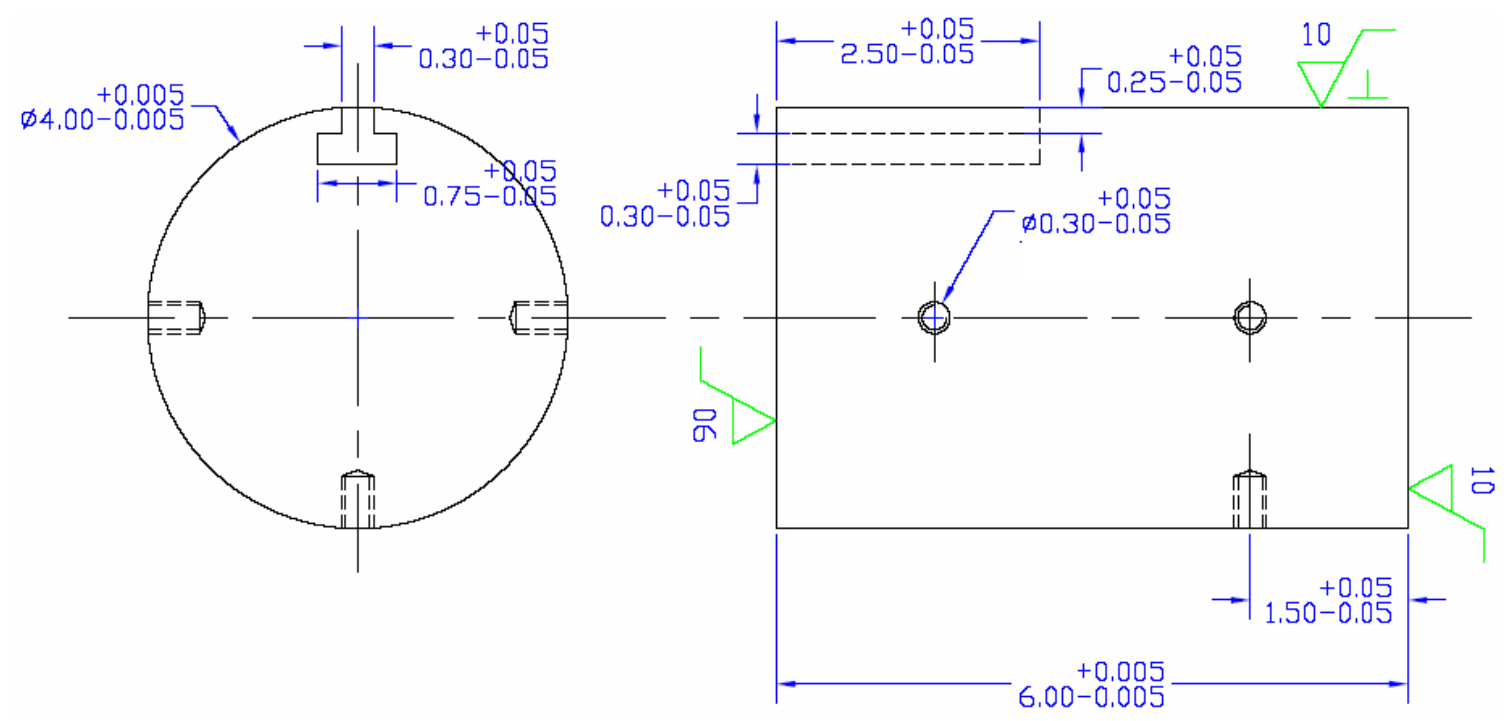

Figure 1.4: Example Part for Process Planning Problem

Some other product characteristics are as follows.

1. The material type is assumed to be ferrous.

2. The material is "as cast".

3. Surface finish of 90 or more is assumed to be "High" and the surface finish of 10 or less is assumed as "Low".

A sample process plan with only the sequence of operations could be as follows.

1. Turning operation to reduce the diameter from 4.5 inches to 4.1 inches

2. Facing operation on one side to reduce the length from 7.0 inches to 6.05 inches

3. Drilling operation to create 2 holes on one side of the cylindrical surface

4. Drilling operation to create 2 holes on second side of the cylindrical surface

5. Drilling operation to create hole on the bottom side of the cylindrical surface

6. Milling operation to crate the slot on top of the cylindrical surface

7. Grinding operation to reduce the length to 6.0 inches and achieve the required surface finish

8. Grinding operation to reduce the diameter to 4.0 inches and achieve the required surface finish 
The sequence of these processes is an important factor in defining the final cost of machining. For example, turning process in step 1 could be performed after the facing operation in step 2 or drilling operations in steps 3, 4, and 5. Similar changes can result in a different process sequence and machining cost. The other point that should be noted here is that the number of passes required to perform a specific step could be more than one; e.g. in step 1, based on the maximum depth of cut allowed for a tool, the number of passes may be two or more. Thus the number of steps performed to convert the stock material into the final product could be more than eight (as shown in the example). Finally, for most of the operation steps described above, different processes may be selected if they are able to achieve surface roughness requirements. For example, for the first step for reducing the diameter, grinding process could be used but may cost a lot more than what it would cost for the turning process. It is evident that there are too many variables and conditions that govern the process planning task, and the cost of the final product depends on what parameters are chosen to perform the processes.

There are numerous discussions and publications on how to solve this problem and minimize the cost of operation; but the most important element that the present models lack is the selection of machine and tool to perform any specific operation step. And in cases where this aspect was considered, the actual cost of machining was not taken into account. Assuming that the set of tools and machines are predefined, existing optimization approaches can be used to minimize the total cost of machining for this product. In this case, the process characteristics are constant since the tools and machines are known in advance and the corresponding values can be used to minimize the cost of machining for any process. On the other hand, if there are several machines and tools that can be used to perform the required processes and achieve the product characteristics, it is computationally expensive to evaluate each and every combination of machines and tools to minimize the cost of a certain operation. As an example, the first pass of turning in step 1 can have three candidate machines and six candidate tools that can be used, and they may have different costs associated with them. To find the combination of machines and tools that will result in the minimum cost, the process planner will need to perform $18(=3 * 6)$ optimization calculations for this step only. 
Also, the following process may have one or more machines and tools that are same as in this process; therefore it may be beneficial to choose the same machine and/or tool to save on setup cost. This suggests that the two processes may interact. Finally, the total number of iterations could be as much as the product of the possible combinations in the two adjacent processes. It is apparent that the total number of combinations that the user may need to evaluate could become too large with an increase in the number of steps required for the product. At the same time, the process of finding the speed, feed, and depth of cut may be based on some mathematical formulae or may come from different tables developed by the process planner. Though not impossible, it may not be economical to perform all these iterations and/or the process planner may not have enough time to do so, especially in today's environment where custom manufacturing is practiced in almost every industry and no two products may be the same in terms of processing requirements.

The other problem that the process planner may face is to manually input the output data from machine and tool selection models into the machining parameter selection models. An example of the output file from a process planning model is given in Appendix 2. The useful information in this output file is shown in Table 1.2. The machines and tools selected to perform the process under consideration are:

Machines: $\quad$ NC Lathe, Single Spindle Automatic

Tools: Carbide (including grades C6 and C7), High Speed Steel (including grades M2 and M3)

It may be noted that the amount of useful information may be very little as compared to the length of the output file. Currently, the process of finding the relevant output (machines and tools selected for the process under consideration) is manual.

Table 1.2: Information in the Output File Useful for Resource Selection

\begin{tabular}{|l|l|}
\hline carbide $=$ selected CNF 100 & single_sp_auto = selected CNF 100 \\
\hline hi_sp_steel $=$ selected CNF 100 & sp_cr_c7_c6 = selected CNF 100 \\
\hline nc_lathe $=$ selected CNF 100 & sp_hss_m2_m3 = selected CNF 100 \\
\hline
\end{tabular}

*CNF: confidence limit as defined in expert system 


\subsection{Problem Complexity}

To demonstrate the complexity involved in the process planning problem under the present research, a numerical example is considered in this section. Assume that the part to be machined is similar to the one given in Section 1.2.3, and requires only 2 processes: turning and facing. The initial dimension of 4.5 inches diameter and 7.0 inches length is to be reduced to 4.1 inches diameter and 6.1 inches length. Also, the surface finish requirements for both the process are considered as 90 micro-inches. It may be noted that the sequence of the processes could be one of the following:

1. Turning operation (reduce diameter from 4.5 to 4.1 inches) followed by a facing operation (reduce length from 7.0 inches to 6.1 inches)

2. Facing operation (reduce length from 7.0 inches to 6.1 inches) followed by a turning operation (reduce diameter from 4.5 to 4.1 inches)

Assuming that the machines and tools are defined for the two processes, the models available in the literature could be used to find the "best sequence" for the machining operation for the work-piece. Using the MPSEL expert system (Gopalakrishnan, 1989), the following machines and tools are selected for the processes, based on the sequence of operation.

\section{Sequence 1}

Turning operation:

Tools: Carbide, Carbide grade c6, Carbide grade c7, High speed steel (HSS), HSS grade m2, and HSS grade m3

Machines: NC lathe, Single spindle automatic machine, and Engine lathe

\section{Facing operation:}

Tools: Carbide, Carbide grade c6, Carbide grade c7, High speed steel (HSS), HSS grade m2, and HSS grade m3

Machines: NC lathe, Single spindle automatic machine, and Engine lathe 


\section{Sequence 2}

Facing operation:

Tools: Carbide, Carbide grade c6, Carbide grade c7, High speed steel (HSS), HSS grade m2, and HSS grade m3

Machines: NC lathe, Single spindle automatic machine, and Engine lathe

\section{Turning operation:}

Tools: Carbide, Carbide grade c6, Carbide grade c7, High speed steel

(HSS), HSS grade m2, and HSS grade m3

Machines: NC lathe and Single spindle automatic machine

The most interesting fact to note at this point is that Engine lathe was not selected to perform the turning operation in the second sequence because of change in the input parameters which was caused by performing the facing operation before the turning operation. Here, the total number of combinations to perform the first sequence is 36 [18 (6 tools * 3 machines) for the turning operation and 18 (6 tools $* 3$ machines) for the facing operation] and for the second sequence it is only 30 [18 (6 tools * 3 machines) for the facing operation and 12 (6 tools * 2 machines) for the turning operation]. Therefore, a total of $66(36+30)$ combinations should be evaluated to find the "minimum cost" for machining the example work-piece. It may be noted that in the present literature, only 2 combinations were present (related to the sequence) since the machine and tool for each process was predefined. Therefore, the present problem is more complicated than the ones presented in the literature so far.

It is evident that the complexity involved with getting the information from several sources (machine database, tool database, parameter database, etc.) limits the expertise a process planner may have by himself/herself. A small change in one of the parameters may lead to significant difference in the final cost for machining and the planner may need to develop a new plan from scratch. Therefore, it is hard to generalize the selection process of machines and tools to minimize the cost of machining a piece that needs several operations to convert the stock material to the final shape. The selection process 
can be facilitated by using a computer based model that will link all the databases together with the MPSEL program (Gopalakrishnan, 1989) and the user input interface so the possible combinations are quickly evaluated. Also, the change in the sequence will lead to new dimensions and therefore new combinations of machine and tool required for the process. To minimize the evaluation of number of possible combinations, a heuristic method can be utilized.

\subsection{Need for Research}

The process planning problem is one of the very complex problems in manufacturing industry. The final cost of any machined product is dependent on the effectiveness of the process plan developed for different operations required to convert the raw material into finished products. Several models have been developed in this area to deal with individual or several components together in the process planning phase. All the models address the issue of operation sequencing, machine and tool selection, and finally the parameter optimization process on individual basis. Some of the models that were developed to address more than one components lack the amount of variation they can handle. As an example, some of the models deal with process selection and parameter optimization but they assume that the type of machines and tools for a given process are fixed. It is obvious that there may be a better solution if all the components in the process planning phase are addressed together. This research is an attempt to integrate the main activities, the process sequencing, machine and tool selection, and machining parameter selection. It is clear that an integrated model is required to automate the process of sequencing the operations, machine and tool selection, exporting the relevant output to the machining parameter models, and finally reporting a solution that minimizes the total machining cost. To the best of the author's knowledge, this analysis has not been performed in any of the process planning models developed so far. Since the results from this research will not only benefit the machining industries but other industries wherein similar decisions may be required, it is important to develop an analytical tool that can eliminate or reduce the amount of manual iterations required to obtain the best solution and guarantee a reasonable and quick response to the process planning problem. 


\subsection{Research Objectives}

The main objectives of this research are.

1. Develop an integrated model for the process planning problems in machining (sequencing, machine and tool selection, and machining parameter selection).

2. Develop a computer based system to facilitate the analysis.

3. Validate the results from the proposed model by comparing it with results from complete enumeration for smaller problems.

A simple representation of the current models and the proposed model is shown in Figure 1.5 and Figure 1.6 respectively.

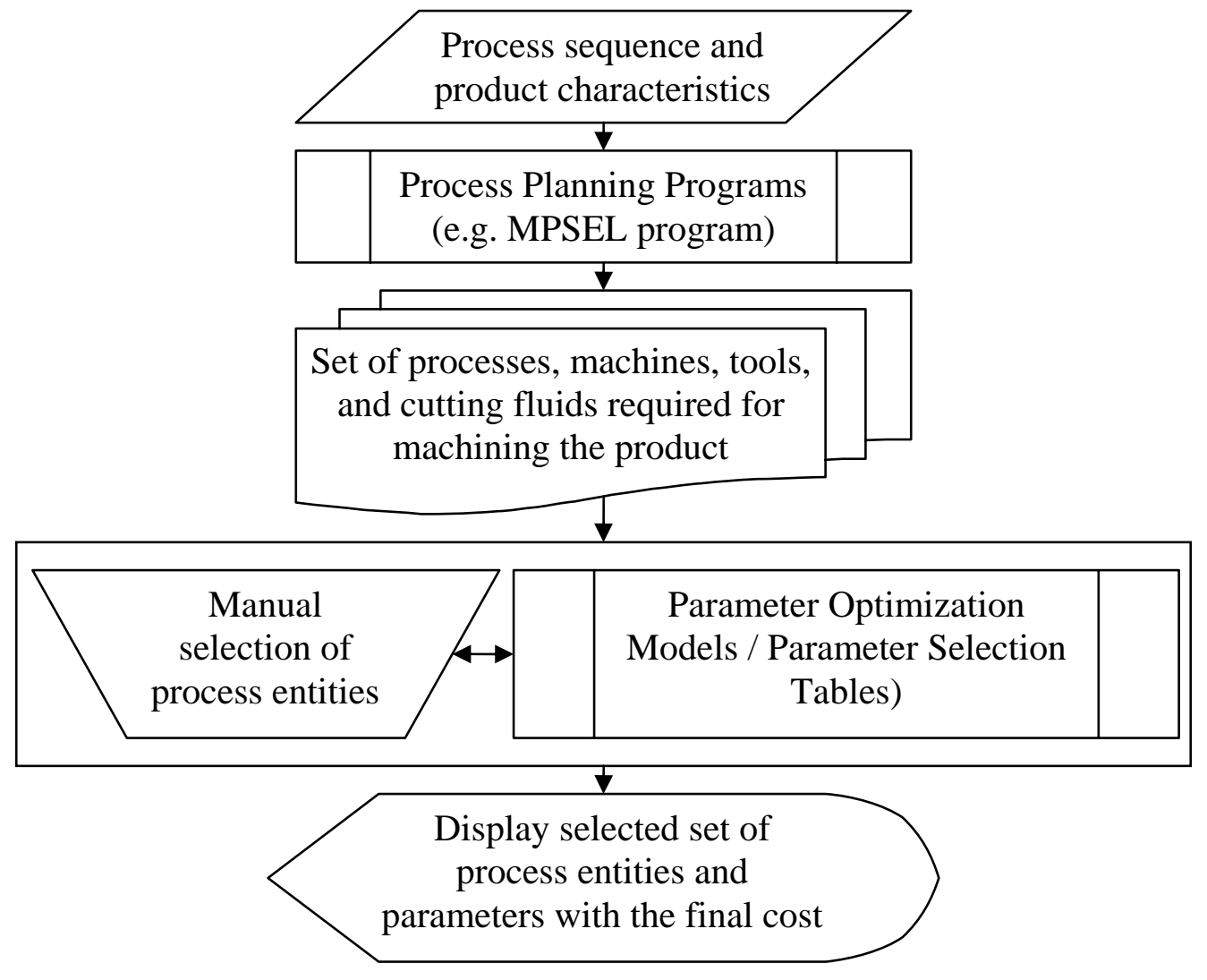

Figure 1.5: Current Procedure of Machine Tool and Process Parameter Selection 


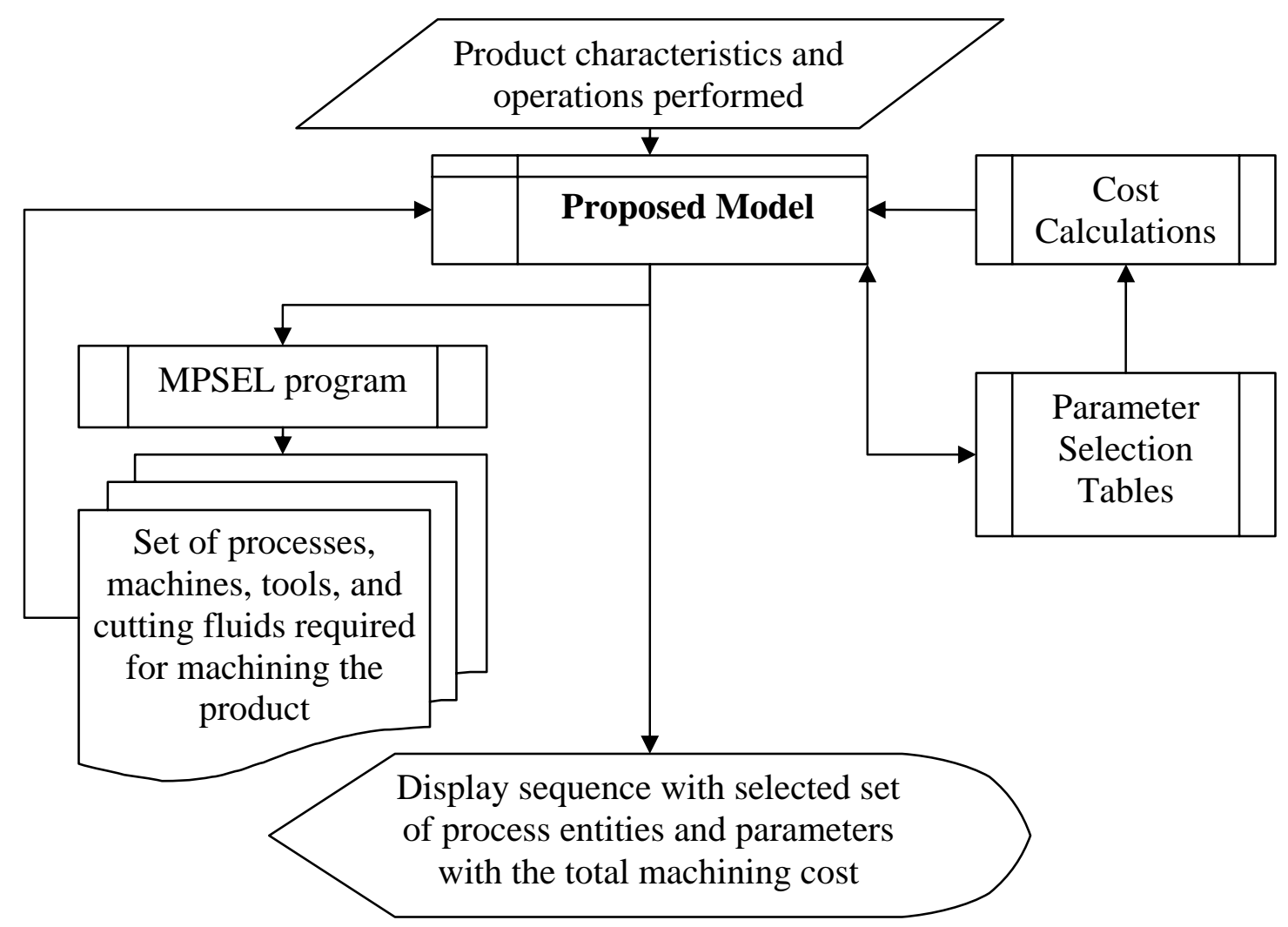

Figure 1.6: Proposed Procedure of Machine Tool and Process Parameter Selection

\subsection{Conclusion}

Process planning is very important to minimize the cost of products in machining industry. The final goal of a process plan is to convert the product drawings into machining instructions. This includes the steps such as process selection, process sequencing, machine and tool selection, and parameter selection/optimization. Since each step required to achieve this goal includes complex analysis, several models have been developed to address the need(s) of individual stages. It is obvious that the individual models lack the information from the next steps and the process planning activity in a specific stage assumes certain parameter that will be decided in the next stage, the final cost of the machined product may not be optimized. The proposed model is focused on integrating the process sequencing, resource (machine and tool) selection, and machining parameter selection. 


\section{CHAPTER 2 : LITERATURE REVIEW}

Several research papers have been published in the area of process planning optimization. A survey of these papers is presented by Zhang et al. (1994) and a sample list of publications discussed in this research is given in Table 2.1.

Marri et al. (1998) published a survey on existing CAPP models and indicated that the current systems lack the integration of process planning and cost estimation. They also concluded that the present models offer partial solutions and are limited in scope. The authors pointed out that the integrated and intelligent process planning required a knowledge-based system for CAPP. A summary of some of the research in process planning field is given in the following sections.

\subsection{Expert Systems for Process Planning}

Descotte et al. (1981) presented a process planning expert system (GARI) for machining mechanical parts. The program was written in MACLISP language and describes the part in terms of entities such as holes, grooves, notches and faces. The model includes both geometrical and technological data.

Nau et al. (1985) presented a frame based expert system for process planning. Branch and bound algorithm was used to develop the model. The objective function was to minimize the cost of process plan.

Gopalakrishnan (1989) developed MPSEL, an expert system for machining parameter selection in job shop environment. The proposed model harnesses the benefits of expert systems and couples it with an algorithm for efficient decision making. The paper outlines the factors and procedures for selecting machines, tools, cutting fluids, tool angles and interaction between work material and the operations. 
Table 2.1: Sample Computer-Aided Process Planning Models

\begin{tabular}{|c|c|c|c|}
\hline System & Approach & Reference & Year \\
\hline EXAPT & Variant & Budde & 1973 \\
\hline CAR & Variant & Akiba and Hitomi & 1975 \\
\hline CAPP & Variant & Link & 1976 \\
\hline APPS & Generative & Wysk & 1977 \\
\hline CAPSY & Generative & Spur et al. & 1978 \\
\hline AUTAP & Generative & Eversheim et al. & 1980 \\
\hline GLIM & Variant & Holevi and Weill & 1980 \\
\hline DCLASS & Variant and Generative & Allen & 1980 \\
\hline GARI & Generative & Descotte and Latombe & 1981 \\
\hline AUTODAK & Generative & Weill et al. & 1982 \\
\hline ACAPS & Semi-generative & Emerson and Ham & 1982 \\
\hline СРРР & Generative & Nau Chang & 1983 \\
\hline XPS-1 & Variant and Generative & Sack Jr. & 1983 \\
\hline CUTTECH & Generative & Barkocy and Zdeblick & 1984 \\
\hline AUTOPROS & Variant & Moseng & 1984 \\
\hline APS & Variant and Generative & Moseng & 1984 \\
\hline APLAN & Generative & Eversheim and Schulz & 1985 \\
\hline АВTOTPZK & Variant & Eversheim and Schulz & 1985 \\
\hline AUTOPLAN & Variant and Generative & Wolfe & 1985 \\
\hline AGFPO & Generative & Chryssolouris & 1986 \\
\hline MICRO-GEPPS & Semi-generative & Wang and Wysk & 1986 \\
\hline ARPL & Variant & Rembold and Dillman & 1986 \\
\hline AC/PLAN & Variant and Generative & Appolo Computer Catalogue & 1986 \\
\hline APP & Generative & Haas and Chang & 1987 \\
\hline AUSPLAN & Semi-generative & Lin and Bedworth & 1987 \\
\hline AUTOCAP & Variant & Wright et al. & 1987 \\
\hline System & Approach & Reference & Year \\
\hline ZCAPPS & Variant and Generative & Haas and Chang & 1987 \\
\hline AMPS & Generative & Inui et al. & 1988 \\
\hline AVOGEN & Generative & Tonshoff et al. & 1989 \\
\hline CIMPP & Generative & Lai and Cai & 1990 \\
\hline
\end{tabular}


Gopalakrishnan (1990) presented the design aspects for an expert system to facilitate the selection of machining parameters. Based on the inbuilt knowledge base and user inputs, the model recommends the set of machines and tools along with cutting fluids that may be used for the process under consideration. It also outputs the machining conditions such as "thermal shock", "tool chip friction” etc. for certain operations.

Yeo et al. (1991) presented an integrated knowledge-based machining system that could model and generate a practical machining plan for rotational parts. A frame-based approach was used to generate the sequence of machining tasks for turned parts.

Singh et al. (1992) developed an expert system for machining planning. The model was called as METEX and was developed to find the cutting conditions based on the desired set of parameters. The prototype model was used for a turning process problem and was able to find the impacts such as high temperature zones, and compressive stress development etc.

Wong and Siu (1995) developed a knowledge-based expert module to automate the machining process selection and sequencing. The algorithm was named as APSS (Automatic Process Selection and Sequencing) and was written in Prolog. The algorithm can generate operation sequences of minimum number of cutting tool changes and part loading/unloading to the machine tool.

Wong (2003) et al. proposed a machining process sequencing model using fuzzy expert system and genetic algorithms. This model was able to consider the fuzziness in the input data and find the process sequence with best solution. Once again, there was no choice of machines and tool for any process. For sequencing any specific process, the model had to simply look into the machining cost parameters for a given set of machines, tools and other variables and find the solution for the problem. 


\subsection{Optimization/Heuristics Approach for Process Planning}

Lin et al. (1993) presented integer programming based solution approach for the process planning problem. The objective of this approach was to minimize the tool changeover.

Batchu et al. (1995) developed a user-assisted iterative approach to process planning. The model was particularly useful to the situations where the evaluation criteria may change based on the user interaction. One of the problems this model faces is that it is based on hill-climbing heuristic and therefore, it may not result into a good solution.

Zhang et al. (1997) presented a Genetic Algorithm (GA) based approach for generating process plans by considering the selection of machines, tools, tool approach directions, and operations sequencing. The actual cost of machining was not considered in this method as well.

Khoshnevis et al. (1999) presented 3I-PP model that was focused towards integrating feature completion, process selection, and process sequencing operations in the process planning phase for milling and drilling operations. The model presented by the authors lacks the number of options that a single process may have and did not include the parameter optimization concept.

Reddy et al. (1999) demonstrated the application of genetic algorithms for quick identification of optimal or near optimal operation sequences in a dynamic planning environment. For sequencing the operations, the model considered the costs parameters as 1,11 , and 100 for changes that required machining parameter change, setup change, and machine change respectively. Since the model did not consider the actual cost of machining operations, it is obvious that the machining cost may not be optimized based on the model proposed by the authors.

Chang et al. (2000) presented an integrated system for computer aided process planning. The disadvantage of this system was that it was capable of selecting the process, machines, and machine tools based on the capabilities, not on the cost. 
A simulated annealing based solution approach was developed by Ma et al. (2000) to solve the machining process planning problem. The proposed model considered the machine, tool, machine change, tool change, and setup change cost while minimizing the total cost of the process plan. The cost factors were represented in terms of indices and therefore do not change based on when the operations is performed.

Keung et al. (2001) presented a Genetic Algorithm (GA) based methodology to the multiple machine tool selection problems. The model was focused on minimizing the number of tool switches and tool switching instances. It was shown that GA is an appropriate solution to the problem.

Lee et al. (2001) presented six local search algorithms to solve the process planning problem. The algorithms were based on Simulated Annealing and Tabu Search heuristics. It was shown that one of the Tabu Search based algorithms resulted in optimal solutions for most small sized problems.

Lee et al. (2001) developed algorithms based on branch and fathoming to solve the operations sequencing problem. The authors tried to minimize the cost of machining that included the machine, setup and tool change cost.

An agent based optimization approach was developed by Deshpande et al. (2004). This work combines the process planning and parameter optimization for manufacturing processes. The proposed agent based knowledge is based on the domain knowledge and stochastic search process.

Wang et al. (2005) indicated that tolerance synthesis, process selection, and machining parameter optimization are key issues to reduce production cost. They also mentioned that these key issues are rarely addressed simultaneously. Therefore, the decision form different segments of the overall process planning may conflict with each other. A bicriterion model was developed to optimize the cost and tolerance for the product. It may 
be noted that the model had predetermined set of processes and tools and tries to optimize the process parameters (feed rate, cutting speed, and depth of cut etc.)

Liu et al. (2007) devised a hybrid tool involving knowledge base and geometric reasoning rules for process planning problems. The model helps in determining machining precedence constraints by using set of defined knowledge based rules and groups the operations based on tool approaching directions.

Several other researchers have worked on integrating different aspects in the process planning process. Chen et al. (1994) developed an unsupervised learning approach for solving the setup generation and sequencing problems. Zhang et al. (1995) presented a hybrid approach to solve the setup concerns in process planning problems. Usher et al. (1996) developed a Genetic Algorithm (GA) based solution approach for solving the operations sequencing problem in process planning. A Petri Net model was developed by Kiritsis et al. (1996) to address the problem of dynamic process planning problems. Hopfield Net and Simulated Annealing (SA) were used by Chen et al. (1998) for setup planning of prismatic parts.

\subsection{Conclusion}

The problem of process planning has received great attention of researchers in the past. Several algorithms have been developed to address one of the many components in the process planning problems. Some approaches were developed to integrate two or more of these components but to the best of author's knowledge, no algorithm has been developed that addresses the integrated approach. Therefore, there is a need to develop a systematic approach that not only considers the cost of machine and tool change from one operation to the other but also considers the actual machining cost based on the current dimensions in the process sequence. 


\section{CHAPTER 3 : Research Approach}

The present research combines the process sequencing, tool and machine selection, and machine parameter selection process to minimize the cost of machining. Since the cost parameter optimization process is too complex with all the problems together, the methodology explained in this research tries to achieve a "good result" rather than finding an "optimal solution". Thus the cutting parameters (feed, speed, and maximum depth of cut are selected from the database to reduce the complexity of the proposed problem. The assumptions for the proposed model are as follows:

1. The proposed model is applicable to cylindrical part only.

2. The objective function of the model is to minimize the machining cost.

3. Only the direct machining costs (labor and tool costs) are considered but the labor rate may be given as fully burdened rate.

4. The model considers turning and cylindrical grinding processes only.

5. List of machines and tools that can be used for a process are generated using the existing expert system (MPSEL) and therefore are limited to the existing factory database.

6. The machining parameters for a process and combination of machine and tool are chosen from the given database. The database is defined in advance but may be changed as needed.

7. The precedence relationship among all the operations is predefined (e.g. operation 2 can be performed only after 1 is finished).

8. Rough and finish cuts are differentiated by the user and given as two processes.

9. The surface finish that the process will achieve is given by the user in advance.

The model is not only able find all the sequences based on the precedence relationship but is also able to generate possible options which help the user to combine different sections in the final work piece. An option is defined to reflect the combination of sections that can be machined together. For example, if a 4 inch (diameter) workpiece is to be turned in two sections with final diameters as 2 inches and 3 inches, the turning 
process can be performed to first reduce the entire diameter to 3 inches followed by another turning operation to reduce the diameter from 3 inches to 2 inches for a section of the workpiece. Thus part of another section(s) can be performed at the same time. On the other hand, the turning operation can be performed to reduce the diameter from 4 in. to 3 inch. for one section and from 4 inches to 2 inches for the other section. The possibility of combination like this one increases the complexity of the model since the model has to keep track of the parent process along with all the details in terms of which machine and tool were used in that process and what was the cost and time value till that point.

\subsection{Automated Dimension Tracking}

It is evident that the process planning operation can be fully automated only if there is a way to track the current work piece dimensions and the surface characteristics. An example is presented to illustrate the importance of this requirement.

\section{Example problem}

The part that is considered in this example is required to be machined in two sections with different diameters. The initial stock material and the final shape of the work piece are shown in Figure 3.1.
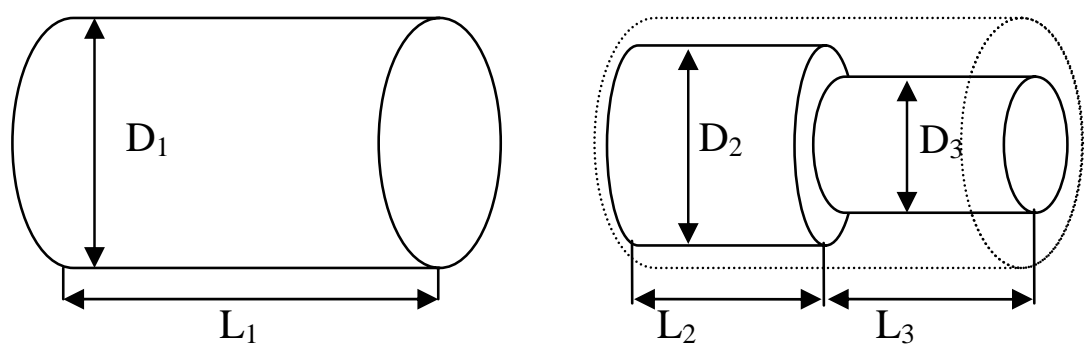

Figure 3.1: Example Problem

As shown in Figure 3.1, the final shape can be achieved in one of the following ways.

1. Reduce the diameter from $D_{1}$ to $D_{2}$ for a length of $L_{2}$ then reduce the diameter from $D_{1}$ to $\mathrm{D}_{3}$ for a length of $\mathrm{L}_{3}$. 
2. Reduce the diameter from $D_{1}$ to $D_{3}$ for a length of $L_{3}$ then reduce the diameter from $D_{1}$ to $\mathrm{D}_{2}$ for a length of $\mathrm{L}_{2}$.

3. Reduce the diameter from $D_{1}$ to $D_{2}$ for a length of $L_{1}$ then reduce the diameter from $D_{2}$ to $D_{3}$ for a length of $L_{3}$.

It may be noted that for this simple problem, there are three different possibilities that a machinist can choose from. In the first two sequences, the cost of machining may not change since the material that should be removed and the machining process (turning) does not change. But the set of machines and tools that may be used can change based on the current dimensions at that time. In the last case, the material that should be removed in a specific setup is different from the first two cases. For example, the total depth and length of cut for the first two cases are $\left[\left(D_{1}-D_{2}\right), L_{2}\right]$ and $\left[\left(D_{1}-D_{3}\right), L_{3}\right]$ respectively and the number of passes that is required will be dependent on the maximum depth of cut allowed for turning operation in one pass. The depth and length of cut that is required for the last sequence is $\left[\left(D_{1}-D_{2}\right), L_{1}\right]$ and $\left[\left(D_{2}-D_{3}\right), L_{3}\right]$ respectively for the two turning processes. Again the number of passes is dependent on the maximum depth of cut allowed for the turning process and may be different from the first two cases. These differences will lead to a difference in the total cost to machine the work piece.

Assuming that the initial diameter for the stock material is $1.0\left(D_{1}\right)$, the final diameters are $0.7\left(\mathrm{D}_{2}\right)$ and $0.4\left(\mathrm{D}_{3}\right)$, and the maximum depth of cut per pass is 0.1 , the number of passes that are required in the first two cases are five [two $\{=(1.0-0.7) /(0.1 * 2)\}$ plus three $\{=(1.0-0.4) /(0.1 * 2)\}]$. In the final case, the number of passes would be four [two $\{=(1.0-0.7) /(0.1 * 2)\}$ plus two $\{=(0.7-0.4) /(0.1 * 2)\}$. Therefore, based on the setup time and other parameters in the process, the cost for machining may be different in these cases.

At this point, it is interesting to note that the starting diameter for the second turning step is dependent on what happened before this operation (it is $D_{1}$ in the first two cases and $D_{2}$ in the last case). Since the automated process planning can pick any of the two operations (as there is no precedence relationship between the two turning steps), the 
starting diameter should automatically be calculated and carried forward as an input value for the machining cost calculation. The proposed model considers all the possible combinations for the length of work-piece that needs to be machined. The process of combination generation (options) is explained in the following section.

\subsection{Generation of Possible Options in Turning Process}

For any section in the current sequence, the model considers the following cases:

1. Check if the adjacent section to the left has smaller or equal final diameter than the one for the current section to be machined. If yes, then combine the sections and the length of the current section is included in the length of machining.

2. Repeat step 1 until all the sections to the left have been verified to have smaller diameter or until the section that is evaluated at present has larger diameter than the one for the current section to be machined.

3. Check if the adjacent section to the right has smaller or equal final diameter than the one for the current section to be machined. If yes, then combine the sections and the length of the current section is included in the length of machining.

4. Repeat step 3 until all the sections to the right have been verified to have smaller diameter or until the section that is evaluated at present has larger diameter than the one for the current section to be machined.

5. Check if the adjacent section to the left and to the right of the current section (that is being considered for machining) have smaller or equal final diameters than the one for the current section to be machined. If yes, then combine the sections and the length of the current sections is included in the length of machining.

6. Repeat step 5 to add sections on the left and right (of the current section to be machined) until the next section to the left or to the right has final diameter larger than the one for the current section.

The logic of generation of possible options is illustrated with an example here. Consider that the work-piece has an initial diameter of four inches and a length of five inches. Assuming that there are five sections, each with one inch length, and the final diameters for these sections are 2.5, 3.0, 3.5, 3.2, and 3.6 inches respectively (Figure 3.2). 


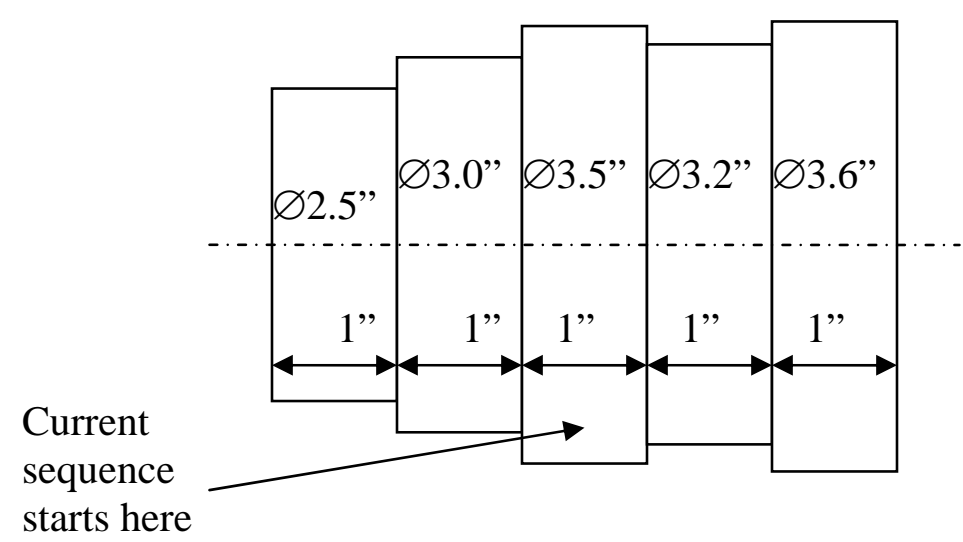

Figure 3.2: Example for Option Generation to Combine Sections

Considering that the current sequence of operations starts with section three, the possible options are as follows.

1. Reduce the diameter of section three from 4 in. to $3.5 \mathrm{in}$. with length of machining as 1 in.

2. Reduce the diameter of sections two and three from 4 in. to 3.5 in. with length of machining as 2 in.

3. Reduce the diameter of sections one, two and three from 4 in. to 3 . 5 in. with length of machining as 3 in.

4. Reduce the diameter of sections three and four from 4 in. to 3.5 in. with length of machining as 2 in.

5. Reduce the diameter of sections two, three, and four from 4 in. to 3.5 in. with length of machining as 3 in.

6. Reduce the diameter of sections one, two, three, and four from 4 in. to 3.5 in. with length of machining as 4 in.

Similar options are generated when the model considers options 3 and 6 while considering sections one or two in the next position in the sequence. The logic of option generation is repeated in each step. The model was prepared in Visual Basic ${ }^{\circledR}$ and Microsoft Excel ${ }^{\circledR}$. The steps involved in the model execution with the corresponding model window are explained in the following section. 


\subsection{Model execution}

The model starts with the execution of VP Expert application. The "Consult" command is executed and the file named " 1 " is selected from the list of all the files. This starts the Visual Basic ${ }^{\circledR}$ application and the welcome screen is shown in Figure 3.3.

\section{G. Form 1}

\section{An Integrated Process Planning Model for Sequence Generation, Machine and Tool Selection, Cutting Parameter Selection, and Cost Calculations}

Click to Start

Exit

Figure 3.3: Welcome Screen

The "Click to Start" button initiates the program and opens the Microsoft Excel ${ }^{\circledR}$ application with the input sheet (Figure 3.4) required for the model. The following steps are performed in the current model.

1. Input the number of operations, lot size, and click "Create Precedence Table" button to create the precedence table. In case of a precedence relationship between any two processes, a value of " 1 " is assigned to the corresponding cell. As an example, a value of " 1 " between successor process " 2 " and the predecessor process " 1 " means that process " 2 " must be performed after process " 1 " has been completed. Similarly, process "3" must be completed before "4" can be performed (Figure 3.4). In case there is no relationship between two processes, the corresponding cell can be left blank or a value of " 0 " can be assigned to it. After all the precedence relationships have been entered in respective cells, the "Enter Process Information" button is clicked to go to the next screen. 


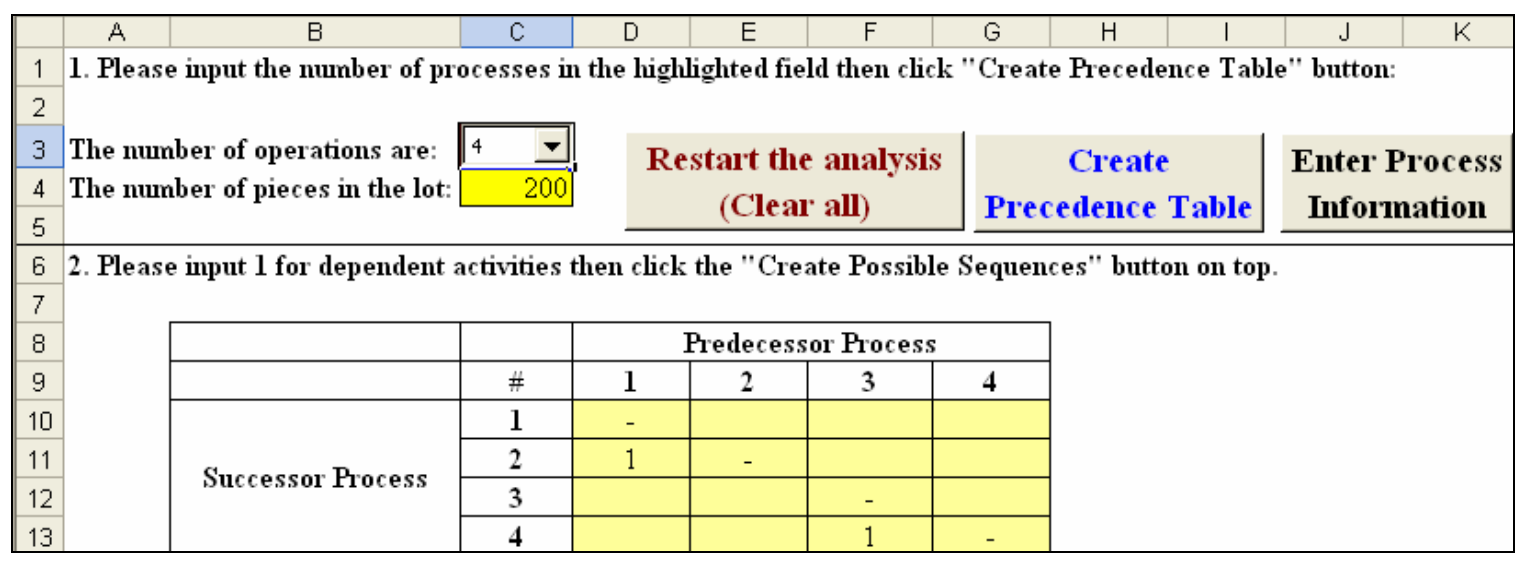

Figure 3.4: Input Screen for Precedence Relationships

2. Input process types (i.e. turning or grinding) with corresponding section number, desired roughness and tolerance, and final diameter for that section after the process is completed. For grinding process, a value of " 1 " should be assigned to confirm “cylindrical grinding” process. It may be noted that the sequence generation model has options for Facing, Milling, flat and slot grinding, and Drilling but they have not been included in the cost calculation process. As an example, for a cylindrical part requiring four turning operations to generate four sections, the operations are listed with the corresponding section number and other required information (Figure 3.5).

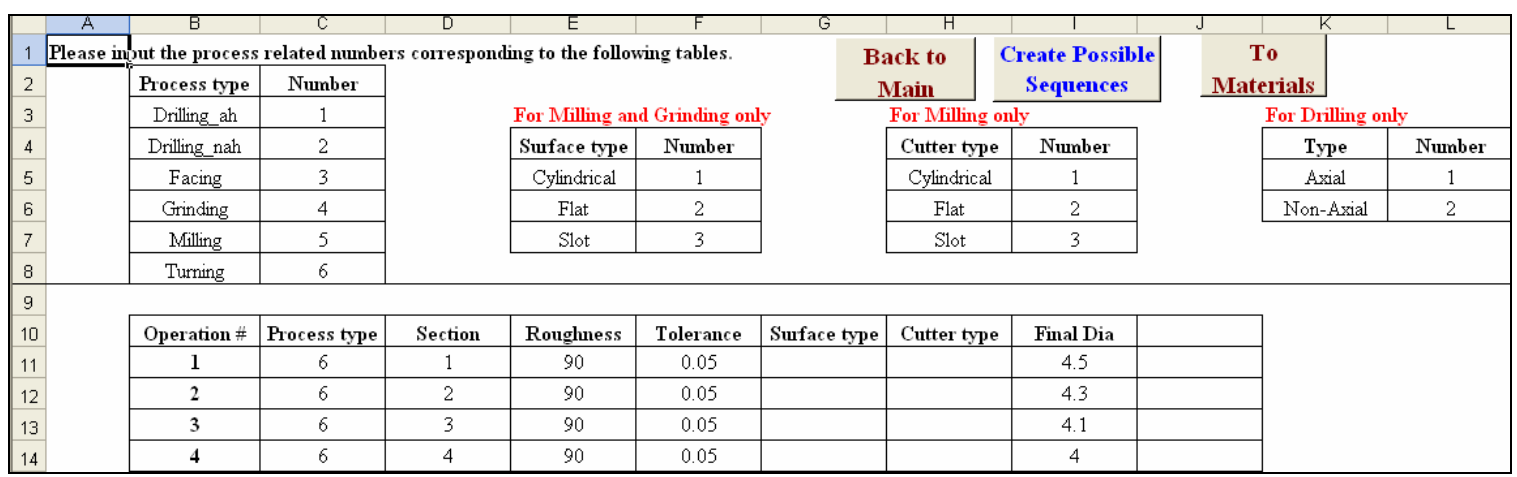

\section{Figure 3.5: Input Screen for Process Characteristics}

3. After all the information is entered in respective cells, the "Create Possible Sequences” button is clicked to generate the sequences (Figure 3.6) based on the precedence relationships. As an example, for the precedence relationship shown in 
figure 3.4, the model generated six sequences. The user then clicks the "To Materials" button to go to the next input screen for work piece material and section changes information.

\begin{tabular}{|c|c|c|c|c|c|}
\hline 16 & \multicolumn{5}{|c|}{ The possible sequences are as follows. $\quad 6$} \\
\hline 17 & & Operation \#1 & Operation \#2 & Operation \#3 & Operation \#4 \\
\hline 18 & Sequence \#1 & Turning & Turning & Turning & Turning \\
\hline 19 & Sequence \#2 & Turning & Turning & Turning & Turning \\
\hline 20 & Sequence \#3 & Turning & Turning & Turning & Turning \\
\hline 21 & Sequence \#4 & Turning & Turning & Turning & Turning \\
\hline 22 & Sequence \#5 & Turning & Turning & Turning & Turning \\
\hline 23 & Sequence \#6 & Turning & Turning & Turning & Turning \\
\hline 24 & & & & & \\
\hline 25 & Sequence \#1 & 1 & 2 & 3 & 4 \\
\hline 26 & Sequence \#2 & 1 & 3 & 2 & 4 \\
\hline 27 & Sequence \#3 & 1 & 3 & 4 & 2 \\
\hline 28 & Sequence \#4 & 3 & 1 & 2 & 4 \\
\hline 29 & Sequence \#5 & 3 & 1 & 4 & 2 \\
\hline 30 & Sequence \#6 & 3 & 4 & 1 & 2 \\
\hline
\end{tabular}

\section{Figure 3.6: Sequence Generation Output}

4. Select or input the material type, work-piece material, heat treatment condition, melting temperature and hardness (Brinell or Rockwell) value for the material. Finally, input the initial length, diameter for each section along with corresponding length and final diameter (after turning) of the sections (Figure 3.7).

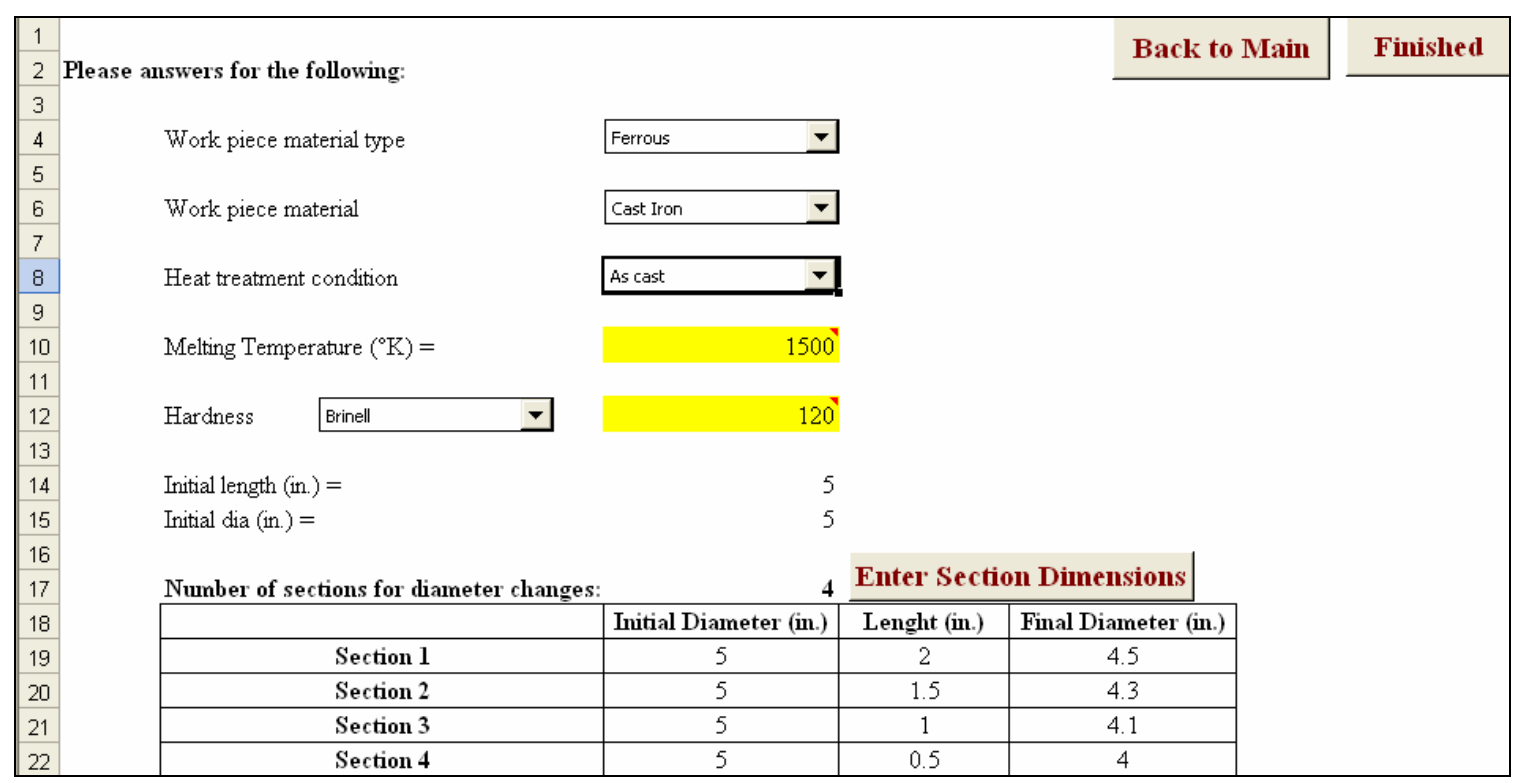

Figure 3.7: Input for Work Material Properties 
5. The model will start with the first process in the first sequence. If this process is a turning operation, the model will generate the possible options in terms of combining the number of sections, as explained in the "generation of possible sequences" section. If there are two or more possible options, the model will start with the first option for performing this operation.

6. The model will find the current maximum length and diameter of the work-piece for input to the expert system program (MPSEL) and find the list of machines and tools suitable for performing the operation.

7. The next step is to find the combination of machine and tool that result in the lowest cost for this operation. The model interacts with the user generated machine and tool database (Appendix 1) to find the suitable speed, feed, maximum depth of cut and other parameters required to calculate the cost of the present operation. If there are two or more options to perform the current operation, the model will repeat steps 6 and 7 for this process. In case the depth of material that should be machined is more than the maximum depth of cut allowed for the process, the model considers two different scenarios and finds the depth of cut that results in minimum cost. The selection process for the depth of cut is explained in the next section.

8. Once all the options for the current process have been evaluated, the model will go to the next process in the current sequence and repeat steps $5,6,7$, and 8 . It may be noted that each option for a process in any sequence will create its own branch in the cost tree.

9. Finally, when all the sequences, processes, and options are evaluated, the model will stop and the results are available to the user with cost value, and selected machine, tool, and depth of cut information.

A process flow diagram of the proposed model is shown in Figure 3.8. 


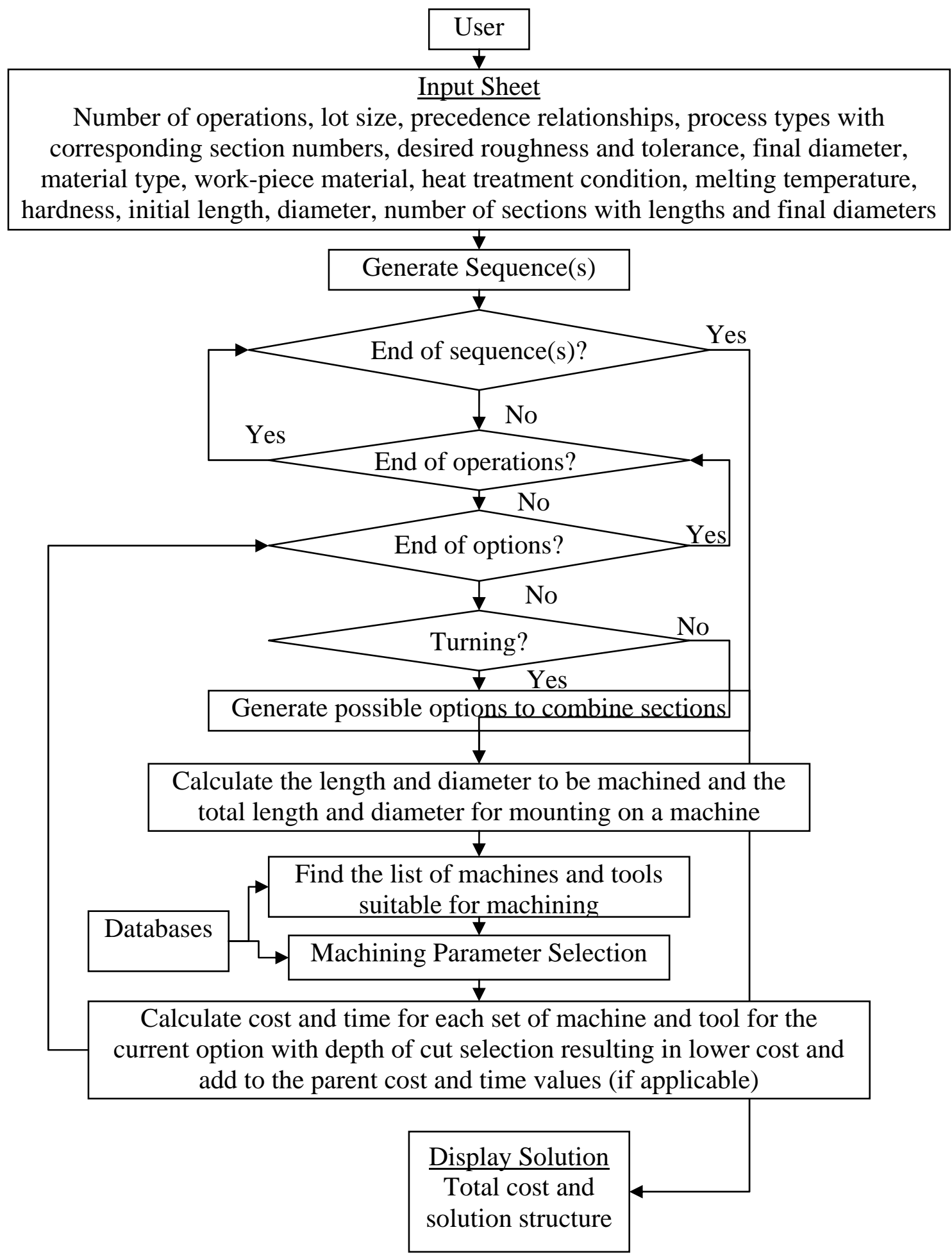

Figure 3.8: Flow Diagram for the Proposed Model 
The depth of cut decision is made in the following steps:

1. if the total material to be removed is less than or equal to the maximum depth of cut allowed for the work piece material and the tool material, the value for depth of cut is the value for depth of material to be removed.

2. if the total depth of material to be removed is more than the maximum depth of cut allowed for the tool and work piece material combination, the value of depth of cut is decided so that the cost to perform the current machining operation is minimized. The options for depth of cut in this case are:

a. Choose the maximum depth of cut for initial passes same as maximum depth allowed for the tool and material combination, and the depth of left over material that is required to be machined is considered as the final depth of cut. As an example, if the total depth of material that is required to be machined is 0.5 inch and the maximum allowed depth of cut for the current combination is 0.2 inches, the depth of cut for the first two passes are considered as 0.2 inches and the depth of cut or the final pass is 0.1 inch.

b. This option considers the equal depth of cut for all the passes if the number of passes required to achieve the final dimension is more than one. As an example, if the depth of cut required to be machined is 0.15 inches and the maximum depth of cut allowed is 0.2 inches, the depth of cut for the current pass is 0.15 inch. On the other hand, if the depth of total material required to be machined is 0.3 with maximum depth of cut allowed for the material combination as 0.2 , the depth of cut for each pass is considered as 0.15 .

The depth of cut that results in the lowest cost is selected for the operation under consideration. It may be noted that the cost values are based on the selected cutting parameters from the database and the database has specific values given in terms of maximum depth of cut. Thus the selection of a different depth of cut may not affect the final solution since the values for feed and speed are not changed if a lower depth of cut is used instead of the maximum depth of cut. This feature may be incorporated by using the cutting equations that will change the feed and/or speed based on a different depth of cut. 


\section{Results for example problems:}

An example problem (Figure 3.9) is considered here to explain the format of the results. It was assumed that there are no precedence requirements for the two sections. The material properties are as follows:

$\begin{array}{ll}\text { Work piece material type } & =\text { Ferrous } \\ \text { Work piece material } & =\text { Cast Iron } \\ \text { Heat treatment condition } & =\text { As Cast } \\ \text { Melting Temperature }\left({ }^{\circ} \mathrm{K}\right) & =1500 \\ \text { Hardness (Brinell) } & =120 \\ \text { Initial length (in.) } & =5 \\ \text { Initial diameter (in.) } & =2.5 \\ \text { Lot size } & =200 \\ \text { Surface finish }(\mu \text {-in.) } & =90 \\ \text { Tolerance (in.) } & =0.05\end{array}$

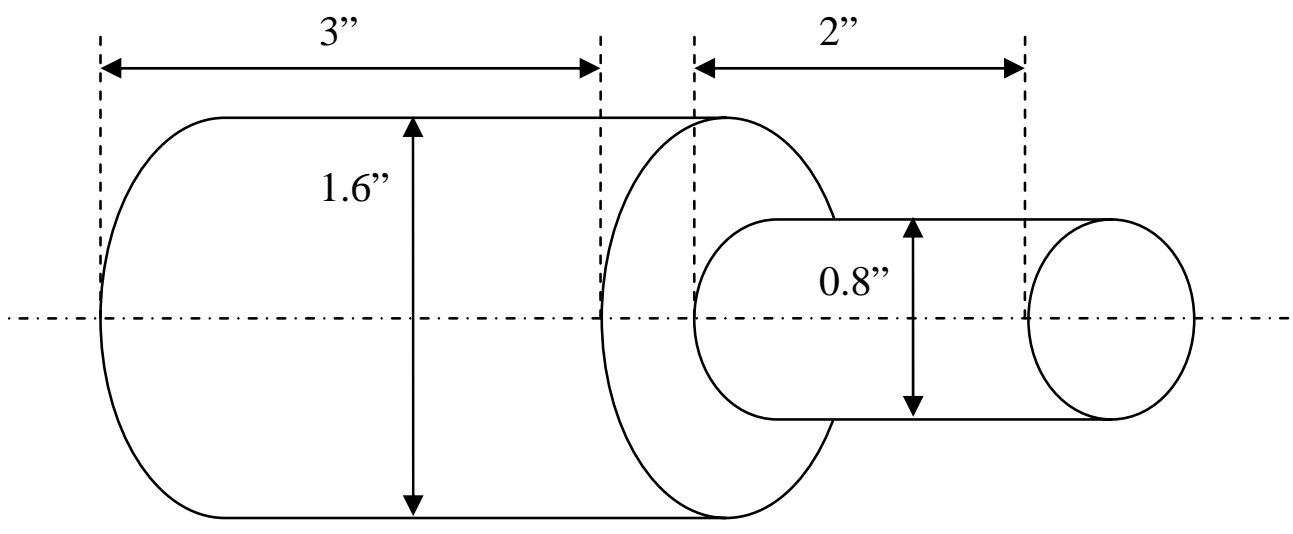

Figure 3.9: Example Problem

The model outputs the results for each sequence and the corresponding process in the following manner (Table 3.0):

1. The results are displayed in the order of the sequences (as generated by the model).

2. For each sequence, the results are presented in the order of the process performed in that sequence. The process type information can be seen in the input sheet. 
3. The results for each of the options (as generated by combining sections of the work piece) are shown in separate columns.

4. Under any sequence, the results are grouped (in rows) as follows (Table 3.0):

a. machining cost (\$/unit) until that operation,

b. machine selected for the operation,

c. tool selected for the operation,

d. machining time (minutes) until that operation, and

e. a group of numbers showing:

i. the diameter selection option (2 for equal depth of cut for each pass and 1 if maximum depth of cut is used for all the passes except the last pass where it can be less than the maximum depth of cut),

ii. parent option (from where the current option is generated),

iii. starting diameter, and

iv. length of machining.

Table 3.0: Output Format

\begin{tabular}{|c|c|c|c|c|c|c|}
\hline Sequence & $\begin{array}{c}\text { Process/operation } \\
\text { number }\end{array}$ & Option 1 & Option 2 & .... & Option n & \multirow{5}{*}{$\begin{array}{l}\text { Cost (\$/unit) } \\
\text { until operation } \\
\text { "n" }\end{array}$} \\
\hline \multirow{20}{*}{1} & 1 & & & & & \\
\hline & 2 & & & & & \\
\hline & $\ldots$ & & & & & \\
\hline & $\mathrm{n}$ & & & & & \\
\hline & 1 & & & & & \multirow{3}{*}{$\begin{array}{l}\text { Machine } \\
\text { selected for } \\
\text { operation “n” }\end{array}$} \\
\hline & 2 & & & & & \\
\hline & $\ldots$. & & & & & \\
\hline & $\mathrm{n}$ & & & & & \multirow{5}{*}{$\begin{array}{l}\text { Tool selected } \\
\text { for operation } \\
\text { “n” }\end{array}$} \\
\hline & 1 & & & & & \\
\hline & 2 & & & & & \\
\hline & $\ldots$ & & & & & \\
\hline & $\mathrm{n}$ & & & & & \\
\hline & 1 & & & & & \multirow{8}{*}{$\begin{array}{l}\text { Machining time } \\
\text { (minutes) until } \\
\text { operation "n” } \\
\text { Grouped } \\
\text { values for } \\
\text { operation "n" }\end{array}$} \\
\hline & 2 & & & & & \\
\hline & $\ldots$. & & & & & \\
\hline & $\mathrm{n}$ & & & & & \\
\hline & 1 & & & & & \\
\hline & 2 & & & & & \\
\hline & $\ldots$ & & & & & \\
\hline & $\mathrm{n}$ & & & & & \\
\hline
\end{tabular}


Table 3.1: Example Results

\begin{tabular}{|c|c|c|c|}
\hline Sequence & Process/operation number & Option 1 & Option 2 \\
\hline \multirow[t]{10}{*}{1} & 1 & $\$ 0.83$ & $\$ 1.11$ \\
\hline & 2 & $\$ 1.5317$ & $\$ 1.6217$ \\
\hline & 1 & single_sp_auto & single_sp_auto \\
\hline & 2 & single_sp_auto & single_sp_auto \\
\hline & 1 & SP_CR_C7 & SP_CR_C7 \\
\hline & 2 & SP_CR_C7 & SP_CR_C7 \\
\hline & 1 & 1.1115 minutes & 1.3896 minutes \\
\hline & 2 & 2.1727 minutes & 2.2454 minutes \\
\hline & 1 & $1,1,2.5,3$ & $1,1,2.5,5$ \\
\hline & 2 & $1,1,2.5,2$ & $1,2,1.6,2$ \\
\hline \multirow[t]{10}{*}{2} & 1 & $\$ 0.76$ & \\
\hline & 2 & $\$ 1.5317$ & \\
\hline & 1 & single_sp_auto & \\
\hline & 2 & single_sp_auto & \\
\hline & 1 & SP_CR_C7 & \\
\hline & 2 & SP_CR_C7 & \\
\hline & 1 & 1.0612 minutes & \\
\hline & 2 & 2.1727 minutes & \\
\hline & 1 & $1,1,2.5,2$ & \\
\hline & 2 & $1,1,2.5,3$ & \\
\hline
\end{tabular}

The model results are shown in Table 3.1. As an example, for the first sequence (turning the first section followed by turning the second section) and first operation, there were two options which resulted in cost values as \$0.83 and \$1.11 per unit with machining time as 1.1115 and 1.3896 minutes respectively. In both these options, the machine and tool selected for the operation were Single Spindle Automatic machine and Carbide (grade C7). Finally, the group values for these options (“1,1,2.5,3” and “1,1,2.5,5”) can be explained as:

- The depth of cut for each pass was not equal (the first value in the groups are 1). This means that for the initial pass(es), the maximum depth of cut was used and in the last pass, the depth of cut was used as the depth of remaining material to be removed.

- Since there were no parent options to these processes, the corresponding (second in the group) value is " 1 ", which in this case does not convey any useful information. 
- The values for initial diameter and length of machining $\left(3^{\text {rd }}\right.$ and $4^{\text {th }}$ values in the group) for these options were (2.5 inch diameter with 3 inch length) and (2.5 inch diameter with 5 inch length) respectively.

For the second process in the first sequence, the cost for two options (as shown in the columns “Option 1” and “Option 2”) until that operation is \$1.5317 and \$1.6217 per unit respectively. Once again, the same machine and tool were selected in both cases. The total time to perform the machining until this operation was 2.1727 and 2.2454 minutes respectively. The depth of cut in each pass was not equal since the first value is “ 1 ”. The first option was generated from the first option in the previous step and the second option was generated from the second option in the previous step. It was noted that the initial diameter and length of machining in these two cases were (2.5 inch, 2 inch) and (1.6 inch, 2 inch) respectively.

The results for the second sequence (turning the second section followed by turning the first section) can be explained in a similar way. It was found that the minimum machining cost for all the operations was \$1.5317 (minimum of \$1.5317 from option 1 in sequence 1, \$1.6217 from option 2 in sequence 1, and \$1.5317 from option 1 in sequence 2) and with total machining time as 2.1727 minutes per piece (minimum of 2.1727 minutes from option 1 in sequence 1, 2.2454 minutes from option 2 in sequence 1, and 2.1727 minutes from option 1 in sequence 2). There were two results with the same minimum machining cost and are as follows: (a) reduce the diameter of the first section followed by the reduction of diameter of the second section, or (b) reduce the diameter of the second section followed by the reduction of diameter for the first section. It may be noted that even though these two results are same, this may not be the case in complicated problems with several operations and options.

The second example created to test the model is shown in Figure 3.10. The input and sequence information is shown in Tables 3.2 through 3.5. As shown in Table 3.2, three turning operations (one in each section) are required to achieve the final shape. The required surface roughness is given as 90,80 , and 85 micro-inches for section 1,2 , and 3 
respectively. The tolerance requirements are $0.04 \mathrm{in.,} 0.05 \mathrm{in}$., and $0.05 \mathrm{in}$. respectively. The final diameters are 1.6 in., 0.8 in., and 0.6 in. for section 1, 2, and 3 respectively.

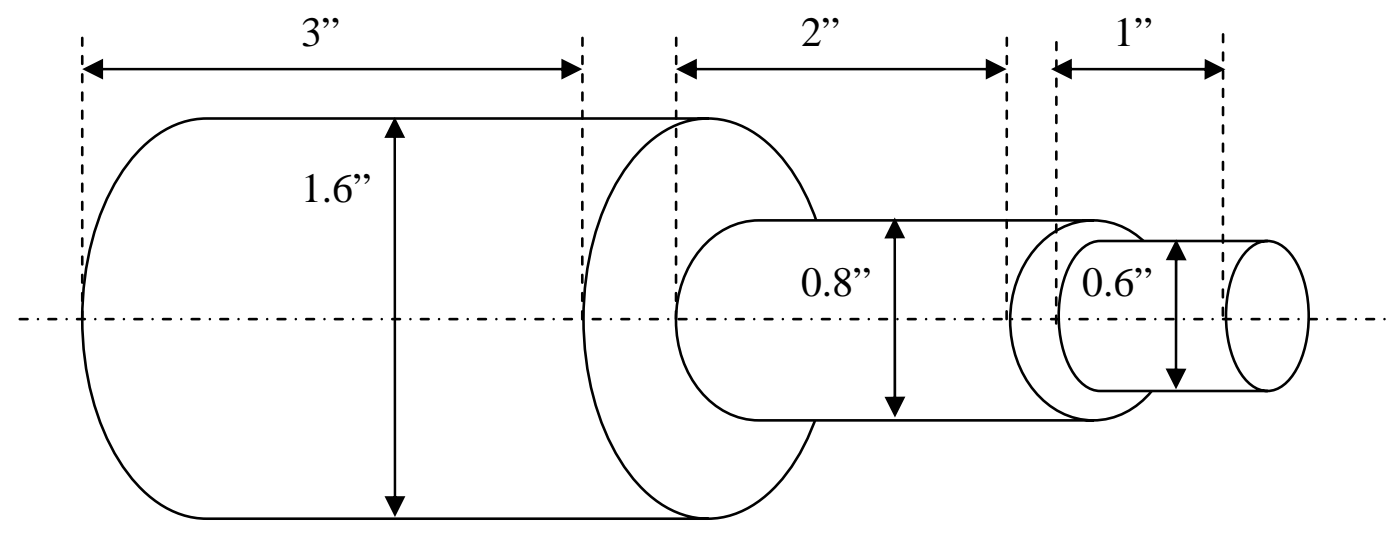

Figure 3.10: Example Problem

Table 3.2: Example Process Input

\begin{tabular}{|c|c|c|c|c|c|c|}
\hline Operation \# & $\begin{array}{c}\text { Process } \\
\text { type }\end{array}$ & Section & $\begin{array}{c}\text { Roughness } \\
(\boldsymbol{\mu} \text {-in.) }\end{array}$ & $\begin{array}{c}\text { Tolerance } \\
\text { (in.) }\end{array}$ & $\begin{array}{c}\text { Surface } \\
\text { type }\end{array}$ & $\begin{array}{c}\text { Final } \\
\text { Diameter } \\
\text { (in.) }\end{array}$ \\
\hline $\mathbf{1}$ & 6 & 1 & 90 & 0.04 & - & 1.6 \\
\hline $\mathbf{2}$ & 6 & 2 & 80 & 0.05 & - & 0.8 \\
\hline $\mathbf{3}$ & 6 & 3 & 85 & 0.05 & - & 0.6 \\
\hline
\end{tabular}

Note: Process type “6” means turning

As shown in Table 3.2, three turning operations (one in each section) are required to achieve the final shape. The required surface roughness is given as 90,80 , and 85 microinches for section 1, 2, and 3 respectively. The tolerance requirements are 0.04 in., 0.05 in., and 0.05 in. respectively. The final diameters are 1.6 in., 0.8 in., and 0.6 in. for section 1, 2, and 3 respectively. It was assumed that there are no precedence relationships for these turning operations. Based on these input parameters, the model could find six possible sequences. The sequence combinations are shown in Table 3.3. The material information provided to the model is shown in Table 3.4. The initial diameter of the stock material was 2.5 inches and the length was 6 inches. As seen in Figure 3.10, there are three sections and the corresponding length and final diameter was provided in Table 3.5. The results from the model are shown in Table 3.6. 
Table 3.3: Example Sequence Generation

\begin{tabular}{|l|c|c|c|}
\hline & $\begin{array}{c}\text { Operation } \\
\text { \#1 }\end{array}$ & $\begin{array}{c}\text { Operation } \\
\text { \#2 }\end{array}$ & $\begin{array}{c}\text { Operation } \\
\text { \#3 }\end{array}$ \\
\hline Sequence \#1 & Turning & Turning & Turning \\
\hline Sequence \#2 & Turning & Turning & Turning \\
\hline Sequence \#3 & Turning & Turning & Turning \\
\hline Sequence \#4 & Turning & Turning & Turning \\
\hline Sequence \#5 & Turning & Turning & Turning \\
\hline Sequence \#6 & Turning & Turning & Turning \\
\hline & & & \\
\hline Sequence \#1 & 1 & 2 & 3 \\
\hline Sequence \#2 & 1 & 3 & 2 \\
\hline Sequence \#3 & 2 & 1 & 3 \\
\hline Sequence \#4 & 2 & 3 & 1 \\
\hline Sequence \#5 & 3 & 1 & 2 \\
\hline Sequence \#6 & 3 & 2 & 1 \\
\hline
\end{tabular}

Table 3.4: Material Information Input

\begin{tabular}{|l|c|}
\hline Work piece material type & Ferrous \\
\hline Work piece material & Cast iron \\
\hline Heat treatment condition & As cast \\
\hline Melting Temperature $\left({ }^{\circ} \mathrm{K}\right)=$ & 1500 \\
\hline Hardness (Brinell) & 120 \\
\hline Initial length (in.) $=$ & 6 \\
\hline Initial diameter (in.) $=$ & 2.5 \\
\hline
\end{tabular}

Table 3.5: Section Diameter Change Input

\begin{tabular}{|c|c|c|c|}
\hline & $\begin{array}{c}\text { Initial Diameter } \\
\text { (in.) }\end{array}$ & Length (in.) & $\begin{array}{c}\text { Final Diameter } \\
\text { (in.) }\end{array}$ \\
\hline Section 1 & 2.5 & 3 & 1.6 \\
\hline Section 2 & 2.5 & 2 & 0.8 \\
\hline Section 3 & 2.5 & 1 & 0.6 \\
\hline
\end{tabular}


Table 3.6: Example Output

\begin{tabular}{|c|c|c|c|c|c|c|}
\hline $\begin{array}{c}\text { Sequence } \\
\text { number }\end{array}$ & $\begin{array}{l}\text { Process } \\
\text { number }\end{array}$ & Option 1 & Option 2 & Option 3 & Option 4 & Option 5 \\
\hline \multirow[t]{15}{*}{1} & 1 & $\$ 0.83$ & $\$ 1.11$ & $\$ 1.25$ & & \\
\hline & 2 & $\$ 1.5317$ & $\$ 1.7017$ & $\$ 1.7417$ & $\$ 1.7617$ & $\$ 1.8517$ \\
\hline & 3 & $\$ 2.0434$ & $\$ 2.0734$ & $\$ 2.2534$ & $\$ 2.1834$ & $\$ 2.2234$ \\
\hline & 1 & single_sp_auto & single_sp_auto & single_sp_auto & & \\
\hline & 2 & single_sp_auto & single_sp_auto & single_sp_auto & single_sp_auto & single_sp_auto \\
\hline & 3 & single_sp_auto & single_sp_auto & single_sp_auto & single_sp_auto & single_sp_auto \\
\hline & 1 & SP_CR_C7 & SP_CR_C7 & SP_CR_C7 & & \\
\hline & 2 & SP_CR_C7 & SP_CR_C7 & SP_CR_C7 & SP_CR_C7 & SP_CR_C7 \\
\hline & 3 & carbide & carbide & carbide & carbide & carbide \\
\hline & 1 & 1.1115 minutes & 1.3896 minutes & 1.5288 minutes & & \\
\hline & 2 & 2.1727 minutes & 2.3428 minutes & 2.3618 minutes & 2.3846 minutes & 2.4769 minutes \\
\hline & 3 & 3.0508 minutes & 3.0352 minutes & 3.2399 minutes & 3.1465 minutes & 3.1693 minutes \\
\hline & 1 & \begin{tabular}{|l|}
$1,1,2.5,3$ \\
\end{tabular} & $1,1,2.5,5$ & $1,1,2.5,6$ & & \\
\hline & 2 & $1,1,2.5,2$ & $1,1,2.5,3$ & $1,2,2.5,2$ & $1,3,1.6,2$ & $1,3,1.6,3$ \\
\hline & 3 & $1,1,2.5,1$ & 1,2,1.6,1 & $1,3,2.5,1$ & $1,4,1.6,1$ & $1,5,1.6,1$ \\
\hline \multirow[t]{15}{*}{2} & 1 & $\$ 0.83$ & $\$ 1.11$ & $\$ 1.25$ & & \\
\hline & 2 & $\$ 1.3417$ & $\$ 1.6217$ & $\$ 1.6717$ & & \\
\hline & 3 & $\$ 2.0434$ & $\$ 2.1334$ & $\$ 2.1834$ & & \\
\hline & 1 & single_sp_auto & single_sp_auto & single_sp_auto & & \\
\hline & 2 & single_sp_auto & single_sp_auto & single_sp_auto & & \\
\hline & 3 & single_sp_auto & single_sp_auto & single_sp_auto & & \\
\hline & 1 & SP_CR_C7 & SP_CR_C7 & SP_CR_C7 & & \\
\hline & 2 & carbide & carbide & carbide & & \\
\hline & 3 & SP_CR_C7 & SP_CR_C7 & SP_CR_C7 & & \\
\hline & 1 & 1.1115 minutes & 1.3896 minutes & 1.5288 minutes & & \\
\hline & 2 & 1.9896 minutes & 2.2677 minutes & 2.2907 minutes & & \\
\hline & 3 & 3.0508 minutes & 3.1235 minutes & 3.1465 minutes & & \\
\hline & 1 & $1,1,2.5,3$ & $1,1,2.5,5$ & $1,1,2.5,6$ & & \\
\hline & 2 & $1,1,2.5,1$ & $1,2,2.5,1$ & $1,3,1.6,1$ & & \\
\hline & 3 & $1,1,2.5,2$ & $1,2,1.6,2$ & $1,3,1.6,2$ & & \\
\hline \multirow[t]{10}{*}{3} & 1 & $\$ 0.76$ & $\$ 0.93$ & & & \\
\hline & 2 & $\$ 1.5317$ & $\$ 1.7017$ & $\$ 2.1217$ & & \\
\hline & 3 & $\$ 2.0434$ & $\$ 2.0734$ & $\$ 2.5434$ & & \\
\hline & 1 & single_sp_auto & single_sp_auto & & & \\
\hline & 2 & single_sp_auto & single_sp_auto & single_sp_auto & & \\
\hline & 3 & single_sp_auto & single_sp_auto & single_sp_auto & & \\
\hline & 1 & SP CR C7 & SP CR C7 & & & \\
\hline & 2 & SP_CR_C7 & SP_CR_C7 & SP_CR_C7 & & \\
\hline & 3 & carbide & carbide & carbide & & \\
\hline & & & & & & \\
\hline
\end{tabular}


Table 3.6: Example Output (Contd.)

\begin{tabular}{|c|c|c|c|c|c|c|}
\hline $\begin{array}{c}\text { Sequence } \\
\text { number }\end{array}$ & $\begin{array}{l}\text { Process } \\
\text { number }\end{array}$ & Option 1 & Option 2 & Option 3 & Option 4 & Option 5 \\
\hline \multirow[t]{6}{*}{3} & 1 & 1.0612 minutes & 1.2313 minutes & & & \\
\hline & 2 & 2.1727 minutes & 2.3428 minutes & 2.7601 minutes & & \\
\hline & 3 & 3.0508 minutes & 3.0352 minutes & 3.522 minutes & & \\
\hline & 1 & $1,1,2.5,2$ & $1,1,2.5,3$ & & & \\
\hline & 2 & $1,1,2.5,3$ & $1,2,2.5,3$ & $1,2,2.5,6$ & & \\
\hline & 3 & $1,1,2.5,1$ & $1,2,1.6,1$ & $1,3,1.6,1$ & & \\
\hline \multirow[t]{15}{*}{4} & 1 & $\$ 0.76$ & $\$ 0.93$ & & & \\
\hline & 2 & $\$ 1.2717$ & $\$ 1.3317$ & & & \\
\hline & 3 & $\$ 2.0434$ & $\$ 2.1034$ & & & \\
\hline & 1 & single_sp_auto & single_sp_auto & & & \\
\hline & 2 & single_sp_auto & single_sp_auto & & & \\
\hline & 3 & single_sp_auto & single_sp_auto & & & \\
\hline & 1 & SP_CR_C7 & SP_CR_C7 & & & \\
\hline & 2 & carbide & carbide & & & \\
\hline & 3 & SP_CR_C7 & SP_CR_C7 & & & \\
\hline & 1 & 1.0612 minutes & 1.2313 minutes & & & \\
\hline & 2 & 1.9393 minutes & 1.9581 minutes & & & \\
\hline & 3 & 3.0508 minutes & 3.0696 minutes & & & \\
\hline & 1 & $1,1,2.5,2$ & $1,1,2.5,3$ & & & \\
\hline & 2 & $1,1,2.5,1$ & $1,2,2.5,1$ & & & \\
\hline & 3 & $1,1,2.5,3$ & $1,2,2.5,3$ & & & \\
\hline \multirow[t]{15}{*}{5} & 1 & $\$ 0.57$ & & & & \\
\hline & 2 & $\$ 1.3417$ & $\$ 1.6217$ & & & \\
\hline & 3 & $\$ 2.0434$ & $\$ 2.1334$ & & & \\
\hline & 1 & single_sp_auto & & & & \\
\hline & 2 & single_sp_auto & single_sp_auto & & & \\
\hline & 3 & single_sp_auto & single_sp_auto & & & \\
\hline & 1 & carbide & & & & \\
\hline & 2 & SP_CR_C7 & SP_CR_C7 & & & \\
\hline & 3 & SP_CR_C7 & SP_CR_C7 & & & \\
\hline & 1 & 0.8781 minutes & & & & \\
\hline & 2 & 1.9896 minutes & 2.2677 minutes & & & \\
\hline & 3 & 3.0508 minutes & 3.1235 minutes & & & \\
\hline & 1 & $1,1,2.5,1$ & & & & \\
\hline & 2 & $1,1,2.5,3$ & $1,1,2.5,5$ & & & \\
\hline & 3 & $1,1,2.5,2$ & $1,2,1.6,2$ & & & \\
\hline
\end{tabular}


Table 3.6: Example Output (Contd.)

\begin{tabular}{|c|c|c|c|c|c|c|}
\hline $\begin{array}{c}\text { Sequence } \\
\text { number }\end{array}$ & $\begin{array}{l}\text { Process } \\
\text { number }\end{array}$ & Option 1 & Option 2 & Option 3 & Option 4 & Option 5 \\
\hline \multirow[t]{15}{*}{6} & 1 & $\$ 0.57$ & & & & \\
\hline & 2 & $\$ 1.2717$ & & & & \\
\hline & 3 & $\$ 2.0434$ & & & & \\
\hline & 1 & single_sp_auto & & & & \\
\hline & 2 & single_sp_auto & & & & \\
\hline & 3 & single_sp_auto & & & & \\
\hline & 1 & $\begin{array}{l}\text { carbide } \\
\end{array}$ & & & & \\
\hline & 2 & SP_CR_C7 & & & & \\
\hline & 3 & SP_CR_C7 & & & & \\
\hline & 1 & 0.8781 minutes & & & & \\
\hline & 2 & 1.9393 minutes & & & & \\
\hline & 3 & 3.0508 minutes & & & & \\
\hline & 1 & $1,1,2.5,1$ & & & & \\
\hline & 2 & $1,1,2.5,2$ & & & & \\
\hline & 3 & $1,1,2.5,3$ & & & & \\
\hline
\end{tabular}

Based on the output from the proposed model, the minimum cost was $\$ 2.0434$ per piece and the total time to machine the work piece was 3.0508 minutes. It was noted that the work piece could be machined in several sequences which will result in the same cost and time values. The results were verified with manual calculation for each option for the processes and sequences.

The final example was considered as a combination of turning and cylindrical grinding operations. The problem was the same as the one given in Figure 3.9 with an addition of cylindrical grinding operation to both cylindrical surfaces. Thus, there is a precedence relationship between the turning and grinding operations. The values used in the examples are as follows:

Table 3.7: Example Precedence Input

\begin{tabular}{|l|c|c|c|c|c|}
\hline & & \multicolumn{5}{|c|}{ Predecessor Process } \\
\hline & $\#$ & $\mathbf{1}$ & $\mathbf{2}$ & $\mathbf{3}$ & $\mathbf{4}$ \\
\hline \multirow{4}{*}{ Successor Process } & $\mathbf{1}$ & - & & & \\
\cline { 2 - 6 } & $\mathbf{2}$ & 1 & - & & \\
\cline { 2 - 6 } & $\mathbf{3}$ & & & - & \\
\cline { 2 - 6 } & $\mathbf{4}$ & & & 1 & - \\
\hline
\end{tabular}


Table 3.8: Example Process Input

\begin{tabular}{|c|c|c|c|c|c|c|}
\hline Operation \# & $\begin{array}{c}\text { Process } \\
\text { type }\end{array}$ & Section & Roughness & Tolerance & $\begin{array}{c}\text { Surface } \\
\text { type }\end{array}$ & $\begin{array}{c}\text { Final } \\
\text { Dia }\end{array}$ \\
\hline $\mathbf{1}$ & 6 & 1 & 90 & 0.05 & & 1.6 \\
\hline $\mathbf{2}$ & 4 & 1 & 10 & 0.005 & 1 & 1.5 \\
\hline $\mathbf{3}$ & 6 & 2 & 80 & 0.05 & & 0.8 \\
\hline $\mathbf{4}$ & 4 & 2 & 10 & 0.005 & 1 & 0.7 \\
\hline
\end{tabular}

Note: Process type "6" means turning and "4" means grinding. Surface type "1" means cylindrical.

Table 3.9: Example Sequence Output

\begin{tabular}{|l|c|c|c|c|}
\hline & $\begin{array}{c}\text { Operation } \\
\text { \#1 }\end{array}$ & $\begin{array}{c}\text { Operation } \\
\text { \#2 }\end{array}$ & $\begin{array}{c}\text { Operation } \\
\text { \#3 }\end{array}$ & $\begin{array}{c}\text { Operation } \\
\text { \#4 }\end{array}$ \\
\hline Sequence \#1 & Turning & Grinding & Turning & Grinding \\
\hline Sequence \#2 & Turning & Turning & Grinding & Grinding \\
\hline Sequence \#3 & Turning & Turning & Grinding & Grinding \\
\hline Sequence \#4 & Turning & Turning & Grinding & Grinding \\
\hline Sequence \#5 & Turning & Turning & Grinding & Grinding \\
\hline Sequence \#6 & Turning & Grinding & Turning & Grinding \\
\hline & & & & \\
\hline Sequence \#1 & 1 & 2 & 3 & 4 \\
\hline Sequence \#2 & 1 & 3 & 2 & 4 \\
\hline Sequence \#3 & 1 & 3 & 4 & 2 \\
\hline Sequence \#4 & 3 & 1 & 2 & 4 \\
\hline Sequence \#5 & 3 & 1 & 4 & 2 \\
\hline Sequence \#6 & 3 & 4 & 1 & 2 \\
\hline
\end{tabular}

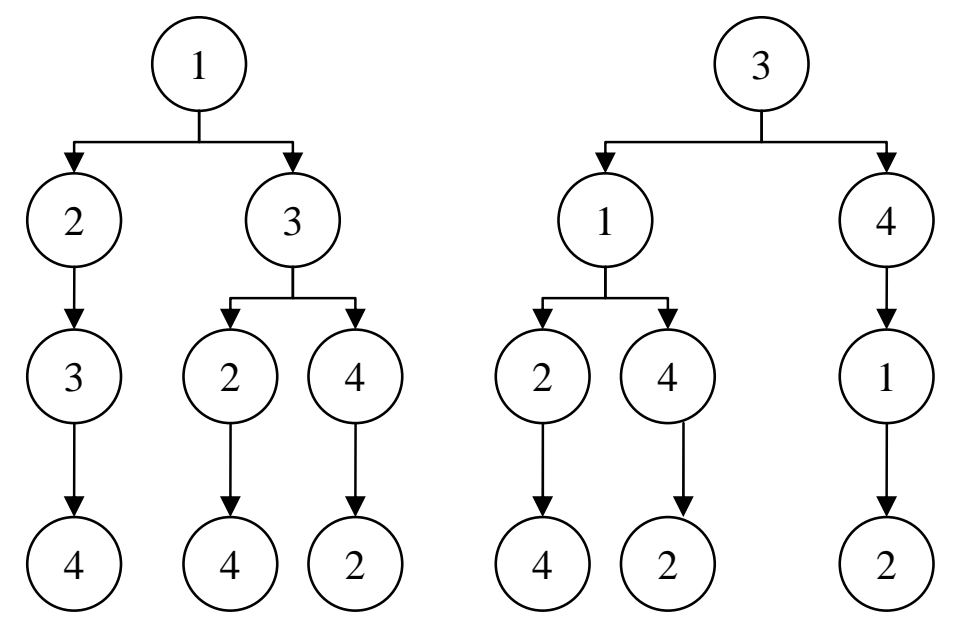

Figure 3.11: Sequence Generation Logic Tree 
It may be noted that the model considers all possible combination to generate the process sequences. The first step in the sequence generation process is to check which process(es) does(do) not have any predecessor(s). These operations become the parent nodes to generate the possible sequences. For the example problem, processes " 2 " and "4" have predecessors as " 1 " and " 3 ". Therefore, the root nodes are defined as " 1 " and " 3 " which means that the machining can be started with any of these processes in the first position in the sequence (Figure 3.11). The next step of the sequence generation involves the processes for which either the precedence relationship is met or it has no predecessor. Considering the first root node (with process " 1 " in the first position), processes " 2 " and "3" can be selected because "2" has "1" as predecessor which is placed in the first position and " 3 " does not have any precedence requirement. Therefore, the sequence is branched off with "2" and "3" as possible processes in the next position in the sequence. Assuming that " 2 " is placed in the second position in the sequence, the next process can only be process "3" since " 4 " cannot be done until " 3 " is completed. Therefore, under process "2" the tree has only one process (" 3 "). The next process in this sequence is " 4 " since this is the only process remaining and the precedence requirement for this process is met as " 3 " was done in the last step. On the other hand, if " 3 " was selected instead of " 2 " in the second position in the sequence, any of the remaining processes ("2" or "4") could be performed in the third position in the sequence. Finally, based on which one is selected for the third position, the remaining process goes in the fourth position. The other tree (with process " 3 " in the first position) is generated in the same manner.

Table 3.10: Example Section Change Input

\begin{tabular}{|c|c|c|c|}
\hline $\begin{array}{c}\text { Note: For turning } \\
\text { only }\end{array}$ & $\begin{array}{c}\text { Initial Diameter } \\
\text { (in.) }\end{array}$ & Length (in.) & $\begin{array}{c}\text { Final Diameter } \\
\text { (in.) }\end{array}$ \\
\hline Section 1 & 2.5 & 3 & 1.6 \\
\hline Section 2 & 2.5 & 2 & 0.8 \\
\hline
\end{tabular}

Based on the input values, the model resulted in the minimum cost as $\$ 7.1084$ with minimum machining time as 8.6844 minutes. It was noted that the same result was obtained in more than one sequence. Thus, the process planner could choose any of the sequences and the corresponding machining option that resulted in the minimum 
machining time and/or cost. An example solution for the first sequence is shown in Table 3.11 .

Table 3.11: Example Output for First Sequence

\begin{tabular}{|c|c|c|}
\hline $\begin{array}{l}\text { Process } \\
\text { number }\end{array}$ & Option 1 & Option 2 \\
\hline 1 & $\$ 0.83$ & $\$ 1.11$ \\
\hline 2 & $\$ 4.0$ & $\$ 4.28$ \\
\hline 3 & $\$ 4.76$ & $\$ 4.85$ \\
\hline 4 & $\$ 7.25$ & 47.34 \\
\hline 1 & single_sp_auto & single_sp_auto \\
\hline 2 & cyl_gr_mc & cyl_gr_mc \\
\hline 3 & single_sp_auto & single_sp_auto \\
\hline 4 & cyl_gr_mc & cyl_gr_mc \\
\hline 1 & SP_CR_C7 & SP_CR_C7 \\
\hline 2 & gr_wheel_soft & gr_wheel_soft \\
\hline 3 & SP_CR_C7 & SP_CR_C7 \\
\hline 4 & gr_wheel_soft & gr_wheel_soft \\
\hline 1 & 1.1115 minutes & 1.3896 minutes \\
\hline 2 & 4.6332 minutes & 4.9113 minutes \\
\hline 3 & 5.6944 minutes & 5.7671 minutes \\
\hline 4 & 8.6844 minutes & 8.7571 minutes \\
\hline 1 & $1,1,2.5,3$ & $1,1,2.5,5$ \\
\hline 2 & $1,1,1.6,3$ & $1,2,1.6,3$ \\
\hline 3 & $1,1,2.5,2$ & $1,2,1.6,2$ \\
\hline 4 & $1,1,0.8,2$ & $1,2,0.8,2$ \\
\hline
\end{tabular}

\subsection{Other Possible Approaches}

Some other models that were considered during this research are discussed briefly in the following section.

\subsubsection{Predefined Process Sequences}

This approach deals with a set of process sequences predefined by the user. The model evaluates each process plan by selecting the machine and tool for all the operations in the process plan and finally recommends one of the process sequences as the best sequence found. 
This simple approach has great applications for the machining personnel. In many cases, the sequence of machining operations may be limited by the number and type of features produced on the work piece surface. Therefore, the possible sequence of operations to generate the required features may be limited and can be predefined. One of the benefits of this approach is that the dimensions and surface characteristics for each of the operations are predefined based on the process sequence. With this information, the model will use the expert system, find the set of machines and tools for each of the operations in the sequence, connect this information with the databases that contain the information regarding machines, tools and cost values, and finally select the best combination suited for the operations.

The main focus with this approach will be the synthesis of information presented by the user and finding the best solution for the process planning problem. Also, this approach helps the user with post process planning and analysis in terms of different parameters considered in the model. For example, the process planner can change some of the surface finish requirements and may want to know the effect on the cost and change in the process plan. The proposed model can quickly do this analysis and present the corresponding results to the user.

The benefits and limitations for this approach can be summarized as follows.

\section{Pros:}

1. The model is easy to understand and program.

2. The solution can be obtained in almost no time.

\section{Cons:}

1. The model is prone to leading towards local optima since the set of process plans are limited (given by the user).

2. The user should be familiar with the process plan. S/he should be able to provide correct dimensions and other parameters required in each step of the process plan. 


\subsubsection{Interactive Process Planning Model}

This approach considers the case when the process plan is generated one step at a time. It means that for a problem with four different operations, the model will start with questions such as which operations can be sequenced in the first place and what are the corresponding dimensions. Based on the input from the user and the databases, the model will result in the least cost process (i.e. turning vs. facing to reduce length etc.) and parameters that should be used for the selected process. In the next step, the user will manually adjust the dimensions and tell the model which operations are candidates for the next in the sequence. This process will continue until all the operations are assigned a place in the process sequence. It can be seen that there will be lot of work for the user since in each step of the sequence, the user may need to update the dimensions for each of the candidate processes and other required parameters even though the model will select only one of them as the selected operation. Thus, for a four operations process, the maximum number of dimensions provided by the user is $10(=4+3+2+1)$. Another problem with this approach is that after one complete cycle, only one sequence is generated and that may not be the best sequence. Therefore, the same cycle should be

repeated a few times to find a good solution. The benefits and limitations for this approach can be summarized as follows.

\section{Pros:}

1. Infeasible sequences are not considered.

2. The model calculates the cost for all the combinations between machines and tools defined from the database.

\section{Cons:}

1. The user is burdened with a lot of computations and other process inputs.

2. The model may never find the optimal or near optimal solution.

\subsubsection{Development of Expert Rules}

This approach deals with the development of expert rules to help the user decide on the sequence of operations. The model then does the cost analysis using the parameters related to the machine and tool for selected process and dimensions in each step of the 
sequence. As an example, let us consider the development of a process plan. It is assumed that, based on the precedence relationship, turning, milling, drilling, and facing operations can be performed in the next place in the sequence under consideration. The model may look into these options and based on the dimension for each of the operations and "expected cost values", it may suggest that the turning operations should be placed

next in the sequence (using rules such as cost per in $^{3}$ of material removed). This approach will be helpful for people who have little knowledge in machining operations but may know the precedence relationships.

As evident with the example, the model will have a user interface and the operations' sequence will be generated one step at a time. Once the sequence is decided, the model may integrate the parameter and cost databases with the proposed operations' sequence and find the set of machines and tools that should be used to minimize the cost of machining the stock material. The benefits and limitations for this approach can be summarized as follows.

\section{Pros:}

1. Infeasible sequences are not considered since the user interacts with the model during the sequence consideration.

2. The user is supported with expert rules so that s/he does not consider options that have low probability of resulting in least cost and thus expediting the selection process.

\section{Cons:}

1. The user is burdened with a lot of computations and other process inputs.

2. The model may not reach the optimal solution and is dependent on the selection criteria built in the model.

\subsection{Validation}

The model was validated by comparing the final solutions to the one calculated manually for the first two examples given in Figures 3.9 and 3.10. It was noted that the model was able to find the same solution in both cases. 


\subsection{Conclusions}

This chapter discusses the details on model development to solve the problem of process planning in machining. The model was developed in Visual Basic ${ }^{\circledR}$ and Microsoft Excel ${ }^{\circledR}$ and was tested on several problems. Three work piece materials have been incorporated in the model as default materials and more can be included if needed. It was found that the model was able to find the best solution from all the possible sequences. Since the model does not considers parameter optimization or tool life equations, it does not change the tool life or other parameters if the depth of cut used in a process is less than the maximum depth of cut corresponding to the given speed, feed, and tool life values in the database. This limitation of the model can be eliminated by incorporating Taylor's tool life equations to calculate the new tool life but all the coefficients in the equation must be known in advance. 


\section{CONCLUSION AND FUTURE WORK}

\section{Conclusions}

Based on the model demonstrations and the corresponding results in the last chapter, it is evident that the process planning problem is one of the challenging problems that requires numerous iterations to find a "good solution”. The proposed model was formulated to find the minimum cost (based on predefined databases for speed, feed and depth of cut) for machining cylindrical parts with turning and cylindrical grinding processes. The model was able to develop all the possible sequences and generated more options by combining one or more sections during turning process. The proposed model used the existing expert system model (MPSEL) to find the list of machines and tools that can be used for a process/operation with required surface and material characteristics. The model used a hypothetical database to find the cutting parameters for selected process. Since the database is separate from the model, it can be changed to reflect the values from any machining factory database. Even though the model is not intended to be an optimization approach, it uses an intelligent approach to select the depth of cut for a given process. In case the depth of material removal is more than the maximum depth of cut allowed for the material, machine, and tool combination, it considers the cases with equal depth of cut for each pass and the case with maximum depth of cut for initial passes and remainder for the final pass. The model then selects the depth of cut that results in the least cost to perform that machining step. It should be noted that the proposed model does not consider any relationship (such as Taylor's too life equation) among the machining parameters (feed, speed and depth of cut). Therefore, in the examples considered in this research, the depth of cut did impact the final solution. This approach can make a difference in the final solution if one or more parameters can be considered as a function of the depth of cut considered for a particular machining pass.

\section{Future work}

The following points may be considered for the future work:

1. Integrate parameter optimization with the current model. 
2. Consider other machining processes such as drilling, tapping, facing, reaming, surface grinding, milling etc.

3. Integrate process selection (such as turning vs. grinding) with the current model.

4. Develop heuristics based solution to minimize the computational time for an overall integrated model.

5. Consider other expert systems or models to find the set of machines and tool for a process.

6. Enhance database to include other parameters 


\section{REFERENCES}

Allen, D.K, An Introduction to Computer-Aided Process Planning, CIM Review, Fall 1987.

Batchu, S., Kambhampati, S., Kartheek, H., and Shah, J., “An Iterative and Interactive Approach for Process Planning”, ASU CSE TR 95-023, September 1995.

Chang, P., and Chang, C., “An Integrated Artificial Intelligent Computer-Aided Process Planning System”, International Journal of Computer Integrated Manufacturing, Vol. 13, No. 6, 2000, Pages 483-497.

Chen, C. L. P. and Leclair, S. R., "Integration of Design and Manufacturing: Solving SetUp Generation and Feature Sequencing Using an Unsupervised-Learning Approach”, Computer Aided Design, 26, 1994, Pages 59-75.

Chen, J., Zhang, Y.F., and Nee, A.Y.C., "Set-Up Planning Using Hopfield Net and Simulated Annealing”, International Journal of Production Research, Vol. 36, No. 4, 1998, Pages 981-1000.

Creese, R.C., Adithan M., and Pabla, B.S., Estimating and Costing for the Metal Manufacturing Industries, Marcel Dekker, Inc., 1992.

Descotte, Y. and Latombe, J. C., "GARI: A Problem Solver That Plans How to Machine Mechanical Parts”, Proceedings of International Joint Conference on Artificial Intelligence, Vancouver, 1981, Pages 766-772.

Deshpande, S., Cagan, J., “An Agent Based Optimization Approach to Manufacturing Process Planning”, Transactions of the ASME, Vol. 126, January 2004, Pages 46-55.

Gopalakrishnan, B., “Computer Integrated Machining Parameter Selection In A Job Shop Using Expert Systems”, Journal of Mechanical Working Technology, Vol. 20, 1989, Pages 163-170. 
Gopalakrishnan, B., "Expert Systems for Machining Parameter Selection: Design Aspects”, Advance Manufacturing Engineering, Vol. 2, April 1990, Pages 59-63.

Keung, K.W., IP, W.H., and Lee, T.C., “A Genetic Algorithm Approach to the Multiple Machine Tool Selection Problem”, Journal of Intelligent Manufacturing, Vol. 12, 2001, Pages 331-342.

Khoshnevis, B., Sormaz, D.N., and Park, J.Y., An Integrated Process Planning System Using Feature Reasoning and Space Search-Based Optimization, IIE Transactions, 31, 1999, Pages 597-616.

Kiritsis, D. and Porchet, M., “A Generic Petri Net Model for Dynamic Process Planning and Sequence Optimization”, Advances in Engineering Software, Volume 25, Issue 1, 1996, Pages 61-71.

Kusiak, A., Intelligent Manufacturing Systems, Prentice-Hall International Series in Industrial and Systems Engineering, 1990, Pages 206-246.

Lee, D.-H., Kiritsis, D., and Xirouchakis, P., "Branch and Fathoming Algorithms for Operation Sequencing in Process Planning”, International Journal of Production Research, Vol. 39, No. 8, 2001, Pages 1649 - 1669.

Lee, D.-H., Kiritsis, D., and Xirouchakis, P., "Search Heuristics for Operation Sequencing in Process Planning”, International Journal of Production Research, Vol. 39, No. 16, 2001, Pages 3771-3788.

Lin, C.-J. and Wang, H.-P., “Optimal Operations Planning and Sequencing: Minimization of Tool Changeovers”, International Journal of Production Research, Vol. 31, No. 2, 1993, Pages 311-324.

Liu, Z. and Wang, L., "Sequencing of Interacting Prismatic Machining Features for Process Planning”, Computers in Industry, Vol. 58, Issue 4, May 2007, Pages 295-303. 
MA, G.H., Zhang, Y.F., and Nee, A.Y.C., “A Simulated Annealing-Based Optimization Algorithm for Process Planning”, International Journal of Production Research, Vol. 38, No. 12, 2000, Pages 2671-2687.

Machining Data Handbook, $3^{\text {rd }}$ edition, Vol. 2, 1980.

Marri, H. B., Gunasekaran, A. and Grieve, R. J., Computer-Aided Process Planning: A State of Art, The International Journal Advanced Manufacturing Technology, 14, 1998, Pages 261-268.

Nau, D.S. and Chang, T.-C., "A Knowledge-Based Approach to Generative Process Planning”, In Production Engineering Conference at ASME Winter Annual Meeting, Nov. 1985, Pages 65-71.

Reddy, S. V. B. Shunmugam, M. S., and Narendran, T. T., “Operation Sequencing In CAPP Using Genetic Algorithms”, International Journal of Production Research, Vol. 37, No. 5, 1999, Pages 1063-1074.

Singh, N., Systems Approach to Computer-Integrated Design and Manufacturing, john Wiley and Sons, Inc., 1996, Pages 477-528.

Singh, R., and Raman, S., "METEX - An Expert System for Machining Planning”, International Journal of Production Research, Vol. 30, No. 7, 1992, Pages 1501-1516.

Snead, C. S., Group Technology: Foundations for Competitive Manufacturing, Van Nostrand Reinhold, New York, 1989.

Usher, J.M. and Bowden, R.O., "The Application of Genetic Algorithms to Operation Sequencing for Use in Computer-Aided Process Planning”, Computer \& Industrial Engineering, 30, 1996, Pages 999-1013.

Wang, P. and Liang, M., “An Integrated Approach to Tolerance Synthesis, Process Selection and Machining Parameter Optimization Problems”, International Journal of Production Research, Vol. 43, No. 11, 1 June 2005, Pages 2237-2262. 
Wong, T.N. and Siu, S.L., "A Knowledge Based Approach to Automated Machining Process Selection and Sequencing”, International Journal of Production Research, Vol. 33, No. 12, 1995, Pages 3465-3484.

Wong, T. N., Chan, L. C. F., and Lau, H. C. W., "Machining Process Sequencing With Fuzzy Expert System And Genetic Algorithms”, Engineering with Computers, 19, 2003, Pages 191-202.

Yeo, S.H., Wong, Y.S., and Rahman, M., "Integrated Knowledge-Based Machining System for Rotational Parts”, International Journal of Production Research, Vol. 29, No. 7, 1991, Pages 1325-1337.

Zang, H., and Alting, L., Computerized Manufacturing Process Planning, Chapman \& Hall, 1994.

Zhang, F., Zhang, Y. F. and Nee, A. Y. C., "Using Genetic Algorithms in Process Planning for Job Shop Machining”, IEEE Transactions on Evolutionary Computation, 1, 1997, Pages 278-289.

Zhang, Y.F., Nee, A.Y.C., and ONG, S.K., “A Hybrid Approach for Set-Up Planning”, International Journal of Advanced Manufacturing Technology, 10, 1995, Pages 183-190. 


\section{APPENDIX 1: MACHINING PARAMETER DATABASE}

\begin{tabular}{|c|c|c|c|c|c|c|c|c|}
\hline Material & Process & Machine & Tool & $\begin{array}{c}\text { Surface } \\
\text { finish }\end{array}$ & $\begin{array}{l}\text { Maximum } \\
\text { Depth of } \\
\text { cut (in.) }\end{array}$ & $\begin{array}{l}\text { Feed } \\
\text { (ipr) }\end{array}$ & $\begin{array}{l}\text { Speed } \\
\text { (fpm) }\end{array}$ & $\begin{array}{c}\text { Tool life } \\
\text { (minutes) }\end{array}$ \\
\hline Cast iron & Turning & Engine Lathe & High Speed Steel & low & 0.04 & 0.007 & 175 & 50 \\
\hline Cast iron & Turning & Engine Lathe & High Speed Steel & medium & 0.15 & 0.015 & 135 & 50 \\
\hline Cast iron & Turning & Engine Lathe & High Speed Steel & high & 0.3 & 0.02 & 110 & 50 \\
\hline Cast iron & Turning & Engine Lathe & Single Point High Speed Steel M2 & low & 0.04 & 0.007 & 185 & 55 \\
\hline Cast iron & Turning & Engine Lathe & Single Point High Speed Steel M2 & medium & 0.15 & 0.015 & 145 & 55 \\
\hline Cast iron & Turning & Engine Lathe & Single Point High Speed Steel M2 & high & 0.3 & 0.02 & 120 & 55 \\
\hline Cast iron & Turning & Engine Lathe & Single Point High Speed Steel M3 & low & 0.04 & 0.007 & 195 & 58 \\
\hline Cast iron & Turning & Engine Lathe & Single Point High Speed Steel M3 & medium & 0.15 & 0.015 & 155 & 58 \\
\hline Cast iron & Turning & Engine Lathe & Single Point High Speed Steel M3 & high & 0.3 & 0.02 & 130 & 58 \\
\hline Cast iron & Turning & Engine Lathe & Single Point High Speed Steel T15 & low & 0.04 & 0.007 & 120 & 60 \\
\hline Cast iron & Turning & Engine Lathe & Single Point High Speed Steel T15 & medium & 0.15 & 0.015 & 80 & 60 \\
\hline Cast iron & Turning & Engine Lathe & Single Point High Speed Steel T15 & high & 0.3 & 0.02 & 65 & 60 \\
\hline Cast iron & Turning & Engine Lathe & Single Point High Speed Steel M42 & low & 0.04 & 0.007 & 130 & 63 \\
\hline Cast iron & Turning & Engine Lathe & Single Point High Speed Steel M42 & medium & 0.15 & 0.015 & 90 & 63 \\
\hline Cast iron & Turning & Engine Lathe & Single Point High Speed Steel M42 & high & 0.3 & 0.02 & 75 & 63 \\
\hline Cast iron & Turning & Engine Lathe & Carbide & low & 0.04 & 0.01 & 490 & 60 \\
\hline Cast iron & Turning & Engine Lathe & Carbide & medium & 0.15 & 0.02 & 390 & 60 \\
\hline Cast iron & Turning & Engine Lathe & Carbide & high & 0.3 & 0.03 & 315 & 60 \\
\hline Cast iron & Turning & Engine Lathe & Single Point Carbide C2 & low & 0.04 & 0.01 & 500 & 61 \\
\hline Cast iron & Turning & Engine Lathe & Single Point Carbide C2 & medium & 0.15 & 0.02 & 400 & 61 \\
\hline Cast iron & Turning & Engine Lathe & Single Point Carbide C2 & high & 0.3 & 0.03 & 325 & 61 \\
\hline
\end{tabular}




\begin{tabular}{|c|c|c|c|c|c|c|c|c|}
\hline Material & Process & Machine & Tool & $\begin{array}{c}\text { Surface } \\
\text { finish }\end{array}$ & $\begin{array}{c}\text { Maximum } \\
\text { Depth of } \\
\text { cut (in.) }\end{array}$ & $\begin{array}{l}\text { Feed } \\
\text { (ipr) }\end{array}$ & $\begin{array}{l}\text { Speed } \\
(\text { fpm) }\end{array}$ & $\begin{array}{c}\text { Tool life } \\
\text { (minutes) }\end{array}$ \\
\hline Cast iron & Turning & Engine Lathe & Single Point Carbide C3 & low & 0.04 & 0.01 & 300 & 63 \\
\hline Cast iron & Turning & Engine Lathe & Single Point Carbide C3 & medium & 0.15 & 0.02 & 210 & 63 \\
\hline Cast iron & Turning & Engine Lathe & Single Point Carbide C3 & high & 0.3 & 0.03 & 175 & 63 \\
\hline Cast iron & Turning & Engine Lathe & Single Point Carbide C4 & low & 0.04 & 0.01 & 310 & 65 \\
\hline Cast iron & Turning & Engine Lathe & Single Point Carbide C4 & medium & 0.15 & 0.02 & 220 & 65 \\
\hline Cast iron & Turning & Engine Lathe & Single Point Carbide C4 & high & 0.3 & 0.03 & 185 & 65 \\
\hline Cast iron & Turning & Engine Lathe & Single Point Carbide C6 & low & 0.04 & 0.01 & 320 & 67 \\
\hline Cast iron & Turning & Engine Lathe & Single Point Carbide C6 & medium & 0.15 & 0.02 & 250 & 67 \\
\hline Cast iron & Turning & Engine Lathe & Single Point Carbide C6 & high & 0.3 & 0.03 & 200 & 67 \\
\hline Cast iron & Turning & Engine Lathe & Single Point Carbide C7 & low & 0.04 & 0.01 & 480 & 70 \\
\hline Cast iron & Turning & Engine Lathe & Single Point Carbide C7 & medium & 0.15 & 0.02 & 375 & 70 \\
\hline Cast iron & Turning & Engine Lathe & Single Point Carbide C7 & high & 0.3 & 0.03 & 310 & 70 \\
\hline Cast iron & Turning & Engine Lathe & Single Point Carbide C8 & low & 0.04 & 0.01 & 500 & 71 \\
\hline Cast iron & Turning & Engine Lathe & Single Point Carbide C8 & medium & 0.15 & 0.02 & 400 & 71 \\
\hline Cast iron & Turning & Engine Lathe & Single Point Carbide C8 & high & 0.3 & 0.03 & 350 & 71 \\
\hline Cast iron & Turning & Engine Lathe & Ceramic & low & 0.04 & 0.005 & 1200 & 65 \\
\hline Cast iron & Turning & Engine Lathe & Ceramic & medium & 0.15 & 0.01 & 750 & 65 \\
\hline Cast iron & Turning & Engine Lathe & Ceramic & high & 0.3 & 0.015 & 550 & 65 \\
\hline Cast iron & Turning & Engine Lathe & Single Point Ceramic HPC & low & 0.04 & 0.005 & 1300 & 67 \\
\hline Cast iron & Turning & Engine Lathe & Single Point Ceramic HPC & medium & 0.15 & 0.01 & 800 & 67 \\
\hline Cast iron & Turning & Engine Lathe & Single Point Ceramic HPC & high & 0.3 & 0.015 & 600 & 67 \\
\hline Cast iron & Turning & Engine Lathe & Single Point Ceramic CPA & low & 0.04 & 0.005 & 1700 & 70 \\
\hline Cast iron & Turning & Engine Lathe & Single Point Ceramic CPA & medium & 0.15 & 0.01 & 1250 & 70 \\
\hline
\end{tabular}




\begin{tabular}{|c|c|c|c|c|c|c|c|c|}
\hline Material & Process & Machine & Tool & $\begin{array}{c}\text { Surface } \\
\text { finish }\end{array}$ & $\begin{array}{l}\text { Maximum } \\
\text { Depth of } \\
\text { cut (in.) }\end{array}$ & $\begin{array}{l}\text { Feed } \\
\text { (ipr) }\end{array}$ & $\begin{array}{l}\text { Speed } \\
\text { (fpm) }\end{array}$ & $\begin{array}{c}\text { Tool life } \\
\text { (minutes) }\end{array}$ \\
\hline Cast iron & Turning & Engine Lathe & Single Point Ceramic CPA & high & 0.3 & 0.015 & 950 & 70 \\
\hline Cast iron & Turning & Engine Lathe & Diamond & low & 0.005 & 0.003 & 3000 & 80 \\
\hline Cast iron & Turning & Engine Lathe & Diamond & medium & 0.015 & 0.006 & 3200 & 80 \\
\hline Cast iron & Turning & Engine Lathe & Diamond & high & 0.05 & 0.012 & 3500 & 80 \\
\hline Cast iron & Turning & SP Auto & High Speed Steel & low & 0.04 & 0.007 & 195 & 50 \\
\hline Cast iron & Turning & SP Auto & High Speed Steel & medium & 0.15 & 0.015 & 150 & 50 \\
\hline Cast iron & Turning & SP Auto & High Speed Steel & high & 0.3 & 0.02 & 120 & 50 \\
\hline Cast iron & Turning & SP Auto & Single Point High Speed Steel M2 & low & 0.04 & 0.007 & 205 & 55 \\
\hline Cast iron & Turning & SP Auto & Single Point High Speed Steel M2 & medium & 0.15 & 0.015 & 160 & 55 \\
\hline Cast iron & Turning & SP Auto & Single Point High Speed Steel M2 & high & 0.3 & 0.02 & 130 & 55 \\
\hline Cast iron & Turning & SP Auto & Single Point High Speed Steel M3 & low & 0.04 & 0.007 & 215 & 58 \\
\hline Cast iron & Turning & SP Auto & Single Point High Speed Steel M3 & medium & 0.15 & 0.015 & 170 & 58 \\
\hline Cast iron & Turning & SP Auto & Single Point High Speed Steel M3 & high & 0.3 & 0.02 & 145 & 58 \\
\hline Cast iron & Turning & SP Auto & Single Point High Speed Steel T15 & low & 0.04 & 0.007 & 130 & 60 \\
\hline Cast iron & Turning & SP Auto & Single Point High Speed Steel T15 & medium & 0.15 & 0.015 & 90 & 60 \\
\hline Cast iron & Turning & SP Auto & Single Point High Speed Steel T15 & high & 0.3 & 0.02 & 70 & 60 \\
\hline Cast iron & Turning & SP Auto & Single Point High Speed Steel M42 & low & 0.04 & 0.007 & 145 & 63 \\
\hline Cast iron & Turning & SP Auto & Single Point High Speed Steel M42 & medium & 0.15 & 0.015 & 100 & 63 \\
\hline Cast iron & Turning & SP Auto & Single Point High Speed Steel M42 & high & 0.3 & 0.02 & 85 & 63 \\
\hline Cast iron & Turning & SP Auto & Carbide & low & 0.04 & 0.01 & 540 & 60 \\
\hline Cast iron & Turning & SP Auto & Carbide & medium & 0.15 & 0.02 & 430 & 60 \\
\hline Cast iron & Turning & SP Auto & Carbide & high & 0.3 & 0.03 & 345 & 60 \\
\hline Cast iron & Turning & SP Auto & Single Point Carbide C2 & low & 0.04 & 0.01 & 550 & 61 \\
\hline
\end{tabular}




\begin{tabular}{|c|c|c|c|c|c|c|c|c|}
\hline Material & Process & Machine & Tool & $\begin{array}{l}\text { Surface } \\
\text { finish }\end{array}$ & $\begin{array}{l}\text { Maximum } \\
\text { Depth of } \\
\text { cut (in.) }\end{array}$ & $\begin{array}{l}\text { Feed } \\
\text { (ipr) }\end{array}$ & $\begin{array}{l}\text { Speed } \\
\text { (fpm) }\end{array}$ & $\begin{array}{c}\text { Tool life } \\
\text { (minutes) }\end{array}$ \\
\hline Cast iron & Turning & SP Auto & Single Point Carbide C2 & medium & 0.15 & 0.02 & 440 & 61 \\
\hline Cast iron & Turning & SP Auto & Single Point Carbide C2 & high & 0.3 & 0.03 & 360 & 61 \\
\hline Cast iron & Turning & SP Auto & Single Point Carbide C3 & low & 0.04 & 0.01 & 330 & 63 \\
\hline Cast iron & Turning & SP Auto & Single Point Carbide C3 & medium & 0.15 & 0.02 & 230 & 63 \\
\hline Cast iron & Turning & SP Auto & Single Point Carbide C3 & high & 0.3 & 0.03 & 195 & 63 \\
\hline Cast iron & Turning & SP Auto & Single Point Carbide C4 & low & 0.04 & 0.01 & 340 & 65 \\
\hline Cast iron & Turning & SP Auto & Single Point Carbide C4 & medium & 0.15 & 0.02 & 240 & 65 \\
\hline Cast iron & Turning & SP Auto & Single Point Carbide C4 & high & 0.3 & 0.03 & 205 & 65 \\
\hline Cast iron & Turning & SP Auto & Single Point Carbide C6 & low & 0.04 & 0.01 & 350 & 67 \\
\hline Cast iron & Turning & SP Auto & Single Point Carbide C6 & medium & 0.15 & 0.02 & 275 & 67 \\
\hline Cast iron & Turning & SP Auto & Single Point Carbide C6 & high & 0.3 & 0.03 & 220 & 67 \\
\hline Cast iron & Turning & SP Auto & Single Point Carbide C7 & low & 0.04 & 0.01 & 530 & 70 \\
\hline Cast iron & Turning & SP Auto & Single Point Carbide C7 & medium & 0.15 & 0.02 & 415 & 70 \\
\hline Cast iron & Turning & SP Auto & Single Point Carbide C7 & high & 0.3 & 0.03 & 340 & 70 \\
\hline Cast iron & Turning & SP Auto & Single Point Carbide C8 & low & 0.04 & 0.01 & 550 & 71 \\
\hline Cast iron & Turning & SP Auto & Single Point Carbide C8 & medium & 0.15 & 0.02 & 440 & 71 \\
\hline Cast iron & Turning & SP Auto & Single Point Carbide C8 & high & 0.3 & 0.03 & 385 & 71 \\
\hline Cast iron & Turning & SP Auto & Ceramic & low & 0.04 & 0.005 & 1320 & 65 \\
\hline Cast iron & Turning & SP Auto & Ceramic & medium & 0.15 & 0.01 & 825 & 65 \\
\hline Cast iron & Turning & SP Auto & Ceramic & high & 0.3 & 0.015 & 605 & 65 \\
\hline Cast iron & Turning & SP Auto & Single Point Ceramic HPC & low & 0.04 & 0.005 & 1430 & 67 \\
\hline Cast iron & Turning & SP Auto & Single Point Ceramic HPC & medium & 0.15 & 0.01 & 880 & 67 \\
\hline Cast iron & Turning & SP Auto & Single Point Ceramic HPC & high & 0.3 & 0.015 & 660 & 67 \\
\hline
\end{tabular}




\begin{tabular}{|c|c|c|c|c|c|c|c|c|}
\hline Material & Process & Machine & Tool & $\begin{array}{c}\text { Surface } \\
\text { finish }\end{array}$ & $\begin{array}{l}\text { Maximum } \\
\text { Depth of } \\
\text { cut (in.) }\end{array}$ & $\begin{array}{l}\text { Feed } \\
\text { (ipr) }\end{array}$ & $\begin{array}{l}\text { Speed } \\
\text { (fpm) }\end{array}$ & $\begin{array}{c}\text { Tool life } \\
\text { (minutes) }\end{array}$ \\
\hline Cast iron & Turning & SP Auto & Single Point Ceramic CPA & low & 0.04 & 0.005 & 1870 & 70 \\
\hline Cast iron & Turning & SP Auto & Single Point Ceramic CPA & medium & 0.15 & 0.01 & 1375 & 70 \\
\hline Cast iron & Turning & SP Auto & Single Point Ceramic CPA & high & 0.3 & 0.015 & 1045 & 70 \\
\hline Cast iron & Turning & SP Auto & Diamond & low & 0.005 & 0.003 & 3300 & 80 \\
\hline Cast iron & Turning & SP Auto & Diamond & medium & 0.015 & 0.006 & 3520 & 80 \\
\hline Cast iron & Turning & SP Auto & Diamond & high & 0.05 & 0.012 & 3850 & 80 \\
\hline Cast iron & Turning & Turret Lathe & High Speed Steel & low & 0.04 & 0.007 & 215 & 50 \\
\hline Cast iron & Turning & Turret Lathe & High Speed Steel & medium & 0.15 & 0.015 & 165 & 50 \\
\hline Cast iron & Turning & Turret Lathe & High Speed Steel & high & 0.3 & 0.02 & 130 & 50 \\
\hline Cast iron & Turning & Turret Lathe & Single Point High Speed Steel M2 & low & 0.04 & 0.007 & 225 & 55 \\
\hline Cast iron & Turning & Turret Lathe & Single Point High Speed Steel M2 & medium & 0.15 & 0.015 & 175 & 55 \\
\hline Cast iron & Turning & Turret Lathe & Single Point High Speed Steel M2 & high & 0.3 & 0.02 & 145 & 55 \\
\hline Cast iron & Turning & Turret Lathe & Single Point High Speed Steel M3 & low & 0.04 & 0.007 & 235 & 58 \\
\hline Cast iron & Turning & Turret Lathe & Single Point High Speed Steel M3 & medium & 0.15 & 0.015 & 185 & 58 \\
\hline Cast iron & Turning & Turret Lathe & Single Point High Speed Steel M3 & high & 0.3 & 0.02 & 160 & 58 \\
\hline Cast iron & Turning & Turret Lathe & Single Point High Speed Steel T15 & low & 0.04 & 0.007 & 145 & 60 \\
\hline Cast iron & Turning & Turret Lathe & Single Point High Speed Steel T15 & medium & 0.15 & 0.015 & 100 & 60 \\
\hline Cast iron & Turning & Turret Lathe & Single Point High Speed Steel T15 & high & 0.3 & 0.02 & 75 & 60 \\
\hline Cast iron & Turning & Turret Lathe & Single Point High Speed Steel M42 & low & 0.04 & 0.007 & 160 & 63 \\
\hline Cast iron & Turning & Turret Lathe & Single Point High Speed Steel M42 & medium & 0.15 & 0.015 & 110 & 63 \\
\hline Cast iron & Turning & Turret Lathe & Single Point High Speed Steel M42 & high & 0.3 & 0.02 & 95 & 63 \\
\hline Cast iron & Turning & Turret Lathe & Carbide & low & 0.04 & 0.01 & 595 & 60 \\
\hline Cast iron & Turning & Turret Lathe & Carbide & medium & 0.15 & 0.02 & 475 & 60 \\
\hline
\end{tabular}




\begin{tabular}{|c|c|c|c|c|c|c|c|c|}
\hline Material & Process & Machine & Tool & $\begin{array}{c}\text { Surface } \\
\text { finish }\end{array}$ & $\begin{array}{l}\text { Maximum } \\
\text { Depth of } \\
\text { cut (in.) }\end{array}$ & $\begin{array}{l}\text { Feed } \\
\text { (ipr) }\end{array}$ & $\begin{array}{l}\text { Speed } \\
\text { (fpm) }\end{array}$ & $\begin{array}{c}\text { Tool life } \\
\text { (minutes) }\end{array}$ \\
\hline Cast iron & Turning & Turret Lathe & Carbide & high & 0.3 & 0.03 & 380 & 60 \\
\hline Cast iron & Turning & Turret Lathe & Single Point Carbide C2 & low & 0.04 & 0.01 & 605 & 61 \\
\hline Cast iron & Turning & Turret Lathe & Single Point Carbide C2 & medium & 0.15 & 0.02 & 485 & 61 \\
\hline Cast iron & Turning & Turret Lathe & Single Point Carbide C2 & high & 0.3 & 0.03 & 395 & 61 \\
\hline Cast iron & Turning & Turret Lathe & Single Point Carbide C3 & low & 0.04 & 0.01 & 365 & 63 \\
\hline Cast iron & Turning & Turret Lathe & Single Point Carbide C3 & medium & 0.15 & 0.02 & 255 & 63 \\
\hline Cast iron & Turning & Turret Lathe & Single Point Carbide C3 & high & 0.3 & 0.03 & 215 & 63 \\
\hline Cast iron & Turning & Turret Lathe & Single Point Carbide C4 & low & 0.04 & 0.01 & 375 & 65 \\
\hline Cast iron & Turning & Turret Lathe & Single Point Carbide C4 & medium & 0.15 & 0.02 & 265 & 65 \\
\hline Cast iron & Turning & Turret Lathe & Single Point Carbide C4 & high & 0.3 & 0.03 & 225 & 65 \\
\hline Cast iron & Turning & Turret Lathe & Single Point Carbide C6 & low & 0.04 & 0.01 & 385 & 67 \\
\hline Cast iron & Turning & Turret Lathe & Single Point Carbide C6 & medium & 0.15 & 0.02 & 305 & 67 \\
\hline Cast iron & Turning & Turret Lathe & Single Point Carbide C6 & high & 0.3 & 0.03 & 240 & 67 \\
\hline Cast iron & Turning & Turret Lathe & Single Point Carbide C7 & low & 0.04 & 0.01 & 585 & 70 \\
\hline Cast iron & Turning & Turret Lathe & Single Point Carbide C7 & medium & 0.15 & 0.02 & 455 & 70 \\
\hline Cast iron & Turning & Turret Lathe & Single Point Carbide C7 & high & 0.3 & 0.03 & 375 & 70 \\
\hline Cast iron & Turning & Turret Lathe & Single Point Carbide C8 & low & 0.04 & 0.01 & 605 & 71 \\
\hline Cast iron & Turning & Turret Lathe & Single Point Carbide C8 & medium & 0.15 & 0.02 & 485 & 71 \\
\hline Cast iron & Turning & Turret Lathe & Single Point Carbide C8 & high & 0.3 & 0.03 & 425 & 71 \\
\hline Cast iron & Turning & Turret Lathe & Ceramic & low & 0.04 & 0.005 & 1450 & 65 \\
\hline Cast iron & Turning & Turret Lathe & Ceramic & medium & 0.15 & 0.01 & 910 & 65 \\
\hline Cast iron & Turning & Turret Lathe & Ceramic & high & 0.3 & 0.015 & 665 & 65 \\
\hline Cast iron & Turning & Turret Lathe & Single Point Ceramic HPC & low & 0.04 & 0.005 & 1575 & 67 \\
\hline
\end{tabular}




\begin{tabular}{|c|c|c|c|c|c|c|c|c|}
\hline Material & Process & Machine & Tool & $\begin{array}{c}\text { Surface } \\
\text { finish }\end{array}$ & $\begin{array}{l}\text { Maximum } \\
\text { Depth of } \\
\text { cut (in.) }\end{array}$ & $\begin{array}{l}\text { Feed } \\
\text { (ipr) }\end{array}$ & $\begin{array}{l}\text { Speed } \\
\text { (fpm) }\end{array}$ & $\begin{array}{c}\text { Tool life } \\
\text { (minutes) }\end{array}$ \\
\hline Cast iron & Turning & Turret Lathe & Single Point Ceramic HPC & medium & 0.15 & 0.01 & 970 & 67 \\
\hline Cast iron & Turning & Turret Lathe & Single Point Ceramic HPC & high & 0.3 & 0.015 & 725 & 67 \\
\hline Cast iron & Turning & Turret Lathe & Single Point Ceramic CPA & low & 0.04 & 0.005 & 2055 & 70 \\
\hline Cast iron & Turning & Turret Lathe & Single Point Ceramic CPA & medium & 0.15 & 0.01 & 1515 & 70 \\
\hline Cast iron & Turning & Turret Lathe & Single Point Ceramic CPA & high & 0.3 & 0.015 & 1150 & 70 \\
\hline Cast iron & Turning & Turret Lathe & Diamond & low & 0.005 & 0.003 & 3630 & 80 \\
\hline Cast iron & Turning & Turret Lathe & Diamond & medium & 0.015 & 0.006 & 3870 & 80 \\
\hline Cast iron & Turning & Turret Lathe & Diamond & high & 0.05 & 0.012 & 4235 & 80 \\
\hline Cast iron & Turning & NC Lathe & High Speed Steel & low & 0.04 & 0.007 & 235 & 50 \\
\hline Cast iron & Turning & NC Lathe & High Speed Steel & medium & 0.15 & 0.015 & 180 & 50 \\
\hline Cast iron & Turning & NC Lathe & High Speed Steel & high & 0.3 & 0.02 & 145 & 50 \\
\hline Cast iron & Turning & NC Lathe & Single Point High Speed Steel M2 & low & 0.04 & 0.007 & 250 & 55 \\
\hline Cast iron & Turning & NC Lathe & Single Point High Speed Steel M2 & medium & 0.15 & 0.015 & 195 & 55 \\
\hline Cast iron & Turning & NC Lathe & Single Point High Speed Steel M2 & high & 0.3 & 0.02 & 160 & 55 \\
\hline Cast iron & Turning & NC Lathe & Single Point High Speed Steel M3 & low & 0.04 & 0.007 & 260 & 58 \\
\hline Cast iron & Turning & NC Lathe & Single Point High Speed Steel M3 & medium & 0.15 & 0.015 & 205 & 58 \\
\hline Cast iron & Turning & NC Lathe & Single Point High Speed Steel M3 & high & 0.3 & 0.02 & 175 & 58 \\
\hline Cast iron & Turning & NC Lathe & Single Point High Speed Steel T15 & low & 0.04 & 0.007 & 160 & 60 \\
\hline Cast iron & Turning & NC Lathe & Single Point High Speed Steel T15 & medium & 0.15 & 0.015 & 110 & 60 \\
\hline Cast iron & Turning & NC Lathe & Single Point High Speed Steel T15 & high & 0.3 & 0.02 & 85 & 60 \\
\hline Cast iron & Turning & NC Lathe & Single Point High Speed Steel M42 & low & 0.04 & 0.007 & 175 & 63 \\
\hline Cast iron & Turning & NC Lathe & Single Point High Speed Steel M42 & medium & 0.15 & 0.015 & 120 & 63 \\
\hline Cast iron & Turning & NC Lathe & Single Point High Speed Steel M42 & high & 0.3 & 0.02 & 105 & 63 \\
\hline
\end{tabular}




\begin{tabular}{|c|c|c|c|c|c|c|c|c|}
\hline Material & Process & Machine & Tool & $\begin{array}{c}\text { Surface } \\
\text { finish }\end{array}$ & $\begin{array}{l}\text { Maximum } \\
\text { Depth of } \\
\text { cut (in.) }\end{array}$ & $\begin{array}{l}\text { Feed } \\
\text { (ipr) }\end{array}$ & $\begin{array}{l}\text { Speed } \\
\text { (fpm) }\end{array}$ & $\begin{array}{c}\text { Tool life } \\
\text { (minutes) }\end{array}$ \\
\hline Cast iron & Turning & NC Lathe & Carbide & low & 0.04 & 0.01 & 655 & 60 \\
\hline Cast iron & Turning & NC Lathe & Carbide & medium & 0.15 & 0.02 & 525 & 60 \\
\hline Cast iron & Turning & NC Lathe & Carbide & high & 0.3 & 0.03 & 420 & 60 \\
\hline Cast iron & Turning & NC Lathe & Single Point Carbide C2 & low & 0.04 & 0.01 & 665 & 61 \\
\hline Cast iron & Turning & NC Lathe & Single Point Carbide C2 & medium & 0.15 & 0.02 & 535 & 61 \\
\hline Cast iron & Turning & NC Lathe & Single Point Carbide C2 & high & 0.3 & 0.03 & 435 & 61 \\
\hline Cast iron & Turning & NC Lathe & Single Point Carbide C3 & low & 0.04 & 0.01 & 400 & 63 \\
\hline Cast iron & Turning & NC Lathe & Single Point Carbide C3 & medium & 0.15 & 0.02 & 280 & 63 \\
\hline Cast iron & Turning & NC Lathe & Single Point Carbide C3 & high & 0.3 & 0.03 & 235 & 63 \\
\hline Cast iron & Turning & NC Lathe & Single Point Carbide C4 & low & 0.04 & 0.01 & 415 & 65 \\
\hline Cast iron & Turning & NC Lathe & Single Point Carbide C4 & medium & 0.15 & 0.02 & 290 & 65 \\
\hline Cast iron & Turning & NC Lathe & Single Point Carbide C4 & high & 0.3 & 0.03 & 250 & 65 \\
\hline Cast iron & Turning & NC Lathe & Single Point Carbide C6 & low & 0.04 & 0.01 & 425 & 67 \\
\hline Cast iron & Turning & NC Lathe & Single Point Carbide C6 & medium & 0.15 & 0.02 & 335 & 67 \\
\hline Cast iron & Turning & NC Lathe & Single Point Carbide C6 & high & 0.3 & 0.03 & 265 & 67 \\
\hline Cast iron & Turning & NC Lathe & Single Point Carbide C7 & low & 0.04 & 0.01 & 645 & 70 \\
\hline Cast iron & Turning & NC Lathe & Single Point Carbide C7 & medium & 0.15 & 0.02 & 500 & 70 \\
\hline Cast iron & Turning & NC Lathe & Single Point Carbide C7 & high & 0.3 & 0.03 & 415 & 70 \\
\hline Cast iron & Turning & NC Lathe & Single Point Carbide C8 & low & 0.04 & 0.01 & 665 & 71 \\
\hline Cast iron & Turning & NC Lathe & Single Point Carbide C8 & medium & 0.15 & 0.02 & 535 & 71 \\
\hline Cast iron & Turning & NC Lathe & Single Point Carbide C8 & high & 0.3 & 0.03 & 470 & 71 \\
\hline Cast iron & Turning & NC Lathe & Ceramic & low & 0.04 & 0.005 & 1595 & 65 \\
\hline Cast iron & Turning & NC Lathe & Ceramic & medium & 0.15 & 0.01 & 1000 & 65 \\
\hline
\end{tabular}




\begin{tabular}{|c|c|c|c|c|c|c|c|c|}
\hline Material & Process & Machine & Tool & $\begin{array}{c}\text { Surface } \\
\text { finish }\end{array}$ & $\begin{array}{l}\text { Maximum } \\
\text { Depth of } \\
\text { cut (in.) } \\
\end{array}$ & $\begin{array}{l}\text { Feed } \\
\text { (ipr) }\end{array}$ & $\begin{array}{l}\text { Speed } \\
\text { (fpm) }\end{array}$ & $\begin{array}{c}\text { Tool life } \\
\text { (minutes) }\end{array}$ \\
\hline Cast iron & Turning & NC Lathe & Ceramic & high & 0.3 & 0.015 & 730 & 65 \\
\hline Cast iron & Turning & NC Lathe & Single Point Ceramic HPC & low & 0.04 & 0.005 & 1735 & 67 \\
\hline Cast iron & Turning & NC Lathe & Single Point Ceramic HPC & medium & 0.15 & 0.01 & 1065 & 67 \\
\hline Cast iron & Turning & NC Lathe & Single Point Ceramic HPC & high & 0.3 & 0.015 & 800 & 67 \\
\hline Cast iron & Turning & NC Lathe & Single Point Ceramic CPA & low & 0.04 & 0.005 & 2260 & 70 \\
\hline Cast iron & Turning & NC Lathe & Single Point Ceramic CPA & medium & 0.15 & 0.01 & 1665 & 70 \\
\hline Cast iron & Turning & NC Lathe & Single Point Ceramic CPA & high & 0.3 & 0.015 & 1265 & 70 \\
\hline Cast iron & Turning & NC Lathe & Diamond & low & 0.005 & 0.003 & 3995 & 80 \\
\hline Cast iron & Turning & NC Lathe & Diamond & medium & 0.015 & 0.006 & 4255 & 80 \\
\hline Cast iron & Turning & NC Lathe & Diamond & high & 0.05 & 0.012 & 4660 & 80 \\
\hline Aluminum & Turning & Engine Lathe & High Speed Steel & low & 0.04 & 0.007 & 900 & 55 \\
\hline Aluminum & Turning & Engine Lathe & High Speed Steel & medium & 0.15 & 0.015 & 800 & 55 \\
\hline Aluminum & Turning & Engine Lathe & High Speed Steel & high & 0.3 & 0.03 & 700 & 55 \\
\hline Aluminum & Turning & Engine Lathe & Single Point High Speed Steel M2 & low & 0.04 & 0.007 & 1000 & 61 \\
\hline Aluminum & Turning & Engine Lathe & Single Point High Speed Steel M2 & medium & 0.15 & 0.015 & 900 & 61 \\
\hline Aluminum & Turning & Engine Lathe & Single Point High Speed Steel M2 & high & 0.3 & 0.03 & 800 & 61 \\
\hline Aluminum & Turning & Engine Lathe & Single Point High Speed Steel M3 & low & 0.04 & 0.007 & 1050 & 64 \\
\hline Aluminum & Turning & Engine Lathe & Single Point High Speed Steel M3 & medium & 0.15 & 0.015 & 950 & 64 \\
\hline Aluminum & Turning & Engine Lathe & Single Point High Speed Steel M3 & high & 0.3 & 0.03 & 850 & 64 \\
\hline Aluminum & Turning & Engine Lathe & Single Point High Speed Steel T15 & low & 0.04 & 0.007 & 1075 & 66 \\
\hline Aluminum & Turning & Engine Lathe & Single Point High Speed Steel T15 & medium & 0.15 & 0.015 & 975 & 66 \\
\hline Aluminum & Turning & Engine Lathe & Single Point High Speed Steel T15 & high & 0.3 & 0.03 & 875 & 66 \\
\hline Aluminum & Turning & Engine Lathe & Single Point High Speed Steel M42 & low & 0.04 & 0.007 & 1100 & 69 \\
\hline
\end{tabular}




\begin{tabular}{|c|c|c|c|c|c|c|c|c|}
\hline Material & Process & Machine & Tool & $\begin{array}{l}\text { Surface } \\
\text { finish }\end{array}$ & $\begin{array}{l}\text { Maximum } \\
\text { Depth of } \\
\text { cut (in.) }\end{array}$ & $\begin{array}{l}\text { Feed } \\
\text { (ipr) }\end{array}$ & $\begin{array}{l}\text { Speed } \\
\text { (fpm) }\end{array}$ & $\begin{array}{c}\text { Tool life } \\
\text { (minutes) }\end{array}$ \\
\hline Aluminum & Turning & Engine Lathe & Single Point High Speed Steel M42 & medium & 0.15 & 0.015 & 1000 & 69 \\
\hline Aluminum & Turning & Engine Lathe & Single Point High Speed Steel M42 & high & 0.3 & 0.03 & 900 & 69 \\
\hline Aluminum & Turning & Engine Lathe & Carbide & low & 0.04 & 0.01 & 1900 & 66 \\
\hline Aluminum & Turning & Engine Lathe & Carbide & medium & 0.15 & 0.02 & 1700 & 66 \\
\hline Aluminum & Turning & Engine Lathe & Carbide & high & 0.3 & 0.04 & 1100 & 66 \\
\hline Aluminum & Turning & Engine Lathe & Single Point Carbide C2 & low & 0.04 & 0.01 & 2000 & 67 \\
\hline Aluminum & Turning & Engine Lathe & Single Point Carbide C2 & medium & 0.15 & 0.02 & 1800 & 67 \\
\hline Aluminum & Turning & Engine Lathe & Single Point Carbide C2 & high & 0.3 & 0.04 & 1200 & 67 \\
\hline Aluminum & Turning & Engine Lathe & Single Point Carbide C3 & low & 0.04 & 0.01 & 2010 & 69 \\
\hline Aluminum & Turning & Engine Lathe & Single Point Carbide C3 & medium & 0.15 & 0.02 & 1810 & 69 \\
\hline Aluminum & Turning & Engine Lathe & Single Point Carbide C3 & high & 0.3 & 0.04 & 1210 & 69 \\
\hline Aluminum & Turning & Engine Lathe & Single Point Carbide C4 & low & 0.04 & 0.01 & 2025 & 72 \\
\hline Aluminum & Turning & Engine Lathe & Single Point Carbide C4 & medium & 0.15 & 0.02 & 1825 & 72 \\
\hline Aluminum & Turning & Engine Lathe & Single Point Carbide C4 & high & 0.3 & 0.04 & 1225 & 72 \\
\hline Aluminum & Turning & Engine Lathe & Single Point Carbide C6 & low & 0.04 & 0.01 & 2040 & 74 \\
\hline Aluminum & Turning & Engine Lathe & Single Point Carbide C6 & medium & 0.15 & 0.02 & 1840 & 74 \\
\hline Aluminum & Turning & Engine Lathe & Single Point Carbide C6 & high & 0.3 & 0.04 & 1240 & 74 \\
\hline Aluminum & Turning & Engine Lathe & Single Point Carbide C7 & low & 0.04 & 0.01 & 2050 & 77 \\
\hline Aluminum & Turning & Engine Lathe & Single Point Carbide C7 & medium & 0.15 & 0.02 & 1850 & 77 \\
\hline Aluminum & Turning & Engine Lathe & Single Point Carbide C7 & high & 0.3 & 0.04 & 1250 & 77 \\
\hline Aluminum & Turning & Engine Lathe & Single Point Carbide C8 & low & 0.04 & 0.01 & 2055 & 78 \\
\hline Aluminum & Turning & Engine Lathe & Single Point Carbide C8 & medium & 0.15 & 0.02 & 1855 & 78 \\
\hline Aluminum & Turning & Engine Lathe & Single Point Carbide C8 & high & 0.3 & 0.04 & 1255 & 78 \\
\hline
\end{tabular}




\begin{tabular}{|c|c|c|c|c|c|c|c|c|}
\hline Material & Process & Machine & Tool & $\begin{array}{c}\text { Surface } \\
\text { finish }\end{array}$ & $\begin{array}{c}\text { Maximum } \\
\text { Depth of } \\
\text { cut (in.) } \\
\end{array}$ & $\begin{array}{l}\text { Feed } \\
\text { (ipr) }\end{array}$ & $\begin{array}{l}\text { Speed } \\
\text { (fpm) }\end{array}$ & $\begin{array}{c}\text { Tool life } \\
\text { (minutes) }\end{array}$ \\
\hline Aluminum & Turning & Engine Lathe & Ceramic & low & 0.04 & 0.01 & 1955 & 72 \\
\hline Aluminum & Turning & Engine Lathe & Ceramic & medium & 0.15 & 0.02 & 1755 & 72 \\
\hline Aluminum & Turning & Engine Lathe & Ceramic & high & 0.3 & 0.04 & 1155 & 72 \\
\hline Aluminum & Turning & Engine Lathe & Single Point Ceramic HPC & low & 0.04 & 0.01 & 1960 & 74 \\
\hline Aluminum & Turning & Engine Lathe & Single Point Ceramic HPC & medium & 0.15 & 0.02 & 1760 & 74 \\
\hline Aluminum & Turning & Engine Lathe & Single Point Ceramic HPC & high & 0.3 & 0.04 & 1160 & 74 \\
\hline Aluminum & Turning & Engine Lathe & Single Point Ceramic CPA & low & 0.04 & 0.01 & 1975 & 77 \\
\hline Aluminum & Turning & Engine Lathe & Single Point Ceramic CPA & medium & 0.15 & 0.02 & 1775 & 77 \\
\hline Aluminum & Turning & Engine Lathe & Single Point Ceramic CPA & high & 0.3 & 0.04 & 1175 & 77 \\
\hline Aluminum & Turning & Engine Lathe & Diamond & low & 0.005 & 0.003 & 1200 & 88 \\
\hline Aluminum & Turning & Engine Lathe & Diamond & medium & 0.015 & 0.006 & 800 & 88 \\
\hline Aluminum & Turning & Engine Lathe & Diamond & high & 0.05 & 0.012 & 500 & 88 \\
\hline Aluminum & Turning & SP Auto & High Speed Steel & low & 0.04 & 0.007 & 990 & 55 \\
\hline Aluminum & Turning & SP Auto & High Speed Steel & medium & 0.15 & 0.015 & 880 & 55 \\
\hline Aluminum & Turning & SP Auto & High Speed Steel & high & 0.3 & 0.03 & 770 & 55 \\
\hline Aluminum & Turning & SP Auto & Single Point High Speed Steel M2 & low & 0.04 & 0.007 & 1100 & 61 \\
\hline Aluminum & Turning & SP Auto & Single Point High Speed Steel M2 & medium & 0.15 & 0.015 & 990 & 61 \\
\hline Aluminum & Turning & SP Auto & Single Point High Speed Steel M2 & high & 0.3 & 0.03 & 880 & 61 \\
\hline Aluminum & Turning & SP Auto & Single Point High Speed Steel M3 & low & 0.04 & 0.007 & 1155 & 64 \\
\hline Aluminum & Turning & SP Auto & Single Point High Speed Steel M3 & medium & 0.15 & 0.015 & 1045 & 64 \\
\hline Aluminum & Turning & SP Auto & Single Point High Speed Steel M3 & high & 0.3 & 0.03 & 935 & 64 \\
\hline Aluminum & Turning & SP Auto & Single Point High Speed Steel T15 & low & 0.04 & 0.007 & 1183 & 66 \\
\hline Aluminum & Turning & SP Auto & Single Point High Speed Steel T15 & medium & 0.15 & 0.015 & 1073 & 66 \\
\hline
\end{tabular}




\begin{tabular}{|c|c|c|c|c|c|c|c|c|}
\hline Material & Process & Machine & Tool & $\begin{array}{l}\text { Surface } \\
\text { finish }\end{array}$ & $\begin{array}{l}\text { Maximum } \\
\text { Depth of } \\
\text { cut (in.) }\end{array}$ & $\begin{array}{l}\text { Feed } \\
\text { (ipr) }\end{array}$ & $\begin{array}{l}\text { Speed } \\
\text { (fpm) }\end{array}$ & $\begin{array}{c}\text { Tool life } \\
\text { (minutes) }\end{array}$ \\
\hline Aluminum & Turning & SP Auto & Single Point High Speed Steel T15 & high & 0.3 & 0.03 & 963 & 66 \\
\hline Aluminum & Turning & SP Auto & Single Point High Speed Steel M42 & low & 0.04 & 0.007 & 1210 & 69 \\
\hline Aluminum & Turning & SP Auto & Single Point High Speed Steel M42 & medium & 0.15 & 0.015 & 1100 & 69 \\
\hline Aluminum & Turning & SP Auto & Single Point High Speed Steel M42 & high & 0.3 & 0.03 & 990 & 69 \\
\hline Aluminum & Turning & SP Auto & Carbide & low & 0.04 & 0.01 & 2090 & 66 \\
\hline Aluminum & Turning & SP Auto & Carbide & medium & 0.15 & 0.02 & 1870 & 66 \\
\hline Aluminum & Turning & SP Auto & Carbide & high & 0.3 & 0.04 & 1210 & 66 \\
\hline Aluminum & Turning & SP Auto & Single Point Carbide C2 & low & 0.04 & 0.01 & 2200 & 67 \\
\hline Aluminum & Turning & SP Auto & Single Point Carbide C2 & medium & 0.15 & 0.02 & 1980 & 67 \\
\hline Aluminum & Turning & SP Auto & Single Point Carbide C2 & high & 0.3 & 0.04 & 1320 & 67 \\
\hline Aluminum & Turning & SP Auto & Single Point Carbide C3 & low & 0.04 & 0.01 & 2211 & 69 \\
\hline Aluminum & Turning & SP Auto & Single Point Carbide C3 & medium & 0.15 & 0.02 & 1991 & 69 \\
\hline Aluminum & Turning & SP Auto & Single Point Carbide C3 & high & 0.3 & 0.04 & 1331 & 69 \\
\hline Aluminum & Turning & SP Auto & Single Point Carbide C4 & low & 0.04 & 0.01 & 2228 & 72 \\
\hline Aluminum & Turning & SP Auto & Single Point Carbide C4 & medium & 0.15 & 0.02 & 2008 & 72 \\
\hline Aluminum & Turning & SP Auto & Single Point Carbide C4 & high & 0.3 & 0.04 & 1348 & 72 \\
\hline Aluminum & Turning & SP Auto & Single Point Carbide C6 & low & 0.04 & 0.01 & 2244 & 74 \\
\hline Aluminum & Turning & SP Auto & Single Point Carbide C6 & medium & 0.15 & 0.02 & 2024 & 74 \\
\hline Aluminum & Turning & SP Auto & Single Point Carbide C6 & high & 0.3 & 0.04 & 1364 & 74 \\
\hline Aluminum & Turning & SP Auto & Single Point Carbide C7 & low & 0.04 & 0.01 & 2255 & 77 \\
\hline Aluminum & Turning & SP Auto & Single Point Carbide C7 & medium & 0.15 & 0.02 & 2035 & 77 \\
\hline Aluminum & Turning & SP Auto & Single Point Carbide C7 & high & 0.3 & 0.04 & 1375 & 77 \\
\hline Aluminum & Turning & SP Auto & Single Point Carbide C8 & low & 0.04 & 0.01 & 2261 & 78 \\
\hline
\end{tabular}




\begin{tabular}{|c|c|c|c|c|c|c|c|c|}
\hline Material & Process & Machine & Tool & $\begin{array}{c}\text { Surface } \\
\text { finish }\end{array}$ & $\begin{array}{l}\text { Maximum } \\
\text { Depth of } \\
\text { cut (in.) }\end{array}$ & $\begin{array}{l}\text { Feed } \\
\text { (ipr) }\end{array}$ & $\begin{array}{l}\text { Speed } \\
\text { (fpm) }\end{array}$ & $\begin{array}{c}\text { Tool life } \\
\text { (minutes) }\end{array}$ \\
\hline Aluminum & Turning & SP Auto & Single Point Carbide C8 & medium & 0.15 & 0.02 & 2041 & 78 \\
\hline Aluminum & Turning & SP Auto & Single Point Carbide C8 & high & 0.3 & 0.04 & 1381 & 78 \\
\hline Aluminum & Turning & SP Auto & Ceramic & low & 0.04 & 0.01 & 2151 & 72 \\
\hline Aluminum & Turning & SP Auto & Ceramic & medium & 0.15 & 0.02 & 1931 & 72 \\
\hline Aluminum & Turning & SP Auto & Ceramic & high & 0.3 & 0.04 & 1271 & 72 \\
\hline Aluminum & Turning & SP Auto & Single Point Ceramic HPC & low & 0.04 & 0.01 & 2156 & 74 \\
\hline Aluminum & Turning & SP Auto & Single Point Ceramic HPC & medium & 0.15 & 0.02 & 1936 & 74 \\
\hline Aluminum & Turning & SP Auto & Single Point Ceramic HPC & high & 0.3 & 0.04 & 1276 & 74 \\
\hline Aluminum & Turning & SP Auto & Single Point Ceramic CPA & low & 0.04 & 0.01 & 2173 & 77 \\
\hline Aluminum & Turning & SP Auto & Single Point Ceramic CPA & medium & 0.15 & 0.02 & 1953 & 77 \\
\hline Aluminum & Turning & SP Auto & Single Point Ceramic CPA & high & 0.3 & 0.04 & 1293 & 77 \\
\hline Aluminum & Turning & SP Auto & Diamond & low & 0.005 & 0.003 & 1320 & 88 \\
\hline Aluminum & Turning & SP Auto & Diamond & medium & 0.015 & 0.006 & 880 & 88 \\
\hline Aluminum & Turning & SP Auto & Diamond & high & 0.05 & 0.012 & 550 & 88 \\
\hline Aluminum & Turning & Turret Lathe & High Speed Steel & low & 0.04 & 0.007 & 1089 & 55 \\
\hline Aluminum & Turning & Turret Lathe & High Speed Steel & medium & 0.15 & 0.015 & 968 & 55 \\
\hline Aluminum & Turning & Turret Lathe & High Speed Steel & high & 0.3 & 0.03 & 847 & 55 \\
\hline Aluminum & Turning & Turret Lathe & Single Point High Speed Steel M2 & low & 0.04 & 0.007 & 1210 & 61 \\
\hline Aluminum & Turning & Turret Lathe & Single Point High Speed Steel M2 & medium & 0.15 & 0.015 & 1089 & 61 \\
\hline Aluminum & Turning & Turret Lathe & Single Point High Speed Steel M2 & high & 0.3 & 0.03 & 968 & 61 \\
\hline Aluminum & Turning & Turret Lathe & Single Point High Speed Steel M3 & low & 0.04 & 0.007 & 1271 & 64 \\
\hline Aluminum & Turning & Turret Lathe & Single Point High Speed Steel M3 & medium & 0.15 & 0.015 & 1150 & 64 \\
\hline Aluminum & Turning & Turret Lathe & Single Point High Speed Steel M3 & high & 0.3 & 0.03 & 1029 & 64 \\
\hline
\end{tabular}




\begin{tabular}{|c|c|c|c|c|c|c|c|c|}
\hline Material & Process & Machine & Tool & $\begin{array}{c}\text { Surface } \\
\text { finish }\end{array}$ & $\begin{array}{l}\text { Maximum } \\
\text { Depth of } \\
\text { cut (in.) }\end{array}$ & $\begin{array}{l}\text { Feed } \\
\text { (ipr) }\end{array}$ & $\begin{array}{l}\text { Speed } \\
\text { (fpm) }\end{array}$ & $\begin{array}{c}\text { Tool life } \\
\text { (minutes) }\end{array}$ \\
\hline Aluminum & Turning & Turret Lathe & Single Point High Speed Steel T15 & low & 0.04 & 0.007 & 1301 & 66 \\
\hline Aluminum & Turning & Turret Lathe & Single Point High Speed Steel T15 & medium & 0.15 & 0.015 & 1180 & 66 \\
\hline Aluminum & Turning & Turret Lathe & Single Point High Speed Steel T15 & high & 0.3 & 0.03 & 1059 & 66 \\
\hline Aluminum & Turning & Turret Lathe & Single Point High Speed Steel M42 & low & 0.04 & 0.007 & 1331 & 69 \\
\hline Aluminum & Turning & Turret Lathe & Single Point High Speed Steel M42 & medium & 0.15 & 0.015 & 1210 & 69 \\
\hline Aluminum & Turning & Turret Lathe & Single Point High Speed Steel M42 & high & 0.3 & 0.03 & 1089 & 69 \\
\hline Aluminum & Turning & Turret Lathe & Carbide & low & 0.04 & 0.01 & 2299 & 66 \\
\hline Aluminum & Turning & Turret Lathe & Carbide & medium & 0.15 & 0.02 & 2057 & 66 \\
\hline Aluminum & Turning & Turret Lathe & Carbide & high & 0.3 & 0.04 & 1331 & 66 \\
\hline Aluminum & Turning & Turret Lathe & Single Point Carbide C2 & low & 0.04 & 0.01 & 2420 & 67 \\
\hline Aluminum & Turning & Turret Lathe & Single Point Carbide C2 & medium & 0.15 & 0.02 & 2178 & 67 \\
\hline Aluminum & Turning & Turret Lathe & Single Point Carbide C2 & high & 0.3 & 0.04 & 1452 & 67 \\
\hline Aluminum & Turning & Turret Lathe & Single Point Carbide C3 & low & 0.04 & 0.01 & 2432 & 69 \\
\hline Aluminum & Turning & Turret Lathe & Single Point Carbide C3 & medium & 0.15 & 0.02 & 2190 & 69 \\
\hline Aluminum & Turning & Turret Lathe & Single Point Carbide C3 & high & 0.3 & 0.04 & 1464 & 69 \\
\hline Aluminum & Turning & Turret Lathe & Single Point Carbide C4 & low & 0.04 & 0.01 & 2451 & 72 \\
\hline Aluminum & Turning & Turret Lathe & Single Point Carbide C4 & medium & 0.15 & 0.02 & 2209 & 72 \\
\hline Aluminum & Turning & Turret Lathe & Single Point Carbide C4 & high & 0.3 & 0.04 & 1483 & 72 \\
\hline Aluminum & Turning & Turret Lathe & Single Point Carbide C6 & low & 0.04 & 0.01 & 2468 & 74 \\
\hline Aluminum & Turning & Turret Lathe & Single Point Carbide C6 & medium & 0.15 & 0.02 & 2226 & 74 \\
\hline Aluminum & Turning & Turret Lathe & Single Point Carbide C6 & high & 0.3 & 0.04 & 1500 & 74 \\
\hline Aluminum & Turning & Turret Lathe & Single Point Carbide C7 & low & 0.04 & 0.01 & 2481 & 77 \\
\hline Aluminum & Turning & Turret Lathe & Single Point Carbide C7 & medium & 0.15 & 0.02 & 2239 & 77 \\
\hline
\end{tabular}




\begin{tabular}{|c|c|c|c|c|c|c|c|c|}
\hline Material & Process & Machine & Tool & $\begin{array}{c}\text { Surface } \\
\text { finish }\end{array}$ & $\begin{array}{l}\text { Maximum } \\
\text { Depth of } \\
\text { cut (in.) }\end{array}$ & $\begin{array}{l}\text { Feed } \\
\text { (ipr) }\end{array}$ & $\begin{array}{l}\text { Speed } \\
(\text { fpm) }\end{array}$ & $\begin{array}{c}\text { Tool life } \\
\text { (minutes) }\end{array}$ \\
\hline Aluminum & Turning & Turret Lathe & Single Point Carbide C7 & high & 0.3 & 0.04 & 1513 & 77 \\
\hline Aluminum & Turning & Turret Lathe & Single Point Carbide C8 & low & 0.04 & 0.01 & 2487 & 78 \\
\hline Aluminum & Turning & Turret Lathe & Single Point Carbide C8 & medium & 0.15 & 0.02 & 2245 & 78 \\
\hline Aluminum & Turning & Turret Lathe & Single Point Carbide C8 & high & 0.3 & 0.04 & 1519 & 78 \\
\hline Aluminum & Turning & Turret Lathe & Ceramic & low & 0.04 & 0.01 & 2366 & 72 \\
\hline Aluminum & Turning & Turret Lathe & Ceramic & medium & 0.15 & 0.02 & 2124 & 72 \\
\hline Aluminum & Turning & Turret Lathe & Ceramic & high & 0.3 & 0.04 & 1398 & 72 \\
\hline Aluminum & Turning & Turret Lathe & Single Point Ceramic HPC & low & 0.04 & 0.01 & 2372 & 74 \\
\hline Aluminum & Turning & Turret Lathe & Single Point Ceramic HPC & medium & 0.15 & 0.02 & 2130 & 74 \\
\hline Aluminum & Turning & Turret Lathe & Single Point Ceramic HPC & high & 0.3 & 0.04 & 1404 & 74 \\
\hline Aluminum & Turning & Turret Lathe & Single Point Ceramic CPA & low & 0.04 & 0.01 & 2390 & 77 \\
\hline Aluminum & Turning & Turret Lathe & Single Point Ceramic CPA & medium & 0.15 & 0.02 & 2148 & 77 \\
\hline Aluminum & Turning & Turret Lathe & Single Point Ceramic CPA & high & 0.3 & 0.04 & 1422 & 77 \\
\hline Aluminum & Turning & Turret Lathe & Diamond & low & 0.005 & 0.003 & 1452 & 88 \\
\hline Aluminum & Turning & Turret Lathe & Diamond & medium & 0.015 & 0.006 & 968 & 88 \\
\hline Aluminum & Turning & Turret Lathe & Diamond & high & 0.05 & 0.012 & 605 & 88 \\
\hline Aluminum & Turning & NC Lathe & High Speed Steel & low & 0.04 & 0.007 & 1198 & 55 \\
\hline Aluminum & Turning & NC Lathe & High Speed Steel & medium & 0.15 & 0.015 & 1065 & 55 \\
\hline Aluminum & Turning & NC Lathe & High Speed Steel & high & 0.3 & 0.03 & 932 & 55 \\
\hline Aluminum & Turning & NC Lathe & Single Point High Speed Steel M2 & low & 0.04 & 0.007 & 1331 & 61 \\
\hline Aluminum & Turning & NC Lathe & Single Point High Speed Steel M2 & medium & 0.15 & 0.015 & 1198 & 61 \\
\hline Aluminum & Turning & NC Lathe & Single Point High Speed Steel M2 & high & 0.3 & 0.03 & 1065 & 61 \\
\hline Aluminum & Turning & NC Lathe & Single Point High Speed Steel M3 & low & 0.04 & 0.007 & 1398 & 64 \\
\hline
\end{tabular}




\begin{tabular}{|c|c|c|c|c|c|c|c|c|}
\hline Material & Process & Machine & Tool & $\begin{array}{l}\text { Surface } \\
\text { finish }\end{array}$ & $\begin{array}{l}\text { Maximum } \\
\text { Depth of } \\
\text { cut (in.) }\end{array}$ & $\begin{array}{l}\text { Feed } \\
\text { (ipr) }\end{array}$ & $\begin{array}{l}\text { Speed } \\
\text { (fpm) }\end{array}$ & $\begin{array}{c}\text { Tool life } \\
\text { (minutes) }\end{array}$ \\
\hline Aluminum & Turning & NC Lathe & Single Point High Speed Steel M3 & medium & 0.15 & 0.015 & 1265 & 64 \\
\hline Aluminum & Turning & NC Lathe & Single Point High Speed Steel M3 & high & 0.3 & 0.03 & 1132 & 64 \\
\hline Aluminum & Turning & NC Lathe & Single Point High Speed Steel T15 & low & 0.04 & 0.007 & 1431 & 66 \\
\hline Aluminum & Turning & NC Lathe & Single Point High Speed Steel T15 & medium & 0.15 & 0.015 & 1298 & 66 \\
\hline Aluminum & Turning & NC Lathe & Single Point High Speed Steel T15 & high & 0.3 & 0.03 & 1165 & 66 \\
\hline Aluminum & Turning & NC Lathe & Single Point High Speed Steel M42 & low & 0.04 & 0.007 & 1464 & 69 \\
\hline Aluminum & Turning & NC Lathe & Single Point High Speed Steel M42 & medium & 0.15 & 0.015 & 1331 & 69 \\
\hline Aluminum & Turning & NC Lathe & Single Point High Speed Steel M42 & high & 0.3 & 0.03 & 1198 & 69 \\
\hline Aluminum & Turning & NC Lathe & Carbide & low & 0.04 & 0.01 & 2529 & 66 \\
\hline Aluminum & Turning & NC Lathe & Carbide & medium & 0.15 & 0.02 & 2263 & 66 \\
\hline Aluminum & Turning & NC Lathe & Carbide & high & 0.3 & 0.04 & 1464 & 66 \\
\hline Aluminum & Turning & NC Lathe & Single Point Carbide C2 & low & 0.04 & 0.01 & 2662 & 67 \\
\hline Aluminum & Turning & NC Lathe & Single Point Carbide C2 & medium & 0.15 & 0.02 & 2396 & 67 \\
\hline Aluminum & Turning & NC Lathe & Single Point Carbide C2 & high & 0.3 & 0.04 & 1597 & 67 \\
\hline Aluminum & Turning & NC Lathe & Single Point Carbide C3 & low & 0.04 & 0.01 & 2675 & 69 \\
\hline Aluminum & Turning & NC Lathe & Single Point Carbide C3 & medium & 0.15 & 0.02 & 2409 & 69 \\
\hline Aluminum & Turning & NC Lathe & Single Point Carbide C3 & high & 0.3 & 0.04 & 1610 & 69 \\
\hline Aluminum & Turning & NC Lathe & Single Point Carbide C4 & low & 0.04 & 0.01 & 2696 & 72 \\
\hline Aluminum & Turning & NC Lathe & Single Point Carbide C4 & medium & 0.15 & 0.02 & 2430 & 72 \\
\hline Aluminum & Turning & NC Lathe & Single Point Carbide C4 & high & 0.3 & 0.04 & 1631 & 72 \\
\hline Aluminum & Turning & NC Lathe & Single Point Carbide C6 & low & 0.04 & 0.01 & 2715 & 74 \\
\hline Aluminum & Turning & NC Lathe & Single Point Carbide C6 & medium & 0.15 & 0.02 & 2449 & 74 \\
\hline Aluminum & Turning & NC Lathe & Single Point Carbide C6 & high & 0.3 & 0.04 & 1650 & 74 \\
\hline
\end{tabular}




\begin{tabular}{|c|c|c|c|c|c|c|c|c|}
\hline Material & Process & Machine & Tool & $\begin{array}{l}\text { Surface } \\
\text { finish }\end{array}$ & $\begin{array}{l}\text { Maximum } \\
\text { Depth of } \\
\text { cut (in.) }\end{array}$ & $\begin{array}{l}\text { Feed } \\
\text { (ipr) }\end{array}$ & $\begin{array}{l}\text { Speed } \\
\text { (fpm) }\end{array}$ & $\begin{array}{c}\text { Tool life } \\
\text { (minutes) }\end{array}$ \\
\hline Aluminum & Turning & NC Lathe & Single Point Carbide C7 & low & 0.04 & 0.01 & 2729 & 77 \\
\hline Aluminum & Turning & NC Lathe & Single Point Carbide C7 & medium & 0.15 & 0.02 & 2463 & 77 \\
\hline Aluminum & Turning & NC Lathe & Single Point Carbide C7 & high & 0.3 & 0.04 & 1664 & 77 \\
\hline Aluminum & Turning & NC Lathe & Single Point Carbide C8 & low & 0.04 & 0.01 & 2736 & 78 \\
\hline Aluminum & Turning & NC Lathe & Single Point Carbide C8 & medium & 0.15 & 0.02 & 2470 & 78 \\
\hline Aluminum & Turning & NC Lathe & Single Point Carbide C8 & high & 0.3 & 0.04 & 1671 & 78 \\
\hline Aluminum & Turning & NC Lathe & Ceramic & low & 0.04 & 0.01 & 2603 & 72 \\
\hline Aluminum & Turning & NC Lathe & Ceramic & medium & 0.15 & 0.02 & 2336 & 72 \\
\hline Aluminum & Turning & NC Lathe & Ceramic & high & 0.3 & 0.04 & 1538 & 72 \\
\hline Aluminum & Turning & NC Lathe & Single Point Ceramic HPC & low & 0.04 & 0.01 & 2609 & 74 \\
\hline Aluminum & Turning & NC Lathe & Single Point Ceramic HPC & medium & 0.15 & 0.02 & 2343 & 74 \\
\hline Aluminum & Turning & NC Lathe & Single Point Ceramic HPC & high & 0.3 & 0.04 & 1544 & 74 \\
\hline Aluminum & Turning & NC Lathe & Single Point Ceramic CPA & low & 0.04 & 0.01 & 2629 & 77 \\
\hline Aluminum & Turning & NC Lathe & Single Point Ceramic CPA & medium & 0.15 & 0.02 & 2363 & 77 \\
\hline Aluminum & Turning & NC Lathe & Single Point Ceramic CPA & high & 0.3 & 0.04 & 1564 & 77 \\
\hline Aluminum & Turning & NC Lathe & Diamond & low & 0.005 & 0.003 & 1597 & 88 \\
\hline Aluminum & Turning & NC Lathe & Diamond & medium & 0.015 & 0.006 & 1065 & 88 \\
\hline Aluminum & Turning & NC Lathe & Diamond & high & 0.05 & 0.012 & 666 & 88 \\
\hline Steel & Turning & Engine Lathe & High Speed Steel & low & 0.04 & 0.007 & 135 & 48 \\
\hline Steel & Turning & Engine Lathe & High Speed Steel & medium & 0.15 & 0.015 & 105 & 48 \\
\hline Steel & Turning & Engine Lathe & High Speed Steel & high & 0.3 & 0.02 & 80 & 48 \\
\hline Steel & Turning & Engine Lathe & Single Point High Speed Steel M2 & low & 0.04 & 0.007 & 140 & 53 \\
\hline Steel & Turning & Engine Lathe & Single Point High Speed Steel M2 & medium & 0.15 & 0.015 & 115 & 53 \\
\hline
\end{tabular}




\begin{tabular}{|c|c|c|c|c|c|c|c|c|}
\hline Material & Process & Machine & Tool & $\begin{array}{c}\text { Surface } \\
\text { finish }\end{array}$ & $\begin{array}{l}\text { Maximum } \\
\text { Depth of } \\
\text { cut (in.) }\end{array}$ & $\begin{array}{l}\text { Feed } \\
\text { (ipr) }\end{array}$ & $\begin{array}{l}\text { Speed } \\
\text { (fpm) }\end{array}$ & $\begin{array}{c}\text { Tool life } \\
\text { (minutes) }\end{array}$ \\
\hline Steel & Turning & Engine Lathe & Single Point High Speed Steel M2 & high & 0.3 & 0.02 & 90 & 53 \\
\hline Steel & Turning & Engine Lathe & Single Point High Speed Steel M3 & low & 0.04 & 0.007 & 142 & 56 \\
\hline Steel & Turning & Engine Lathe & Single Point High Speed Steel M3 & medium & 0.15 & 0.015 & 118 & 56 \\
\hline Steel & Turning & Engine Lathe & Single Point High Speed Steel M3 & high & 0.3 & 0.02 & 93 & 56 \\
\hline Steel & Turning & Engine Lathe & Single Point High Speed Steel T15 & low & 0.04 & 0.007 & 100 & 58 \\
\hline Steel & Turning & Engine Lathe & Single Point High Speed Steel T15 & medium & 0.15 & 0.015 & 75 & 58 \\
\hline Steel & Turning & Engine Lathe & Single Point High Speed Steel T15 & high & 0.3 & 0.02 & 60 & 58 \\
\hline Steel & Turning & Engine Lathe & Single Point High Speed Steel M42 & low & 0.04 & 0.007 & 105 & 60 \\
\hline Steel & Turning & Engine Lathe & Single Point High Speed Steel M42 & medium & 0.15 & 0.015 & 80 & 60 \\
\hline Steel & Turning & Engine Lathe & Single Point High Speed Steel M42 & high & 0.3 & 0.02 & 65 & 60 \\
\hline Steel & Turning & Engine Lathe & Carbide & low & 0.04 & 0.007 & 498 & 58 \\
\hline Steel & Turning & Engine Lathe & Carbide & medium & 0.15 & 0.02 & 393 & 58 \\
\hline Steel & Turning & Engine Lathe & Carbide & high & 0.3 & 0.03 & 305 & 58 \\
\hline Steel & Turning & Engine Lathe & Single Point Carbide C2 & low & 0.04 & 0.007 & 508 & 59 \\
\hline Steel & Turning & Engine Lathe & Single Point Carbide C2 & medium & 0.15 & 0.02 & 401 & 59 \\
\hline Steel & Turning & Engine Lathe & Single Point Carbide C2 & high & 0.3 & 0.03 & 311 & 59 \\
\hline Steel & Turning & Engine Lathe & Single Point Carbide C3 & low & 0.04 & 0.007 & 518 & 60 \\
\hline Steel & Turning & Engine Lathe & Single Point Carbide C3 & medium & 0.15 & 0.02 & 409 & 60 \\
\hline Steel & Turning & Engine Lathe & Single Point Carbide C3 & high & 0.3 & 0.03 & 317 & 60 \\
\hline Steel & Turning & Engine Lathe & Single Point Carbide C4 & low & 0.04 & 0.007 & 529 & 62 \\
\hline Steel & Turning & Engine Lathe & Single Point Carbide C4 & medium & 0.15 & 0.02 & 417 & 62 \\
\hline Steel & Turning & Engine Lathe & Single Point Carbide C4 & high & 0.3 & 0.03 & 323 & 62 \\
\hline Steel & Turning & Engine Lathe & Single Point Carbide C6 & low & 0.04 & 0.007 & 540 & 64 \\
\hline
\end{tabular}




\begin{tabular}{|c|c|c|c|c|c|c|c|c|}
\hline Material & Process & Machine & Tool & $\begin{array}{c}\text { Surface } \\
\text { finish }\end{array}$ & $\begin{array}{c}\text { Maximum } \\
\text { Depth of } \\
\text { cut (in.) }\end{array}$ & $\begin{array}{l}\text { Feed } \\
\text { (ipr) }\end{array}$ & $\begin{array}{l}\text { Speed } \\
\text { (fpm) }\end{array}$ & $\begin{array}{c}\text { Tool life } \\
\text { (minutes) }\end{array}$ \\
\hline Steel & Turning & Engine Lathe & Single Point Carbide C6 & medium & 0.15 & 0.02 & 425 & 64 \\
\hline Steel & Turning & Engine Lathe & Single Point Carbide C6 & high & 0.3 & 0.03 & 330 & 64 \\
\hline Steel & Turning & Engine Lathe & Single Point Carbide C7 & low & 0.04 & 0.007 & 567 & 67 \\
\hline Steel & Turning & Engine Lathe & Single Point Carbide C7 & medium & 0.15 & 0.02 & 446 & 67 \\
\hline Steel & Turning & Engine Lathe & Single Point Carbide C7 & high & 0.3 & 0.03 & 347 & 67 \\
\hline Steel & Turning & Engine Lathe & Single Point Carbide C8 & low & 0.04 & 0.007 & 595 & 68 \\
\hline Steel & Turning & Engine Lathe & Single Point Carbide C8 & medium & 0.15 & 0.02 & 468 & 68 \\
\hline Steel & Turning & Engine Lathe & Single Point Carbide C8 & high & 0.3 & 0.03 & 364 & 68 \\
\hline Steel & Turning & Engine Lathe & Ceramic & low & 0.04 & 0.005 & 1600 & 62 \\
\hline Steel & Turning & Engine Lathe & Ceramic & medium & 0.15 & 0.01 & 1100 & 62 \\
\hline Steel & Turning & Engine Lathe & Ceramic & high & 0.3 & 0.015 & 800 & 62 \\
\hline Steel & Turning & Engine Lathe & Single Point Ceramic HPC & low & 0.04 & 0.005 & 1800 & 64 \\
\hline Steel & Turning & Engine Lathe & Single Point Ceramic HPC & medium & 0.15 & 0.01 & 1200 & 64 \\
\hline Steel & Turning & Engine Lathe & Single Point Ceramic HPC & high & 0.3 & 0.015 & 900 & 64 \\
\hline Steel & Turning & Engine Lathe & Single Point Ceramic CPA & low & 0.04 & 0.005 & 2400 & 67 \\
\hline Steel & Turning & Engine Lathe & Single Point Ceramic CPA & medium & 0.15 & 0.01 & 2000 & 67 \\
\hline Steel & Turning & Engine Lathe & Single Point Ceramic CPA & high & 0.3 & 0.015 & 1700 & 67 \\
\hline Steel & Turning & Engine Lathe & Diamond & low & 0.005 & 0.003 & 2800 & 77 \\
\hline Steel & Turning & Engine Lathe & Diamond & medium & 0.015 & 0.006 & 3000 & 77 \\
\hline Steel & Turning & Engine Lathe & Diamond & high & 0.05 & 0.012 & 3200 & 77 \\
\hline Steel & Turning & SP Auto & High Speed Steel & low & 0.04 & 0.007 & 142 & 48 \\
\hline Steel & Turning & SP Auto & High Speed Steel & medium & 0.15 & 0.015 & 110 & 48 \\
\hline Steel & Turning & SP Auto & High Speed Steel & high & 0.3 & 0.02 & 84 & 48 \\
\hline
\end{tabular}




\begin{tabular}{|c|c|c|c|c|c|c|c|c|}
\hline Material & Process & Machine & Tool & $\begin{array}{c}\text { Surface } \\
\text { finish }\end{array}$ & $\begin{array}{l}\text { Maximum } \\
\text { Depth of } \\
\text { cut (in.) }\end{array}$ & $\begin{array}{l}\text { Feed } \\
\text { (ipr) }\end{array}$ & $\begin{array}{l}\text { Speed } \\
\text { (fpm) }\end{array}$ & $\begin{array}{c}\text { Tool life } \\
\text { (minutes) }\end{array}$ \\
\hline Steel & Turning & SP Auto & Single Point High Speed Steel M2 & low & 0.04 & 0.007 & 147 & 53 \\
\hline Steel & Turning & SP Auto & Single Point High Speed Steel M2 & medium & 0.15 & 0.015 & 121 & 53 \\
\hline Steel & Turning & SP Auto & Single Point High Speed Steel M2 & high & 0.3 & 0.02 & 95 & 53 \\
\hline Steel & Turning & SP Auto & Single Point High Speed Steel M3 & low & 0.04 & 0.007 & 149 & 56 \\
\hline Steel & Turning & SP Auto & Single Point High Speed Steel M3 & medium & 0.15 & 0.015 & 124 & 56 \\
\hline Steel & Turning & SP Auto & Single Point High Speed Steel M3 & high & 0.3 & 0.02 & 98 & 56 \\
\hline Steel & Turning & SP Auto & Single Point High Speed Steel T15 & low & 0.04 & 0.007 & 105 & 58 \\
\hline Steel & Turning & SP Auto & Single Point High Speed Steel T15 & medium & 0.15 & 0.015 & 79 & 58 \\
\hline Steel & Turning & SP Auto & Single Point High Speed Steel T15 & high & 0.3 & 0.02 & 63 & 58 \\
\hline Steel & Turning & SP Auto & Single Point High Speed Steel M42 & low & 0.04 & 0.007 & 110 & 60 \\
\hline Steel & Turning & SP Auto & Single Point High Speed Steel M42 & medium & 0.15 & 0.015 & 84 & 60 \\
\hline Steel & Turning & SP Auto & Single Point High Speed Steel M42 & high & 0.3 & 0.02 & 68 & 60 \\
\hline Steel & Turning & SP Auto & Carbide & low & 0.04 & 0.007 & 523 & 58 \\
\hline Steel & Turning & SP Auto & Carbide & medium & 0.15 & 0.02 & 413 & 58 \\
\hline Steel & Turning & SP Auto & Carbide & high & 0.3 & 0.03 & 320 & 58 \\
\hline Steel & Turning & SP Auto & Single Point Carbide C2 & low & 0.04 & 0.007 & 533 & 59 \\
\hline Steel & Turning & SP Auto & Single Point Carbide C2 & medium & 0.15 & 0.02 & 421 & 59 \\
\hline Steel & Turning & SP Auto & Single Point Carbide C2 & high & 0.3 & 0.03 & 327 & 59 \\
\hline Steel & Turning & SP Auto & Single Point Carbide C3 & low & 0.04 & 0.007 & 544 & 60 \\
\hline Steel & Turning & SP Auto & Single Point Carbide C3 & medium & 0.15 & 0.02 & 429 & 60 \\
\hline Steel & Turning & SP Auto & Single Point Carbide C3 & high & 0.3 & 0.03 & 333 & 60 \\
\hline Steel & Turning & SP Auto & Single Point Carbide C4 & low & 0.04 & 0.007 & 555 & 62 \\
\hline Steel & Turning & SP Auto & Single Point Carbide C4 & medium & 0.15 & 0.02 & 438 & 62 \\
\hline
\end{tabular}




\begin{tabular}{|c|c|c|c|c|c|c|c|c|}
\hline Material & Process & Machine & Tool & $\begin{array}{c}\text { Surface } \\
\text { finish }\end{array}$ & $\begin{array}{l}\text { Maximum } \\
\text { Depth of } \\
\text { cut (in.) }\end{array}$ & $\begin{array}{l}\text { Feed } \\
\text { (ipr) }\end{array}$ & $\begin{array}{l}\text { Speed } \\
\text { (fpm) }\end{array}$ & $\begin{array}{c}\text { Tool life } \\
\text { (minutes) }\end{array}$ \\
\hline Steel & Turning & SP Auto & Single Point Carbide C4 & high & 0.3 & 0.03 & 339 & 62 \\
\hline Steel & Turning & SP Auto & Single Point Carbide C6 & low & 0.04 & 0.007 & 567 & 64 \\
\hline Steel & Turning & SP Auto & Single Point Carbide C6 & medium & 0.15 & 0.02 & 446 & 64 \\
\hline Steel & Turning & SP Auto & Single Point Carbide C6 & high & 0.3 & 0.03 & 347 & 64 \\
\hline Steel & Turning & SP Auto & Single Point Carbide C7 & low & 0.04 & 0.007 & 595 & 67 \\
\hline Steel & Turning & SP Auto & Single Point Carbide C7 & medium & 0.15 & 0.02 & 468 & 67 \\
\hline Steel & Turning & SP Auto & Single Point Carbide C7 & high & 0.3 & 0.03 & 364 & 67 \\
\hline Steel & Turning & SP Auto & Single Point Carbide C8 & low & 0.04 & 0.007 & 625 & 68 \\
\hline Steel & Turning & SP Auto & Single Point Carbide C8 & medium & 0.15 & 0.02 & 491 & 68 \\
\hline Steel & Turning & SP Auto & Single Point Carbide C8 & high & 0.3 & 0.03 & 382 & 68 \\
\hline Steel & Turning & SP Auto & Ceramic & low & 0.04 & 0.005 & 1680 & 62 \\
\hline Steel & Turning & SP Auto & Ceramic & medium & 0.15 & 0.01 & 1155 & 62 \\
\hline Steel & Turning & SP Auto & Ceramic & high & 0.3 & 0.015 & 840 & 62 \\
\hline Steel & Turning & SP Auto & Single Point Ceramic HPC & low & 0.04 & 0.005 & 1890 & 64 \\
\hline Steel & Turning & SP Auto & Single Point Ceramic HPC & medium & 0.15 & 0.01 & 1260 & 64 \\
\hline Steel & Turning & SP Auto & Single Point Ceramic HPC & high & 0.3 & 0.015 & 945 & 64 \\
\hline Steel & Turning & SP Auto & Single Point Ceramic CPA & low & 0.04 & 0.005 & 2520 & 67 \\
\hline Steel & Turning & SP Auto & Single Point Ceramic CPA & medium & 0.15 & 0.01 & 2100 & 67 \\
\hline Steel & Turning & SP Auto & Single Point Ceramic CPA & high & 0.3 & 0.015 & 1785 & 67 \\
\hline Steel & Turning & SP Auto & Diamond & low & 0.04 & 0.003 & 2940 & 77 \\
\hline Steel & Turning & SP Auto & Diamond & medium & 0.15 & 0.006 & 3150 & 77 \\
\hline Steel & Turning & SP Auto & Diamond & high & 0.3 & 0.012 & 3360 & 77 \\
\hline Steel & Turning & Turret Lathe & High Speed Steel & low & 0.04 & 0.007 & 149 & 48 \\
\hline
\end{tabular}




\begin{tabular}{|c|c|c|c|c|c|c|c|c|}
\hline Material & Process & Machine & Tool & $\begin{array}{l}\text { Surface } \\
\text { finish }\end{array}$ & $\begin{array}{l}\text { Maximum } \\
\text { Depth of } \\
\text { cut (in.) }\end{array}$ & $\begin{array}{l}\text { Feed } \\
\text { (ipr) }\end{array}$ & $\begin{array}{l}\text { Speed } \\
\text { (fpm) }\end{array}$ & $\begin{array}{c}\text { Tool life } \\
\text { (minutes) }\end{array}$ \\
\hline Steel & Turning & Turret Lathe & High Speed Steel & medium & 0.15 & 0.015 & 116 & 48 \\
\hline Steel & Turning & Turret Lathe & High Speed Steel & high & 0.3 & 0.02 & 88 & 48 \\
\hline Steel & Turning & Turret Lathe & Single Point High Speed Steel M2 & low & 0.04 & 0.007 & 154 & 53 \\
\hline Steel & Turning & Turret Lathe & Single Point High Speed Steel M2 & medium & 0.15 & 0.015 & 127 & 53 \\
\hline Steel & Turning & Turret Lathe & Single Point High Speed Steel M2 & high & 0.3 & 0.02 & 100 & 53 \\
\hline Steel & Turning & Turret Lathe & Single Point High Speed Steel M3 & low & 0.04 & 0.007 & 156 & 56 \\
\hline Steel & Turning & Turret Lathe & Single Point High Speed Steel M3 & medium & 0.15 & 0.015 & 130 & 56 \\
\hline Steel & Turning & Turret Lathe & Single Point High Speed Steel M3 & high & 0.3 & 0.02 & 103 & 56 \\
\hline Steel & Turning & Turret Lathe & Single Point High Speed Steel T15 & low & 0.04 & 0.007 & 110 & 58 \\
\hline Steel & Turning & Turret Lathe & Single Point High Speed Steel T15 & medium & 0.15 & 0.015 & 83 & 58 \\
\hline Steel & Turning & Turret Lathe & Single Point High Speed Steel T15 & high & 0.3 & 0.02 & 66 & 58 \\
\hline Steel & Turning & Turret Lathe & Single Point High Speed Steel M42 & low & 0.04 & 0.007 & 116 & 60 \\
\hline Steel & Turning & Turret Lathe & Single Point High Speed Steel M42 & medium & 0.15 & 0.015 & 88 & 60 \\
\hline Steel & Turning & Turret Lathe & Single Point High Speed Steel M42 & high & 0.3 & 0.02 & 71 & 60 \\
\hline Steel & Turning & Turret Lathe & Carbide & low & 0.04 & 0.007 & 549 & 58 \\
\hline Steel & Turning & Turret Lathe & Carbide & medium & 0.15 & 0.02 & 434 & 58 \\
\hline Steel & Turning & Turret Lathe & Carbide & high & 0.3 & 0.03 & 336 & 58 \\
\hline Steel & Turning & Turret Lathe & Single Point Carbide C2 & low & 0.04 & 0.007 & 560 & 59 \\
\hline Steel & Turning & Turret Lathe & Single Point Carbide C2 & medium & 0.15 & 0.02 & 442 & 59 \\
\hline Steel & Turning & Turret Lathe & Single Point Carbide C2 & high & 0.3 & 0.03 & 343 & 59 \\
\hline Steel & Turning & Turret Lathe & Single Point Carbide C3 & low & 0.04 & 0.007 & 571 & 60 \\
\hline Steel & Turning & Turret Lathe & Single Point Carbide C3 & medium & 0.15 & 0.02 & 450 & 60 \\
\hline Steel & Turning & Turret Lathe & Single Point Carbide C3 & high & 0.3 & 0.03 & 350 & 60 \\
\hline
\end{tabular}




\begin{tabular}{|c|c|c|c|c|c|c|c|c|}
\hline Material & Process & Machine & Tool & $\begin{array}{c}\text { Surface } \\
\text { finish }\end{array}$ & $\begin{array}{l}\text { Maximum } \\
\text { Depth of } \\
\text { cut (in.) }\end{array}$ & $\begin{array}{l}\text { Feed } \\
\text { (ipr) }\end{array}$ & $\begin{array}{l}\text { Speed } \\
(\text { fpm) }\end{array}$ & $\begin{array}{c}\text { Tool life } \\
\text { (minutes) }\end{array}$ \\
\hline Steel & Turning & Turret Lathe & Single Point Carbide C4 & low & 0.04 & 0.007 & 583 & 62 \\
\hline Steel & Turning & Turret Lathe & Single Point Carbide C4 & medium & 0.15 & 0.02 & 460 & 62 \\
\hline Steel & Turning & Turret Lathe & Single Point Carbide C4 & high & 0.3 & 0.03 & 356 & 62 \\
\hline Steel & Turning & Turret Lathe & Single Point Carbide C6 & low & 0.04 & 0.007 & 595 & 64 \\
\hline Steel & Turning & Turret Lathe & Single Point Carbide C6 & medium & 0.15 & 0.02 & 468 & 64 \\
\hline Steel & Turning & Turret Lathe & Single Point Carbide C6 & high & 0.3 & 0.03 & 364 & 64 \\
\hline Steel & Turning & Turret Lathe & Single Point Carbide C7 & low & 0.04 & 0.007 & 625 & 67 \\
\hline Steel & Turning & Turret Lathe & Single Point Carbide C7 & medium & 0.15 & 0.02 & 491 & 67 \\
\hline Steel & Turning & Turret Lathe & Single Point Carbide C7 & high & 0.3 & 0.03 & 382 & 67 \\
\hline Steel & Turning & Turret Lathe & Single Point Carbide C8 & low & 0.04 & 0.007 & 656 & 68 \\
\hline Steel & Turning & Turret Lathe & Single Point Carbide C8 & medium & 0.15 & 0.02 & 516 & 68 \\
\hline Steel & Turning & Turret Lathe & Single Point Carbide C8 & high & 0.3 & 0.03 & 401 & 68 \\
\hline Steel & Turning & Turret Lathe & Ceramic & low & 0.04 & 0.005 & 1764 & 62 \\
\hline Steel & Turning & Turret Lathe & Ceramic & medium & 0.15 & 0.01 & 1213 & 62 \\
\hline Steel & Turning & Turret Lathe & Ceramic & high & 0.3 & 0.015 & 882 & 62 \\
\hline Steel & Turning & Turret Lathe & Single Point Ceramic HPC & low & 0.04 & 0.005 & 1985 & 64 \\
\hline Steel & Turning & Turret Lathe & Single Point Ceramic HPC & medium & 0.15 & 0.01 & 1323 & 64 \\
\hline Steel & Turning & Turret Lathe & Single Point Ceramic HPC & high & 0.3 & 0.015 & 992 & 64 \\
\hline Steel & Turning & Turret Lathe & Single Point Ceramic CPA & low & 0.04 & 0.005 & 2646 & 67 \\
\hline Steel & Turning & Turret Lathe & Single Point Ceramic CPA & medium & 0.15 & 0.01 & 2205 & 67 \\
\hline Steel & Turning & Turret Lathe & Single Point Ceramic CPA & high & 0.3 & 0.015 & 1874 & 67 \\
\hline Steel & Turning & Turret Lathe & Diamond & low & 0.04 & 0.003 & 3087 & 77 \\
\hline Steel & Turning & Turret Lathe & Diamond & medium & 0.15 & 0.006 & 3308 & 77 \\
\hline
\end{tabular}




\begin{tabular}{|c|c|c|c|c|c|c|c|c|}
\hline Material & Process & Machine & Tool & $\begin{array}{l}\text { Surface } \\
\text { finish }\end{array}$ & $\begin{array}{l}\text { Maximum } \\
\text { Depth of } \\
\text { cut (in.) }\end{array}$ & $\begin{array}{l}\text { Feed } \\
\text { (ipr) }\end{array}$ & $\begin{array}{l}\text { Speed } \\
\text { (fpm) }\end{array}$ & $\begin{array}{c}\text { Tool life } \\
\text { (minutes) }\end{array}$ \\
\hline Steel & Turning & Turret Lathe & Diamond & high & 0.3 & 0.012 & 3528 & 77 \\
\hline Steel & Turning & NC Lathe & High Speed Steel & low & 0.04 & 0.007 & 156 & 48 \\
\hline Steel & Turning & NC Lathe & High Speed Steel & medium & 0.15 & 0.015 & 122 & 48 \\
\hline Steel & Turning & NC Lathe & High Speed Steel & high & 0.3 & 0.02 & 92 & 48 \\
\hline Steel & Turning & NC Lathe & Single Point High Speed Steel M2 & low & 0.04 & 0.007 & 162 & 53 \\
\hline Steel & Turning & NC Lathe & Single Point High Speed Steel M2 & medium & 0.15 & 0.015 & 133 & 53 \\
\hline Steel & Turning & NC Lathe & Single Point High Speed Steel M2 & high & 0.3 & 0.02 & 105 & 53 \\
\hline Steel & Turning & NC Lathe & Single Point High Speed Steel M3 & low & 0.04 & 0.007 & 164 & 56 \\
\hline Steel & Turning & NC Lathe & Single Point High Speed Steel M3 & medium & 0.15 & 0.015 & 137 & 56 \\
\hline Steel & Turning & NC Lathe & Single Point High Speed Steel M3 & high & 0.3 & 0.02 & 108 & 56 \\
\hline Steel & Turning & NC Lathe & Single Point High Speed Steel T15 & low & 0.04 & 0.007 & 116 & 58 \\
\hline Steel & Turning & NC Lathe & Single Point High Speed Steel T15 & medium & 0.15 & 0.015 & 87 & 58 \\
\hline Steel & Turning & NC Lathe & Single Point High Speed Steel T15 & high & 0.3 & 0.02 & 69 & 58 \\
\hline Steel & Turning & NC Lathe & Single Point High Speed Steel M42 & low & 0.04 & 0.007 & 122 & 60 \\
\hline Steel & Turning & NC Lathe & Single Point High Speed Steel M42 & medium & 0.15 & 0.015 & 92 & 60 \\
\hline Steel & Turning & NC Lathe & Single Point High Speed Steel M42 & high & 0.3 & 0.02 & 75 & 60 \\
\hline Steel & Turning & NC Lathe & Carbide & low & 0.04 & 0.007 & 576 & 58 \\
\hline Steel & Turning & NC Lathe & Carbide & medium & 0.15 & 0.02 & 456 & 58 \\
\hline Steel & Turning & NC Lathe & Carbide & high & 0.3 & 0.03 & 353 & 58 \\
\hline Steel & Turning & NC Lathe & Single Point Carbide C2 & low & 0.04 & 0.007 & 588 & 59 \\
\hline Steel & Turning & NC Lathe & Single Point Carbide C2 & medium & 0.15 & 0.02 & 464 & 59 \\
\hline Steel & Turning & NC Lathe & Single Point Carbide C2 & high & 0.3 & 0.03 & 360 & 59 \\
\hline Steel & Turning & NC Lathe & Single Point Carbide C3 & low & 0.04 & 0.007 & 600 & 60 \\
\hline
\end{tabular}




\begin{tabular}{|c|c|c|c|c|c|c|c|c|}
\hline Material & Process & Machine & Tool & $\begin{array}{c}\text { Surface } \\
\text { finish }\end{array}$ & $\begin{array}{c}\text { Maximum } \\
\text { Depth of } \\
\text { cut (in.) }\end{array}$ & $\begin{array}{l}\text { Feed } \\
\text { (ipr) }\end{array}$ & $\begin{array}{l}\text { Speed } \\
(\text { fpm) }\end{array}$ & $\begin{array}{c}\text { Tool life } \\
\text { (minutes) }\end{array}$ \\
\hline Steel & Turning & NC Lathe & Single Point Carbide C3 & medium & 0.15 & 0.02 & 473 & 60 \\
\hline Steel & Turning & NC Lathe & Single Point Carbide C3 & high & 0.3 & 0.03 & 368 & 60 \\
\hline Steel & Turning & NC Lathe & Single Point Carbide C4 & low & 0.04 & 0.007 & 612 & 62 \\
\hline Steel & Turning & NC Lathe & Single Point Carbide C4 & medium & 0.15 & 0.02 & 483 & 62 \\
\hline Steel & Turning & NC Lathe & Single Point Carbide C4 & high & 0.3 & 0.03 & 374 & 62 \\
\hline Steel & Turning & NC Lathe & Single Point Carbide C6 & low & 0.04 & 0.007 & 625 & 64 \\
\hline Steel & Turning & NC Lathe & Single Point Carbide C6 & medium & 0.15 & 0.02 & 491 & 64 \\
\hline Steel & Turning & NC Lathe & Single Point Carbide C6 & high & 0.3 & 0.03 & 382 & 64 \\
\hline Steel & Turning & NC Lathe & Single Point Carbide C7 & low & 0.04 & 0.007 & 656 & 67 \\
\hline Steel & Turning & NC Lathe & Single Point Carbide C7 & medium & 0.15 & 0.02 & 516 & 67 \\
\hline Steel & Turning & NC Lathe & Single Point Carbide C7 & high & 0.3 & 0.03 & 401 & 67 \\
\hline Steel & Turning & NC Lathe & Single Point Carbide C8 & low & 0.04 & 0.007 & 689 & 68 \\
\hline Steel & Turning & NC Lathe & Single Point Carbide C8 & medium & 0.15 & 0.02 & 542 & 68 \\
\hline Steel & Turning & NC Lathe & Single Point Carbide C8 & high & 0.3 & 0.03 & 421 & 68 \\
\hline Steel & Turning & NC Lathe & Ceramic & low & 0.04 & 0.005 & 1852 & 62 \\
\hline Steel & Turning & NC Lathe & Ceramic & medium & 0.15 & 0.01 & 1274 & 62 \\
\hline Steel & Turning & NC Lathe & Ceramic & high & 0.3 & 0.015 & 926 & 62 \\
\hline Steel & Turning & NC Lathe & Single Point Ceramic HPC & low & 0.04 & 0.005 & 2084 & 64 \\
\hline Steel & Turning & NC Lathe & Single Point Ceramic HPC & medium & 0.15 & 0.01 & 1389 & 64 \\
\hline Steel & Turning & NC Lathe & Single Point Ceramic HPC & high & 0.3 & 0.015 & 1042 & 64 \\
\hline Steel & Turning & NC Lathe & Single Point Ceramic CPA & low & 0.04 & 0.005 & 2778 & 67 \\
\hline Steel & Turning & NC Lathe & Single Point Ceramic CPA & medium & 0.15 & 0.01 & 2315 & 67 \\
\hline Steel & Turning & NC Lathe & Single Point Ceramic CPA & high & 0.3 & 0.015 & 1968 & 67 \\
\hline
\end{tabular}




\begin{tabular}{|c|c|c|c|c|c|c|c|c|}
\hline Material & Process & Machine & Tool & $\begin{array}{c}\text { Surface } \\
\text { finish }\end{array}$ & $\begin{array}{c}\text { Maximum } \\
\text { Depth of } \\
\text { cut (in.) }\end{array}$ & $\begin{array}{l}\text { Feed } \\
\text { (ipr) }\end{array}$ & $\begin{array}{l}\text { Speed } \\
\text { (fpm) }\end{array}$ & $\begin{array}{c}\text { Tool life } \\
\text { (minutes) }\end{array}$ \\
\hline Steel & Turning & NC Lathe & Diamond & low & 0.04 & 0.003 & 3241 & 77 \\
\hline Steel & Turning & NC Lathe & Diamond & medium & 0.15 & 0.006 & 3473 & 77 \\
\hline Steel & Turning & NC Lathe & Diamond & high & 0.3 & 0.012 & 3704 & 77 \\
\hline Cast iron & Grinding & $\begin{array}{c}\text { Cylindrical } \\
\text { Grinding M/C }\end{array}$ & Grinding Wheel Hard & low & 0.03 & 0.125 & 70 & 50 \\
\hline Cast iron & Grinding & $\begin{array}{c}\text { Cylindrical } \\
\text { Grinding M/C }\end{array}$ & Grinding Wheel Hard & medium & 0.06 & 0.2 & 75 & 50 \\
\hline Cast iron & Grinding & $\begin{array}{c}\text { Cylindrical } \\
\text { Grinding M/C }\end{array}$ & Grinding Wheel Hard & high & 0.1 & 0.25 & 80 & 50 \\
\hline Cast iron & Grinding & $\begin{array}{c}\text { Cylindrical } \\
\text { Grinding } \mathrm{M} / \mathrm{C}\end{array}$ & Grinding Wheel Medium & low & 0.03 & 0.125 & 75 & 50 \\
\hline Cast iron & Grinding & $\begin{array}{c}\text { Cylindrical } \\
\text { Grinding M/C }\end{array}$ & Grinding Wheel Medium & medium & 0.06 & 0.2 & 80 & 50 \\
\hline Cast iron & Grinding & $\begin{array}{c}\text { Cylindrical } \\
\text { Grinding M/C }\end{array}$ & Grinding Wheel Medium & high & 0.1 & 0.25 & 85 & 50 \\
\hline Cast iron & Grinding & $\begin{array}{c}\text { Cylindrical } \\
\text { Grinding M/C }\end{array}$ & Grinding Wheel Soft & low & 0.03 & 0.125 & 80 & 50 \\
\hline Cast iron & Grinding & $\begin{array}{c}\text { Cylindrical } \\
\text { Grinding M/C }\end{array}$ & Grinding Wheel Soft & medium & 0.06 & 0.2 & 85 & 50 \\
\hline Cast iron & Grinding & $\begin{array}{c}\text { Cylindrical } \\
\text { Grinding M/C }\end{array}$ & Grinding Wheel Soft & high & 0.1 & 0.25 & 90 & 50 \\
\hline Aluminum & Grinding & $\begin{array}{c}\text { Cylindrical } \\
\text { Grinding M/C }\end{array}$ & Grinding Wheel Hard & low & 0.03 & 0.17 & 50 & 60 \\
\hline Aluminum & Grinding & $\begin{array}{c}\text { Cylindrical } \\
\text { Grinding M/C }\end{array}$ & Grinding Wheel Hard & medium & 0.06 & 0.25 & 60 & 60 \\
\hline Aluminum & Grinding & $\begin{array}{c}\text { Cylindrical } \\
\text { Grinding M/C }\end{array}$ & Grinding Wheel Hard & high & 0.1 & 0.35 & 70 & 60 \\
\hline
\end{tabular}




\begin{tabular}{|c|c|c|c|c|c|c|c|c|}
\hline Material & Process & Machine & Tool & $\begin{array}{c}\text { Surface } \\
\text { finish }\end{array}$ & $\begin{array}{c}\text { Maximum } \\
\text { Depth of } \\
\text { cut (in.) }\end{array}$ & $\begin{array}{l}\text { Feed } \\
\text { (ipr) }\end{array}$ & $\begin{array}{l}\text { Speed } \\
(\text { fpm) }\end{array}$ & $\begin{array}{c}\text { Tool life } \\
\text { (minutes) }\end{array}$ \\
\hline Aluminum & Grinding & $\begin{array}{c}\text { Cylindrical } \\
\text { Grinding M/C }\end{array}$ & Grinding Wheel Medium & low & 0.03 & 0.17 & 60 & 60 \\
\hline Aluminum & Grinding & $\begin{array}{c}\text { Cylindrical } \\
\text { Grinding M/C }\end{array}$ & Grinding Wheel Medium & medium & 0.06 & 0.25 & 70 & 60 \\
\hline Aluminum & Grinding & $\begin{array}{c}\text { Cylindrical } \\
\text { Grinding M/C }\end{array}$ & Grinding Wheel Medium & high & 0.1 & 0.35 & 80 & 60 \\
\hline Aluminum & Grinding & $\begin{array}{c}\text { Cylindrical } \\
\text { Grinding M/C }\end{array}$ & Grinding Wheel Soft & low & 0.03 & 0.17 & 70 & 60 \\
\hline Aluminum & Grinding & $\begin{array}{c}\text { Cylindrical } \\
\text { Grinding M/C }\end{array}$ & Grinding Wheel Soft & medium & 0.06 & 0.25 & 80 & 60 \\
\hline Aluminum & Grinding & $\begin{array}{c}\text { Cylindrical } \\
\text { Grinding M/C }\end{array}$ & Grinding Wheel Soft & high & 0.1 & 0.35 & 85 & 60 \\
\hline Steel & Grinding & $\begin{array}{c}\text { Cylindrical } \\
\text { Grinding M/C }\end{array}$ & Grinding Wheel Hard & low & 0.03 & 0.125 & 65 & 45 \\
\hline Steel & Grinding & $\begin{array}{c}\text { Cylindrical } \\
\text { Grinding M/C }\end{array}$ & Grinding Wheel Hard & medium & 0.06 & 0.2 & 70 & 45 \\
\hline Steel & Grinding & $\begin{array}{c}\text { Cylindrical } \\
\text { Grinding M/C }\end{array}$ & Grinding Wheel Hard & high & 0.1 & 0.25 & 75 & 45 \\
\hline Steel & Grinding & $\begin{array}{c}\text { Cylindrical } \\
\text { Grinding M/C }\end{array}$ & Grinding Wheel Medium & low & 0.03 & 0.125 & 70 & 45 \\
\hline Steel & Grinding & $\begin{array}{c}\text { Cylindrical } \\
\text { Grinding M/C }\end{array}$ & Grinding Wheel Medium & medium & 0.06 & 0.2 & 75 & 45 \\
\hline Steel & Grinding & $\begin{array}{c}\text { Cylindrical } \\
\text { Grinding M/C }\end{array}$ & Grinding Wheel Medium & high & 0.1 & 0.25 & 80 & 45 \\
\hline Steel & Grinding & $\begin{array}{c}\text { Cylindrical } \\
\text { Grinding M/C }\end{array}$ & Grinding Wheel Soft & low & 0.03 & 0.125 & 75 & 45 \\
\hline
\end{tabular}




\begin{tabular}{|c|l|c|c|c|c|c|c|c|}
\hline Material & Process & Machine & Tool & $\begin{array}{c}\text { Surface } \\
\text { finish }\end{array}$ & $\begin{array}{c}\text { Maximum } \\
\text { Depth of } \\
\text { cut (in.) }\end{array}$ & $\begin{array}{c}\text { Feed } \\
\text { (ipr) }\end{array}$ & $\begin{array}{c}\text { Speed } \\
\text { (fpm) }\end{array}$ & $\begin{array}{c}\text { Tool life } \\
\text { (minutes) }\end{array}$ \\
\hline Steel & Grinding & $\begin{array}{c}\text { Cylindrical } \\
\text { Grinding M/C }\end{array}$ & Grinding Wheel Soft & medium & 0.06 & 0.2 & 80 & 45 \\
\hline Steel & Grinding & $\begin{array}{c}\text { Cylindrical } \\
\text { Grinding M/C }\end{array}$ & Grinding Wheel Soft & high & 0.1 & 0.25 & 85 & 45 \\
\hline
\end{tabular}

\begin{tabular}{|l|c|c|c|c|c|}
\hline \multicolumn{1}{|c|}{ Machine parameters } & $\begin{array}{c}\text { Cylindrical } \\
\text { grinding M/C }\end{array}$ & $\begin{array}{c}\text { Engine } \\
\text { lathe }\end{array}$ & $\begin{array}{c}\text { NC } \\
\text { lathe }\end{array}$ & $\begin{array}{c}\text { SP } \\
\text { auto }\end{array}$ & $\begin{array}{c}\text { Turret } \\
\text { Lathe }\end{array}$ \\
\hline a (inch) & 0.5 & 0.5 & 0.5 & 0.5 & 0.8 \\
\hline e (inch) & 0.5 & 0.5 & 0.5 & 0.5 & 0.5 \\
\hline Labor rate (\$/hr) & 50 & 15 & 60 & 35 & 40 \\
\hline R (inch/min) & 150 & 50 & 200 & 80 & 70 \\
\hline Load/unload time (min) each. & 3 & 3 & 0.5 & 0.5 & 1 \\
\hline Tool change time (min) & 15 & 3 & 0.5 & 0.75 & 1 \\
\hline Machine setup time (min) & 20 & 10 & 35 & 20 & 15 \\
\hline
\end{tabular}




\begin{tabular}{|c|c|c|c|c|c|c|c|}
\hline Tool & Cost (\$) & $\begin{array}{c}\text { Times } \\
\text { resharpened } \\
\text { or times used } \\
\end{array}$ & $\begin{array}{c}\begin{array}{c}\text { Labor+overhead } \\
\text { (tool grinder) } \\
(\$ / \mathrm{min})\end{array} \\
\end{array}$ & $\begin{array}{c}\text { Time to } \\
\text { resharpen } \\
\text { (min.) }\end{array}$ & $\begin{array}{c}\text { Cost of } \\
\text { each } \\
\text { insert }\end{array}$ & $\begin{array}{c}\text { Times inserts } \\
\text { are } \\
\text { resharpened }\end{array}$ & $\begin{array}{c}\text { Cost of } \\
\text { grinding } \\
\text { wheel }\end{array}$ \\
\hline Carbide & 10 & 5 & 1 & 5 & 5 & 2 & 30 \\
\hline Ceramic & 9 & 5 & 1 & 5 & 5 & 2 & 30 \\
\hline Diamond & 50 & 10 & 1 & 5 & 5 & 2 & 30 \\
\hline Grinding Wheel Hard & 20 & 5 & 1 & 5 & 5 & 2 & 30 \\
\hline Grinding Wheel Medium & 22 & 5 & 1 & 5 & 5 & 2 & 30 \\
\hline Grinding Wheel Soft & 25 & 5 & 1 & 5 & 5 & 2 & 30 \\
\hline High Speed Steel & 8 & 4 & 1 & 5 & 5 & 2 & 30 \\
\hline Multi-point Carbide C2 & 12 & 5 & 1 & 5 & 5 & 2 & 30 \\
\hline Multi-point Carbide C5 & 14 & 5 & 1 & 5 & 5 & 2 & 30 \\
\hline Multi-point Carbide C6 & 15 & 5 & 1 & 5 & 5 & 2 & 30 \\
\hline Multi-point High Speed Steel M2 & 9 & 5 & 1 & 5 & 5 & 2 & 30 \\
\hline Multi-point High Speed Steel M3 & 10 & 5 & 1 & 5 & 5 & 2 & 30 \\
\hline Multi-point High Speed Steel M42 & 11 & 5 & 1 & 5 & 5 & 2 & 30 \\
\hline Multi-point High Speed Steel M7 & 12 & 5 & 1 & 5 & 5 & 2 & 30 \\
\hline Multi-point High Speed Steel T15 & 13 & 5 & 1 & 5 & 5 & 2 & 30 \\
\hline Single Point Ceramic CPA & 10 & 5 & 1 & 5 & 5 & 2 & 30 \\
\hline Single Point Ceramic HPC & 11 & 5 & 1 & 5 & 5 & 2 & 30 \\
\hline Single Point Carbide C2 & 11 & 5 & 1 & 5 & 5 & 2 & 30 \\
\hline Single Point Carbide C3 & 12 & 5 & 1 & 5 & 5 & 2 & 30 \\
\hline Single Point Carbide C4 & 12 & 5 & 1 & 5 & 5 & 2 & 30 \\
\hline Single Point Carbide C6 & 12 & 6 & 1 & 5 & 5 & 2 & 30 \\
\hline Single Point Carbide C7 & 15 & 5 & 1 & 5 & 5 & 2 & 30 \\
\hline Single Point Carbide C8 & 15 & 5 & 1 & 5 & 5 & 2 & 30 \\
\hline
\end{tabular}




\begin{tabular}{|c|c|c|c|c|c|c|c|}
\hline Tool & Cost (\$) & $\begin{array}{c}\text { Times } \\
\text { resharpened } \\
\text { or times used }\end{array}$ & $\begin{array}{c}\text { Labor+overhead } \\
\text { (tool grinder) } \\
\text { (\$/min) }\end{array}$ & $\begin{array}{l}\text { Time to } \\
\text { resharpen } \\
\text { (min.) }\end{array}$ & $\begin{array}{c}\text { Cost of } \\
\text { each } \\
\text { insert }\end{array}$ & $\begin{array}{c}\text { Times inserts } \\
\text { are } \\
\text { resharpened }\end{array}$ & $\begin{array}{c}\text { Cost of } \\
\text { grinding } \\
\text { wheel }\end{array}$ \\
\hline Single Point High Speed Steel M2 & 8 & 5 & 1 & 5 & 5 & 2 & 30 \\
\hline Single Point High Speed Steel M3 & 9 & 5 & 1 & 5 & 5 & 2 & 30 \\
\hline Single Point High Speed Steel M42 & 10 & 5 & 1 & 5 & 5 & 2 & 30 \\
\hline Single Point High Speed Steel M7 & 11 & 5 & 1 & 5 & 5 & 2 & 30 \\
\hline
\end{tabular}




\section{APPENDIX 2: SAMPLE RESULTS FROM MPSEL}

angles.kbs $=$ yes CNF 0

angsup1.kbs = yes CNF 0

angsup2.kbs $=$ yes CNF 0

angsup3.kbs $=$ yes CNF 0

c_l $=7$ CNF 100

c_od $=4.5$ CNF 100

carbide $=$ selected $\mathrm{CNF} 100$

ceramic $=$ not_selected CNF 100

cut_fluid_crts $=$ w_sol_oil_LMD CNF 100

cut_fluid_hss = st_cutting_oil_LMD CNF 100

diamond $=$ not_selected CNF 100

EL_FC_SF $=25.00$ CNF 100

EL_FC_TOL $=0.00800$ CNF 100

EL_MAX_DC $=75.00 \mathrm{CNF} 100$

EL_MIN_DC $=6.00$ CNF 100

EL_SWING $=20.00 \mathrm{CNF} 100$

EL_THR_SF $=75.00$ CNF 100

EL_THR_TOL $=0.00600$ CNF 100

EL_TRN_SF $=25.00$ CNF 100

EL_TRN_TOL $=0.00800$ CNF 100

engine_lathe = suitable CNF 100

fluids.kbs $=$ yes CNF 0

hi_sp_steel $=$ selected CNF 100

hss_carbide $=$ suitable CNF 100

m_b_hard $=150$ CNF 100

m_cond $=$ as_cast CNF 100

m_prop $=$ xxx CNF 100

m_type $=$ ferrous CNF 100

MACHINE $=$ nc_lathe CNF 100

material $=$ stainless_steel CNF 100 
NC_BOR_SF $=5.00$ CNF 100

NC_BOR_TOL $=0.00080$ CNF 100

NC_DRL_SF $=10.00$ CNF 100

NC_DRL_TOL $=0.00100$ CNF 100

NC_DRMG_SF $=4.00$ CNF 100

NC_DRMG_TO $=0.00090$ CNF 100

NC_DTPG_SF $=15.00 \mathrm{CNF} 100$

NC_DTPG_TO $=0.00200$ CNF 100

NC_FC_SF $=3.00$ CNF 100

NC_FC_TOL $=0.00080$ CNF 100

nc_lathe = suitable CNF 100

nc_lathe $=$ selected CNF 100

NC_LD_R $=2.56$ CNF 100

NC_MAX_D $=10.00$ CNF 100

NC_MAX_HD $=3.20$ CNF 100

NC_MAX_L $=35.00$ CNF 100

NC_MIN_HD $=0.10$ CNF 100

NC_MIN_L $=1.00$ CNF 100

NC_THRE_SF $=20.00 \mathrm{CNF} 100$

NC_THRE_TO $=0.00300 \mathrm{CNF} 100$

NC_THRI_SF $=20.00$ CNF 100

NC_THRI_TO $=0.00300$ CNF 100

NC_TRN_SF $=3.00$ CNF 100

NC_TRN_TOL $=0.00080$ CNF 100

o_sf $=90$ CNF 100

o_tol $=.005$ CNF 100

operation = turning CNF 100

phdmac1.kbs = yes CNF 0

phdmac2.kbs = yes CNF 0

PHDMAT.kbs $=$ yes CNF 0

phdtls.kbs $=$ yes CNF 0 
phdtls1.kbs $=$ yes CNF 0
phdtls2.kbs $=$ yes CNF 0
record_num $=1$ CNF 100

s_f_req = high CNF 100

search1 = in_process CNF 100

search10 = in_process CNF 100

search12 = in_process CNF 100

search13 = in_process CNF 100

search15 = in_process CNF 100

search17 = in_process CNF 100

search2 = in_process CNF 100

search20 = in_process CNF 100

search3 = in_process CNF 100

search7 = in_process CNF 100

search8 = in_process CNF 100

search9 = in_process CNF 100

single_sp_auto = suitable CNF 100

single_sp_auto $=$ selected CNF 100

SP_BOR_SF $=63.00$ CNF 100

SP_BOR_TOL $=0.00150$ CNF 100

sp_cr_c7_c6 $=$ selected CNF 100

SP_DRL_SF $=63.00 \mathrm{CNF} 100$

SP_DRL_TOL $=0.00300$ CNF 100

SP_DRMG_SF $=32.00$ CNF 100

SP_DRMG_TO $=0.00130$ CNF 100

SP_DTPG_SF $=63.00$ CNF 100

SP_DTPG_TO $=0.00550$ CNF 100

SP_FC_SF $=16.00$ CNF 100

SP_FC_TOL $=0.00400 \mathrm{CNF} 100$

sp_hss_m2_m3 = selected CNF 100

SP_LD_R $=2.90$ CNF 100 


$$
\begin{aligned}
& \text { SP_MAX_D }=8.00 \text { CNF } 100 \\
& \text { SP_MAX_HD }=2.50 \text { CNF } 100 \\
& \text { SP_MAX_L }=40.00 \text { CNF } 100 \\
& \text { SP_MIN_HD }=0.05 \text { CNF } 100 \\
& \text { SP_MIN_L }=0.05 \text { CNF } 100 \\
& \text { SP_THRE_SF }=62.00 \text { CNF } 100 \\
& \text { SP_THRE_TO }=0.00600 \text { CNF } 100 \\
& \text { SP_THRI_SF }=62.00 \text { CNF } 100 \\
& \text { SP_THRI_TO }=0.00600 \text { CNF } 100 \\
& \text { SP_TRN_SF }=16.00 \text { CNF } 100 \\
& \text { SP_TRN_TOL }=0.00400 \text { CNF } 100 \\
& \text { t_cr_bra = low_positive CNF } 100 \\
& \text { t_cr_bra }=0-5 \text { CNF } 100 \\
& \text { t_cr_cutting_edge }=\text { weakened CNF } 100 \\
& \text { t_cr_ra }=\text { 5-7 CNF } 100 \\
& \text { t_cr_sra = low_positive CNF } 100 \\
& \text { t_cr_sra }=5-10 \text { CNF } 100 \\
& \text { t_cr_tool_life = important CNF } 100 \\
& \text { t_hss_bra = low_positive CNF } 100 \\
& \text { t_hss_bra }=\text { 5-10 CNF } 100 \\
& \text { t_hss_cutting_edge }=\text { weakened CNF } 100 \\
& \text { t_hss_ela }=10-13 \text { CNF } 100 \\
& \text { t_hss_sla }=10-13 \text { CNF } 100 \\
& \text { t_hss_sra }=\text { low_positive CNF } 100 \\
& \text { t_hss_sra }=\text { 8-12 CNF } 100 \\
& \text { thermal_shock }=\text { problem CNF } 100 \\
& \text { TL_BOR_SF }=63.00 \text { CNF } 100 \\
& \text { TL_BOR_TOL }=0.00100 \text { CNF } 100 \\
& \text { TL_DRL_SF }=63.00 \mathrm{CNF} 100 \\
& \text { TL_DRL_TOL }=0.00400 \text { CNF } 100 \\
& \text { TL_DRMG_SF }=33.00 \text { CNF } 100
\end{aligned}
$$


TL_DRMG_TO $=0.00100$ CNF 100

TL_DTPG_SF $=63.00$ CNF 100

TL_DTPG_TO $=0.00600 \mathrm{CNF} 100$

TL_FC_SF $=9.00$ CNF 100

TL_FC_TOL $=0.00300$ CNF 100

TL_LD_R $=2.40$ CNF 100

TL_MAX_D $=4.00$ CNF 100

TL_MAX_HD $=3.00$ CNF 100

TL_MAX_L $=56.00$ CNF 100

TL_MIN_HD $=0.25$ CNF 100

TL_MIN_L $=3.00$ CNF 100

TL_THRE_SF $=64.00$ CNF 100

TL_THRE_TO $=0.00500$ CNF 100

TL_THRI_SF $=64.00$ CNF 100

TL_THRI_TO $=0.00500$ CNF 100

TL_TRN_SF $=9.00$ CNF 100

TL_TRN_TOL $=0.00300$ CNF 100

tool_chip_fr = high CNF 100

turning = suitable CNF 100 